\title{
WestVirginiaUniversity
}

THE RESEARCH REPOSITORY @ WVU

Graduate Theses, Dissertations, and Problem Reports

2016

\section{Responses and adaptation strategies of terrestrial ecosystems to climate change}

Zhen Yu

Follow this and additional works at: https://researchrepository.wvu.edu/etd

\section{Recommended Citation}

$\mathrm{Yu}, \mathrm{Zhen}$, "Responses and adaptation strategies of terrestrial ecosystems to climate change" (2016). Graduate Theses, Dissertations, and Problem Reports. 7017.

https://researchrepository.wvu.edu/etd/7017

This Dissertation is protected by copyright and/or related rights. It has been brought to you by the The Research Repository @ WVU with permission from the rights-holder(s). You are free to use this Dissertation in any way that is permitted by the copyright and related rights legislation that applies to your use. For other uses you must obtain permission from the rights-holder(s) directly, unless additional rights are indicated by a Creative Commons license in the record and/ or on the work itself. This Dissertation has been accepted for inclusion in WVU Graduate Theses, Dissertations, and Problem Reports collection by an authorized administrator of The Research Repository @ WVU.

For more information, please contact researchrepository@mail.wvu.edu. 


\title{
Responses and adaptation strategies of terrestrial ecosystems to climate change
}

\section{Zhen Yu}

\author{
Dissertation submitted \\ to the Davis College of Agriculture, Natural Resources and Design at \\ West Virginia University \\ in partial fulfillment of the requirements for the degree of \\ Doctor of Philosophy in \\ Forest Resources Science \\ Jingxin Wang, Ph.D., Chair \\ Shirong Liu, Ph.D. Co-Chair \\ Mary Beth Adams, Ph.D \\ Eungul Lee, Ph.D. \\ James Rentch, Ph.D. \\ Richard Thomas, Ph.D. \\ Nicolas Zegre, Ph.D.
}

Division of Forestry and Natural Resources

Morgantown, West Virginia

2016

Keywords: Global Climate Change, Carbon, Terrestrial Ecosystem, Phenology, Snow, Respiration, Ecosystem Production, Drought, Water Use Efficiency, Forest Ecosystem Management

Copyright 2016 Zhen Yu 


\title{
ABSTRACT
}

\section{Responses and adaptation strategies of regional terrestrial ecosystems to climate change}

\begin{abstract}
Zhen Yu
Terrestrial ecosystems are likely to be affected by climate change, as climate changeinduced shift of water and heat stresses patterns will have significant impacts on species composition, habitat distribution, and ecosystem functions, and thereby weaken the terrestrial carbon (C) sink and threaten global food security and biofuel production. This thesis investigates the responses of terrestrial ecosystems to climate change and is structured in four main chapters.

The first chapter of the thesis is directed towards the impacts of snow variation on ecosystem phenology. Variations in seasonal snowfall regulate regional and global climatic systems and vegetation growth by changing energy budgets of the lower atmosphere and land surface. We investigated the effects of snow on the start of growing season (SGS) of temperate vegetation in China. Across the entire temperate region in China, the winter snow depth increased at a rate of $0.15 \mathrm{~cm}^{\circ} \mathrm{yr}^{-1}(\mathrm{p}=0.07)$ during the period 1982-1998, and decreased

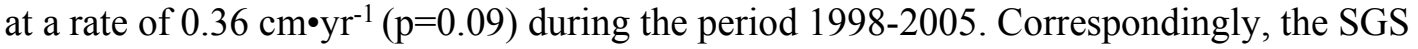
advanced at a rate of $0.68 \mathrm{~d} \cdot \mathrm{yr}^{-1}(\mathrm{p}<0.01)$ during 1982 to 1998 , and delayed at a rate of 2.13 $\mathrm{d} \bullet \mathrm{yr}^{-1}(\mathrm{p}=0.07)$ during 1998 to 2005 , against a warming trend throughout the entire study period of 1982-2005. Spring air temperature strongly regulated the SGS of both deciduous broad-leaf and coniferous forests; whilst the winter snow had a greater impact on the SGS of grassland and shrubs. Snow depth variation combined with air temperature contributed to the variability in the SGS of grassland and shrubs, as snow acted as an insulator and modulated the underground thermal conditions. Additionally, differences were seen between the impacts of winter snow depth and spring snow depth on the SGS; as snow depths increased, the effect associated went from delaying SGS to advancing SGS. The observed thresholds for these effects were snow depths of $6.8 \mathrm{~cm}$ (winter) and $4.0 \mathrm{~cm}$ (spring). The results of this study suggest that the response of the vegetation's SGS to seasonal snow change may be attributed to the coupling effects of air temperature and snow depth associated with the soil thermal conditions.

The second chapter further addresses snow impacts on terrestrial ecosystem with focus on regional carbon exchange between atmosphere and biosphere. Winter snow has been suggested to regulate terrestrial carbon $(\mathrm{C})$ cycling by modifying micro-climate, but the impacts of snow cover change on the annual $\mathrm{C}$ budget at the large scale are poorly understood. Our aim is to quantify the $\mathrm{C}$ balance under changing snow depth. Here, we used site-based eddy covariance flux data to investigate the relationship between snow cover depth and ecosystem respiration (Reco) during winter. We then used the Biome-BGC model to
\end{abstract}


estimate the effect of reductions in winter snow cover on $\mathrm{C}$ balance of Northern forests in non-permafrost region. According to site observations, winter net ecosystem $\mathrm{C}$ exchange (NEE) ranged from $0.028-1.53 \mathrm{gC} \cdot \mathrm{m}^{-2} \cdot$ day $^{-1}$, accounting for $44 \pm 123 \%$ of the annual $\mathrm{C}$ budget. Model simulation showed that over the past 30 years, snow driven change in winter $\mathrm{C}$ fluxes reduced non-growing season $\mathrm{CO}_{2}$ emissions, enhancing the annual $\mathrm{C}$ sink of northern forests. Over the entire study area, simulated winter ecosystem respiration ( $\left.\mathrm{R}_{\mathrm{eco}}\right)$ significantly decreased by $0.33 \mathrm{gC} \cdot \mathrm{m}^{-2} \cdot$ day $^{-1} \cdot \mathrm{yr}^{-1}$ in response to decreasing snow cover depth, which accounts for approximately $25 \%$ of the simulated annual C sink trend from 1982 to 2009 . Soil temperature was primarily controlled by snow cover rather than by air temperature as snow served as an insulator to prevent chilling impacts. A shallow snow cover has less insulation potential, causing colder soil temperatures and potentially lower respiration rates. Both eddy covariance analysis and model-simulated results showed that both Reco and NEE were significantly and positively correlated with variation in soil temperature controlled by variation in snow depth. Overall, our results highlight that a decrease in winter snow cover restrains global warming through emitting less $\mathrm{C}$ to the atmosphere.

The third chapter focused on assessing drought's impact on global terrestrial ecosystems. Drought can affect the structure, composition and function of terrestrial ecosystems, yet the drought impacts and post-drought recovery potential of different land cover types have not been extensively studied at a global scale. Here, we evaluated drought impacts on gross primary productivity (GPP), evapotranspiration (ET), and water use efficiency (WUE) of different global terrestrial ecosystems, as well as the drought-resilience of each ecosystem type during the period of 2000 to 2011 . We found the rainfall and soil moisture during drought period were dramatically lower than these in non-drought period, while air temperatures were higher than normal during drought period with amplitudes varied by land cover types. The length of recovery days (LRD) presented an evident gradient of high ( $>60$ days) in mid- latitude region and low ( $<60$ days) in low (tropical area) and high (boreal area) latitude regions. As average GPP increased, the LRD showed a significantly decreasing trend among different land covers $\left(\mathrm{R}^{2}=0.53, p<0.0001\right)$. Moreover, the most dramatic reduction of the drought-induced GPP was found in the mid-latitude region of north Hemisphere (48\% reduction), followed by the low-latitude region of south Hemisphere (13\% reduction). In contrast, a slightly enhanced GPP (10\%) was showed in the tropical region under drought impact. Additionally, the highest drought-induced reduction of ET was found in the Mediterranean area, followed by Africa. The water use efficiency, however, showed a pattern of decreasing in the north Hemisphere and increasing in the south Hemisphere.

The last chapter compared the differences of performance in trading water for carbon in planted forest and natural forest, with specific focus on China. Planted forests have been widely established in China as an essential approach to improving the ecological environment and mitigating climate change. Large-scale forest planting programs, however, are rarely examined in the context of tradeoffs between carbon sequestration and water yield between planted and natural forests. We reconstructed evapotranspiration (ET) and gross primary production (GPP) data based on remote-sensing and ground observational data, and investigated the differences between natural and planted forests, in order to evaluate the suitability of tree-planting activity in different climate regions where the afforestation and reforestation programs have been extensively implemented during the past three decades in 
China. While the differences changed with latitude (and region), we found that, on average, planted forests consumed $5.79 \%(29.13 \mathrm{~mm})$ more water but sequestered $1.05 \%\left(-12.02 \mathrm{gC} \mathrm{m}^{-}\right.$ $\left.{ }^{2} \mathrm{yr}^{-1}\right)$ less carbon than naturally generated forests, while the amplitudes of discrepancies varied with latitude. It is suggested that the most suitable lands in China for afforestation should be located in the moist south subtropical region (SSTP), followed by the midsubtropical region (MSTP), to attain a high carbon sequestration potential while maintain a relatively low impact on regional water balance. The high hydrological impact zone, including the north subtropical region (NSTP), warm temperate region (WTEM), and temperate region (TEM) should be cautiously evaluated for future afforestation due to water yield reductions associated with plantations. 


\section{Acknowledgements}

I would never have been able to survive during this long journey of dissertation without the guidance of my committee members, help from friends, and support from my family and wife.

I would first like to express my deepest gratitude to my supervisor, Dr. Jingxin Wang, for his excellent guidance, patience, tolerance, and financially supporting me to stubbornly doing research in the field of climate change. I would like to thank Dr. Shirong Liu, who open me the gate to academic career, and gave me strong support to pursue the $\mathrm{PhD}$ degree in the United States. I would also like to thank Dr. Pengsen Sun for inspiring me in my research for the past eight years, and helping me to develop my background in forestry, hydrology, and ecology. I really appreciate my committee members, including Dr. Nicolas Zegre, Dr. Mary Beth Adams, Dr. Richard Thomas, Dr. James Rentch, and Dr. Eungul Lee, for providing me valuable suggestions and the efforts to accommodate their schedules to my defense.

Of course, I would like to thank my friends, Weiguo Liu, Tuhua Zhong, Yuxi Wang, Chen-Chung Lin, Xinfeng Xie, Changle Jiang, Nan Nan, Wu Ma for the precious time we spend together.

Also, I would like to thank my parents, elder sister, and elder brother. They were always supporting me and encouraging me with their best wishes. Finally, I would like to thank my wife, Yuyan Zhan. She was always there cheering me up and support me with unconditional loves. 


\section{Table of Contents}

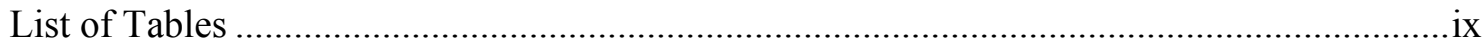

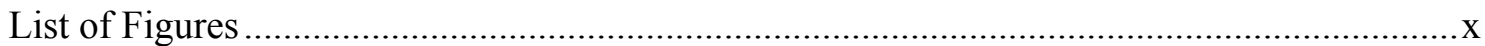

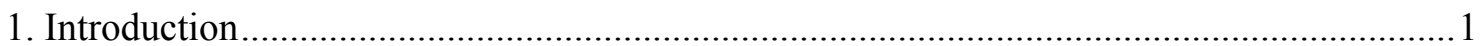

1.1 Snow change impact on the phenology of terrestrial ecosystems............................... 3

1.2 Snow change impact on soil respiration of terrestrial ecosystems ...............................5

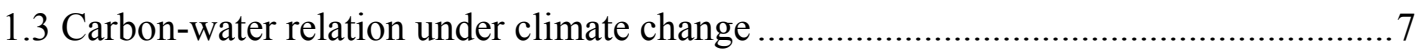

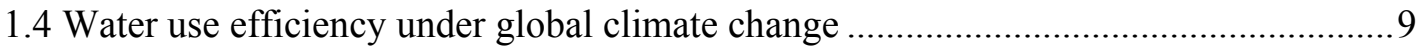

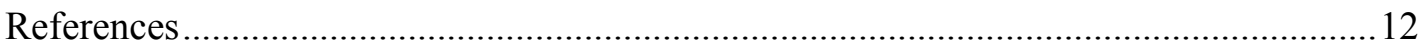

2. Effects of seasonal snow on the growing season of temperate vegetation in China............23

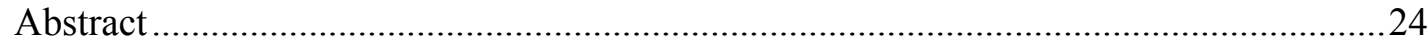

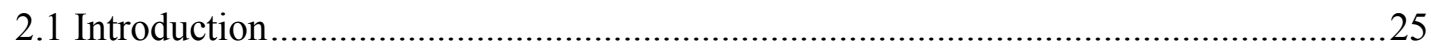

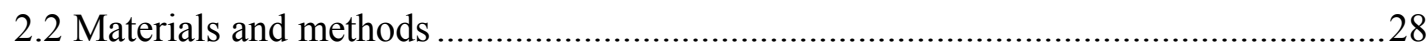

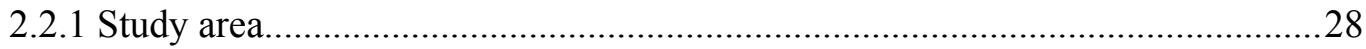

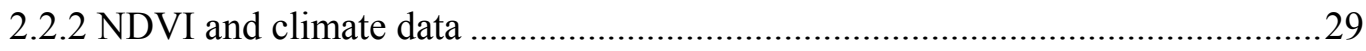

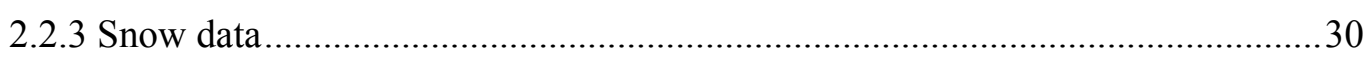

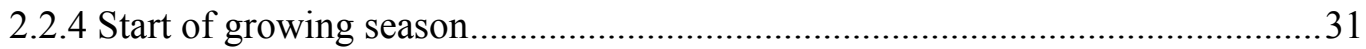

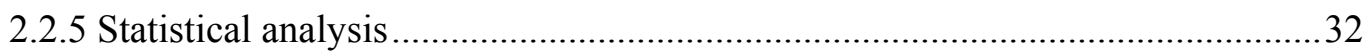

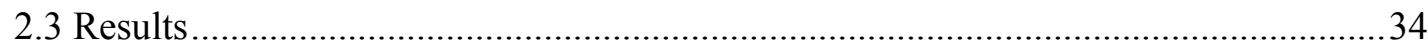

2.3.1 Patterns of air temperature, snow depth and start of growing season.................34

2.3.2 Trends of air temperature and SGS in different vegetation types........................36

2.3.3 Correlations between snow depth, air temperature and SGS ............................39

2.3.4 Seasonal air temperature, snow depth and SGS..............................................4 42

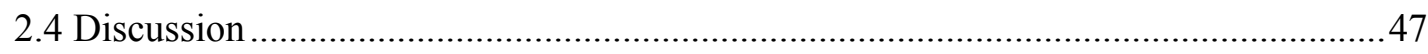

2.4.1 Temperature, snow depth and vegetation phenology ....................................47

2.4.2 Impacts of snow depth and temperature on vegetation leaf-out at large scale ...48

2.4.3 Effects of snow depth on leaf-out of warm-favored vegetation types ................49

2.4.4 Effects of snow depth on leaf-out of chilling-favored vegetation types ..............51

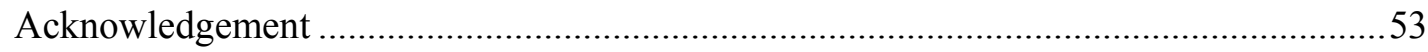

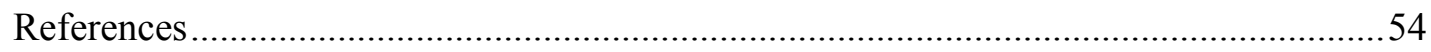

3. Decrease in winter respiration explains $25 \%$ of annual northern forest carbon sink

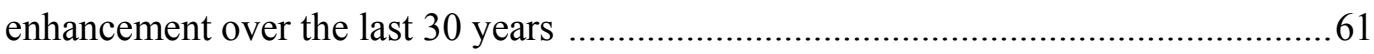

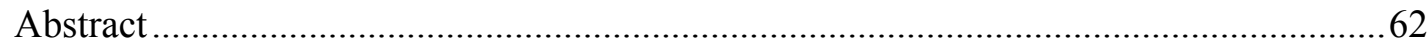

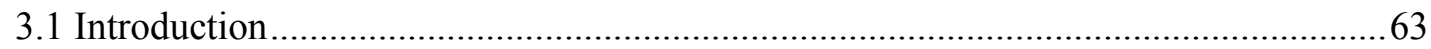

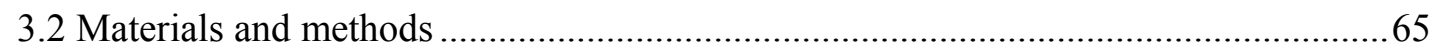

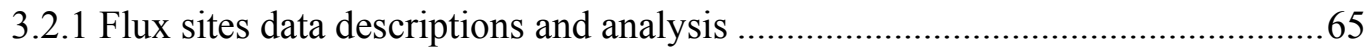

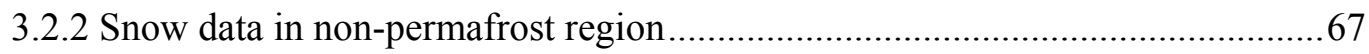

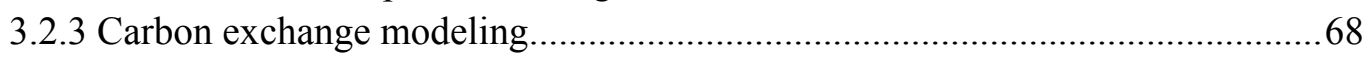

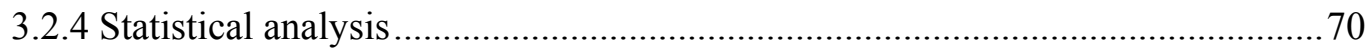

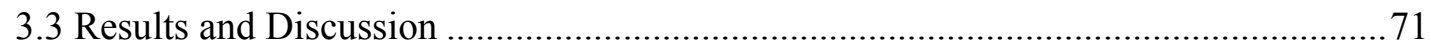

3.3.1 Wintertime carbon flux at site level............................................................... 71

3.3.2 Climatic factors and carbon flux change at regional scale ................................74

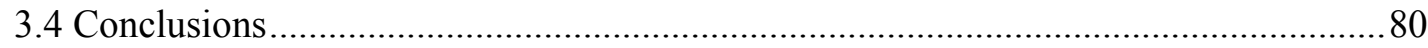




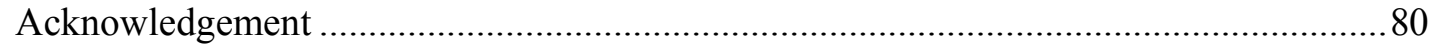

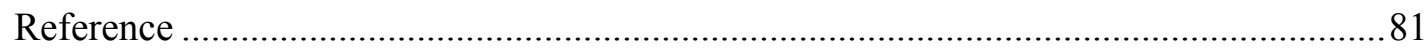

4. Global gross primary productivity and water use efficiency changes under drought stress....

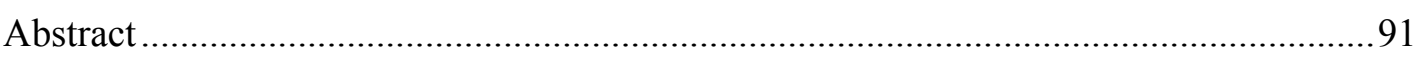

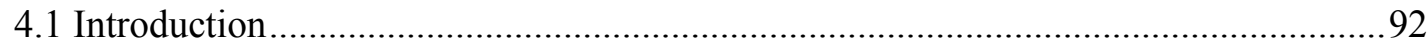

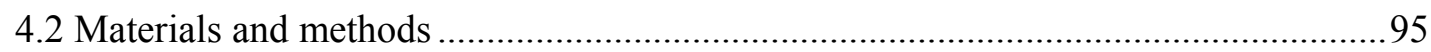

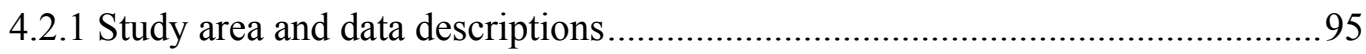

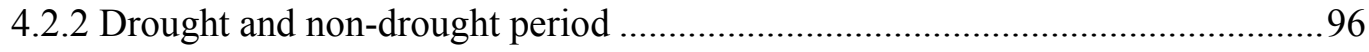

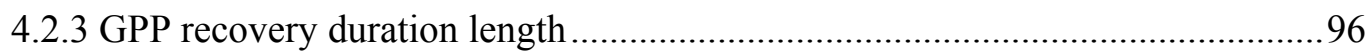

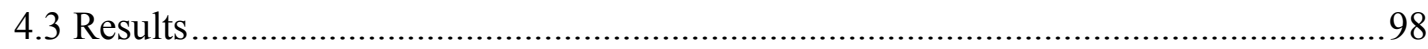

4.3.1 Climatic factors during drought and non-drought periods................................98

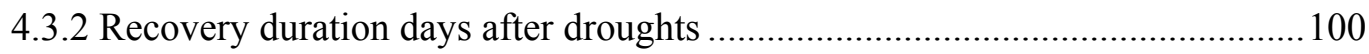

4.3.3 GPP and evapotranspiration after droughts ................................................ 101

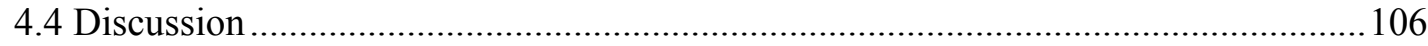

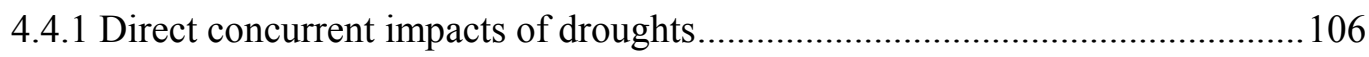

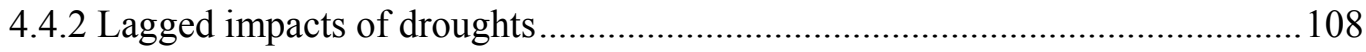

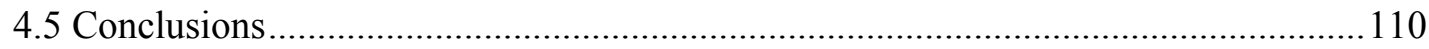

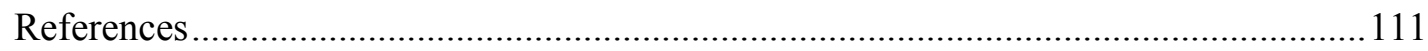

5. Trading water for carbon: Planted forests are not efficient as natural forests in China during

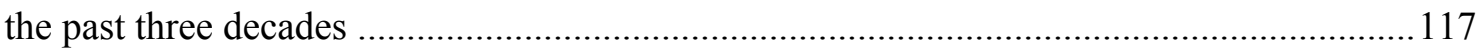

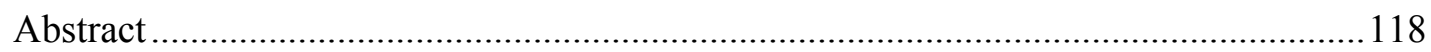

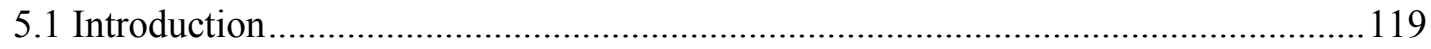

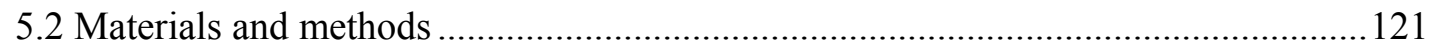

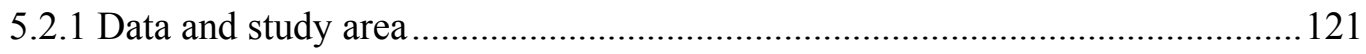

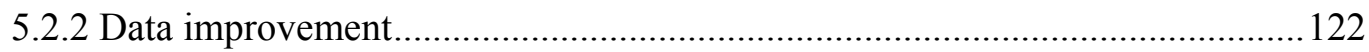

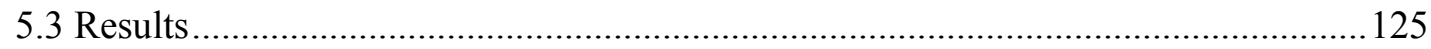

5.3.1 Gross Primary Production and evapotranspiration modeling .......................... 125

5.3.2 Water consumptions derived from different land cover maps ......................... 125

5.3.3 Water yield under dryness stress........................................................... 127

5.3.4 Carbon and water change after afforestation .............................................. 131

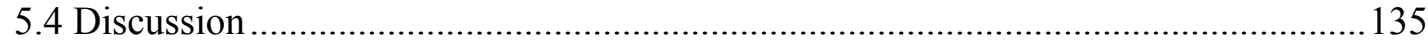

5.4.1 Gross Primary Production and evapotranspiration modeling .......................... 135

5.4.2 Differences between natural and planted forest........................................... 136

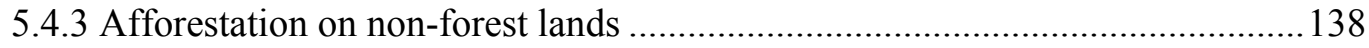

5.4.4 Implications for future afforestation activities............................................ 140

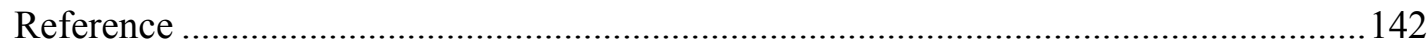

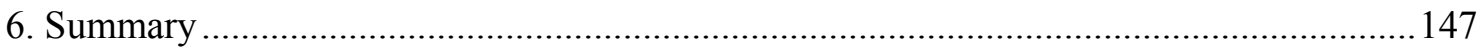

Appendix A. Supplemental Information for Chapter 3 ................................................. 151

Appendix S1 Supplementary information describing full details of validations of the two

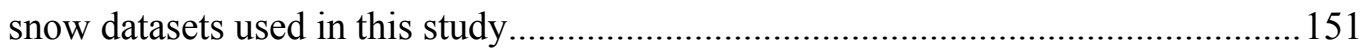

Appendix S2 Supplementary information providing validation of the model simulation

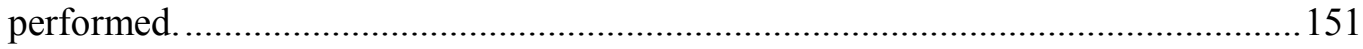


Appendix S3 Supplementary analyses of correlation between interannual winter soil

temperature, snow cover depth, and air temperature in the study area.

Appendix S4 Supplementary analyses of correlation between interannual snow cover depth, winter air temperature, and model simulated net ecosystem exchange .

Appendix S1 Supplementary information describing full details of validations of the two

snow datasets used in this study

Appendix S2 Supplementary information providing validation of the model simulation

performed.

Appendix S3 Supplementary analyses of correlation between interannual winter soil temperature, snow cover depth, and air temperature in the study area..................... 154

Appendix S4 Supplementary analyses of correlation between interannual snow cover depth, winter air temperature, and model simulated net ecosystem exchange. ......... 154

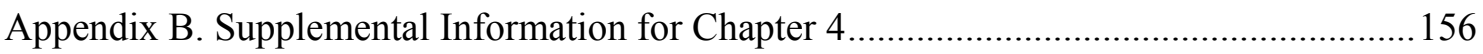

Appendix C. Supplemental Information for Chapter 5 ..................................................159 


\section{List of Tables}

Table 2-1 Correlations and significance levels between seasonal snow depth, air temperature and the SGS in different time periods and vegetation types .............................................4

Table 2-2 Models of best fit stepwise multiple regression analysis in AS and AM areas.......42

Table 2-3 Snow depth thresholds of different vegetation types ...........................................45

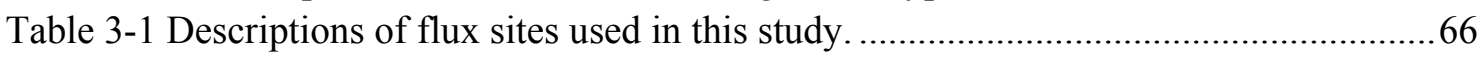

Table 3-2 $\mathrm{CO}_{2}$ flux and changes in the non-permafrost region of Northern forest area by

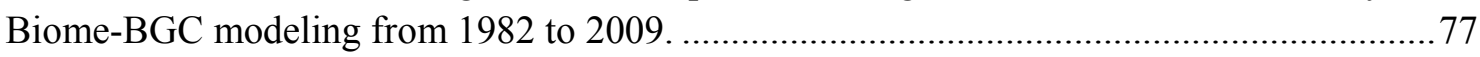

Table 4-1 Rainfall, soil moisture, and average air temperature difference of drought period and the non-drought period by land covers 


\section{List of Figures}

Figure 2-1 Spatial distribution of vegetation types in temperate China.

Figure 2-2 Spatial patterns of annual mean air temperature, snow depth, and start of growing

season

Figure 2-3 Spatial distributions of the trends of annual mean temperature, snow depth, and start of growing season.

Figure 2-4 Inter-annual variations of the start of growing season, seasonal snow depth, and air temperature in the temperate China

Figure 2-5 Trends of the winter and spring temperatures and the start of growing season of different vegetation types.

Figure 2-6 Change trends of the start of growing season during time periods of 1982-1998 and $1998-2005$

Figure 2-7 Seasonal snow depths vs. the start of growing season in the temperate China......43 Figure 2-8 Correlations between snow depth and the start of growing season of different vegetation types

Figure 2-9 Distribution of winter snow depth thresholds

Figure 3-1 Correlations between air temperature and ecosystem respiration; soil temperature and ecosystem respiration; air temperature and net ecosystem exchange; and soil temperature and net ecosystem exchange in winter derived from measurements at 15 flux sites...............72 Figure 3-2 Correlation between ecosystem respiration anomaly and snow anomaly; and the correlation between anomalies of net ecosystem exchange and snow depth.

Figure 3-3 Spatial patterns of winter change trend of air temperature, change trend of soil temperature, and change trend of snow depth from 1982-2009 based on NCEP/CFSR .........75 Figure 3-4 Spatial trends of winter Reco in the non-permafrost region of Northern forest area from 1982 to 2009. The results were derived from Biome-BGC modeling simulations.........76 Figure 3-5 Ecosystem respiration of different regions under snow-free and snow-cover scenarios from 1982 to 2009.

Figure 4-1 Rainfall, soil moisture and average air temperature ratio of drought period and the non-drought period; the right panel shows the average ratios of rainfall, soil moisture, and air temperature in different land covers

Figure 4-2 Days of GPP recovery back to normal after drought impacts.

Figure 4-3 Relationship between GPP and Days recovery after droughts impacts

Figure 4-4 GPP, ET and WUE ratio of recovery period and the non-drought period 103

Figure 4-5 GPP and ET ratio of drought period and the non-drought period by different land covers 104

Figure 4-6 GPP, ET and WUE during recovery period and the non-drought period 105

Figure 5-10 Evaporative index change after afforestation in different regions. 132 
1. Introduction 
Predicted increase in air temperature and changes in precipitation patterns associated with climate change may lead to an increased frequency of extreme weather and a shift of disturbance regimes (Richard, 2007; Parmesan et al., 2000; Puettmann, 2011). Many ecosystems are likely to be affected by climate change, such as tundra, boreal forest, mountain, Mediterranean-type, mangroves and coral reefs, and regions with low adaptive capacity (low-lying coasts, areas dependent on snow and ice melt, and agricultural or forest areas with limited water resource) (Solomon et al., 2007). Additionally, climate changeinduced shift of thermal (temperature) and moisture (precipitation) patterns will have significant impacts on the distribution of species, composition of habitats, and the function of ecosystems (Berry et al., 2002). Though the acclimatization mechanism helps terrestrial ecosystems adapt to climate change, this resilience is limited to a defined range. Community collapse may occur when the water and heat stresses exceed the tolerable threshold (Saleska et al., 2007; Betts et al., 2004). Nevertheless, it is still unknown whether adaptation of the terrestrial ecosystems can keep the pace with the unprecedented strength of disturbances from both human-induced and natural climate changes.

To mitigate the impact of climate change, measures have been taken by governments to stabilize the $\mathrm{CO}_{2}$ concentration in the atmosphere at some realistically attainable and relatively low level (King, 2004). The terrestrial ecosystems may be the most active and manageable intermediate for controlling the $\mathrm{CO}_{2}$ level. On the basis of integration of atmospheric $\mathrm{CO}_{2}$ observations, inverse modeling, and land observations, global terrestrial ecosystems absorbed carbon at a rate of 1.0- 4.0 $\mathrm{Pg} \mathrm{yr}^{-1}$ during the 1980s and 1990s (Battle et al., 2000; Bousquet et al., 2000; Fan et al., 1998), which offset $10-60 \%$ of the fossil-fuel 
emissions in the same period (Solomon et al., 2007; Houghton et al., 2007, Trans et al., 1990). Despite widespread consensus about the existence of a terrestrial carbon sink in the Northern Hemisphere, the size, spatial distribution, and cause of the sink remain uncertain

(Pacala et al., 2001; Trans et al., 1990; Battle et al., 2000; Bousquet et al., 2000).

International negotiations to limit greenhouse gases require an understanding of the current and potential future role of forest $\mathrm{C}$ emissions and sequestration in both managed and unmanaged forests (Pan et al., 2011).

Quantifying the impacts of climate change on $\mathrm{C}$ variation patterns of terrestrial ecosystems is critical for reducing uncertainties on setting future climate mitigation actions (Pan et al., 2011). To slow down the increase of atmospheric $\mathrm{CO}_{2}$ concentration, effective evaluation and proper management of the terrestrial ecosystems is critical. It is essential to improve global understanding about $\mathrm{C}$ efflux variation between soil and atmosphere, reduce the uncertainties of $\mathrm{C}$ emission patterns at different spatial scales, which may potentially benefit international negotiators with rigorous emission limits for greenhouse gases based on scientific studies. Additionally, terrestrial ecosystem vulnerabilities to the shift of water and heat patterns needs to be carefully assessed due to implications of changes in the plant community compositions as well as the ecosystem functions.

\subsection{Snow change impact on the phenology of terrestrial ecosystems}

As a principal part and the largest carbon pool of terrestrial ecosystems, forest plays a key role in global carbon and water cycling, and its growth and distribution pattern are controlled by climate. Warming can alter patterns of global air circulation and hydrologic 
cycling that will change global and regional precipitation regimes (Houghton et al., 2001). In parallel to global warming, snow cover has changed significantly (IPCC, 2007). It was documented that snow cover extent in the mid and high latitudes of the Northern Hemisphere has decreased by about $10 \%$ since the 1980s (Dye, 2002; IPCC, 2007). Changes in snow pack have been shown to significantly affect the global energy balance (Euskirchen et al., 2007) and water cycling (Barnett et al., 2005; Rawlins et al., 2006), which has implications on vegetation phenology and the carbon cycle (Peng et al., 2010; Dorrepaal et al., 2009). Changes in snow depth also influence the carbon cycle by affecting vegetation growth (Wahren et al., 2005) and community composition (Sturm et al., 2005). In addition, an increase in snow depth could reduce soil freezing and lower root mortality which is beneficial for forest growth in the growing seasons (Peng et al., 2010; Wahren et al., 2005). Therefore, climate change poses great uncertainties on the potential of forest carbon sink. The impacts of climate change on plant's growth can also be detected from affected phenology. Changes in phenological events may have potential impact on vegetation Net Primary Production (NPP) (Lucht et al., 2002), altering global carbon, water, and nitrogen cycles, and distribution of diseases (Schwartz \& Reiter, 2000; White et al., 1999; Menzel, 2000). For example, change in growing season length will affect carbon-water balance by altering the carbon uptake period and evapotranspiration (Piao et al., 2006).

Phenological records are a useful proxy in the study of climate change, because the seasonal pattern of vegetation is sensitive to small variations in climate (Tan et al., 2011). Vegetation phenology is an important component of dynamic vegetation models and it reflects the dynamics of the carbon-water exchange between the land surface and the 
atmosphere. Shifts in plant phenology are seen as fingerprints of global warming (Jentsch et al. 2009). Phenological event variation and its response to climate change have drawn a lot of attention due to increasing temperatures in the northern hemisphere since the $1980 \mathrm{~s}$ (Chmielewski et al. 2004). Advances of spring greenup were found in mid and high latitude areas (Schwarz and Reiter 2000, Defila and Clot 2001, Parmesan 2007), and also in low latitude areas (Heumann et al. 2007, Xiao et al. 2006). Still, there is a critical need to examine the relationship between climate change and phenological responses on a large scale.

\subsection{Snow change impact on soil respiration of terrestrial ecosystems}

Underground processes exert a large control on terrestrial carbon cycling, as the soil carbon pool is a large fraction of the carbon stored in the ecosystem in forests (30-90\%) (Dixon 1994; Sun et al. 2004) and in grasslands (>90\%) (Ryan and Law, 2005). Nonetheless, changes in the underground carbon pools may have a dominant impact on carbon storage variation in terrestrial ecosystems and change carbon flux to the atmosphere (Ryan and Law, 2005).

The accurate estimation of soil respiration and its response to global change are of great importance in reducing the uncertainties of carbon balance analysis, but are poorly understood (Valentini et al. 2000). Soil respiration is the primary pathway for $\mathrm{CO}_{2}$ fixed by land plants returning to the atmosphere (Raich et al. 2002). $\mathrm{CO}_{2}$ efflux from soil respiration can strongly influence net carbon uptake from the atmosphere, and change the balance between photosynthesis (GPP) and ecosystem respiration (Ryan and Law, 2005). About 35 $80 \%$ of the carbon fixed in photosynthesis was allocated belowground for root production 
and respiration, mycorrhizae, and root exudates (Raich and Nadelhoffer 1989; Davidson et al. 2002; Giardina et al. 2003; Ryan et al. 2004), while about $10 \%$ of annual photosynthesis was transferred to aboveground litter (Raich and Nadelhoffer 1989). In contrast, eddy covariance studies revealed that about $80 \%$ of GPP is respired back to the atmosphere (Law et al. 2002) and that about $70 \%$ of ecosystem respiration in temperate forests is from soil (Goulden et al. 1996; Law et al. 1999; Janssens et al. 2003). In comparison, during winter at mid-latitudes in the Northern Hemisphere, montane forest ecosystems may lose over half of the carbon assimilated by photosynthesis in the summer (Monson et al, 2006). Therefore, ecosystem respiration may be more important than photosynthesis in controlling interannual variability in Net Ecosystem Production (NEP) (Valentini et al. 2000).

The amount of winter carbon dioxide loss is potentially susceptible to changes in the snow depth (Monson et al, 2006). Snow can be an insulator for forest soils to protect underground ecosystem from chilling impact. Later development of effective snow cover, as may occur in a warmer climate, may result in increases in soil freezing (i.e. colder soils in a warmer world) and could cause negative impacts on fine root and microbial, and hydrologic and gaseous losses of nitrogen (N) (Groffman et al, 2001). A shallower snow cover may be a less effective insulator, resulting in colder soil temperatures and potentially lower soil respiration rates. Recent climate analyses have shown widespread declines in the winter snow cover of mountain ecosystems in the western US and Europe (Mote et al., 2005; Laternser and Schneebeli, 2003; Scherrer et al., 2004) and significant reductions of snow cover extent in Eurasia (Brown and Robinson, 2011). Most past studies have focused on ecosystematmosphere $\mathrm{CO}_{2}$ exchange during the growing season because the instantaneous flux rates are 
so much higher than during colder periods (Monson et al., 2006). However, small but continuous rates of ecosystem respiration during the winter can, in some cases, completely determine annual rates of $\mathrm{C}$ sequestration (Monson et al., 2005; Monson et al., 2006;

Hubbard et al., 2005). Due to significant retreat of snow cover and reductions of snow depth in the North Hemisphere, the shift in the critical role for thermal insulation by snowpack would have exerted great influences on carbon balance between biosphere and atmosphere.

\subsection{Carbon-water relation under climate change}

Evapotranspiration (ET) is a central process in the land and atmospheric interactions and a nexus of the water, energy and carbon cycles. (Jung et al., 2010; Mu et al., 2007). ET returns more than $60 \%$ of precipitation on land back to the atmosphere (Korzoun et al., 1978; L'vovich \& White, 1990; Mu et al., 2011) and thereby restrains the water available for industrial and environmental uses. Changes in ET have increased water supply scarcity around the world, which threatens the food production in both natural and agricultural ecosystems. Additionally, ET is an important energy flux since evaporation and transpiration consume more than half of the total solar energy absorbed by land surfaces (Trenberth et al., 2009; Mu et al., 2011). ET limitations mainly resulted from atmospheric demand or moisture supply. Therefore, a global warming trend, which is faster and unprecedented during the past decades, would have greatly affected the global ET, as temperature can be used as a surrogate for atmospheric demand (Jung et al., 2010). It is validated that the 10 hottest years on record have all occurred since 1998 (NOAA National Climatic Data Center, NASA Goddard Institute for Space Studies, UK Hadley Centre Meteorological Office, Japanese 
Meteorological Agency), making the past decade a great case study to evaluate the responses of ET to global warming.

ET and carbon (C) are highly correlated as $\mathrm{C}$ and water cycle are closely coupled during the process of photosynthetic $\mathrm{C}$ assimilation (Yu et al., 2008). WUE is a measurement of the water and carbon flux exchange between ecosystem and atmosphere (Ito and Inatomi, 2012; Huang et al., 2015). WUE variations influence forest ecosystem GPP which may potentially threaten global food security and future biofuel production and weaken the terrestrial C sink. Additionally, the shift of water-heat stress could change the competitive ability of different plant types, which in turn, may affect the community composition as well as ecosystem functions. Huxman et al. (2004) reported that at the sites with low rainfall, plants with an efficient water use strategy contributed to high growth rates and become more competitive at the ecosystem level. Previous studies also revealed that WUE increased with rising atmospheric $\mathrm{CO}_{2}$ concentration and nitrogen deposition in Western Europe forest and north Eurasia (Bert et al., 1997; Saurer et al., 2004). These studies improved our understanding of the mechanism underlying the coupling of carbon-water cycle, which is of great importance in projecting the impacts of climate change on regional $\mathrm{C}$ budget and water resources (Yu et al., 2008). As an essential indicator of carbon-water balance, WUE should be investigated to predict the associated changes in productivity and distribution of plant species (Xu \& Hsiao, 2004), and clarify the resilience of plant adaptation ability under water and heat stresses. Therefore, investigation of the responses of WUE to past climate change and rising $\mathrm{CO}_{2}$ concentration will provide insight into how carbon and water cycles will 
change under future $\mathrm{CO}_{2}$ and climate conditions (Huang et al., 2015; Niu et al., 2011; Zhu et al., 2011).

\subsection{Water use efficiency under global climate change}

China has the largest afforested area in the world ( $~ 53.26$ million hectares in 2003 to 62 million hectares in 2008), which accounts for approximately $23 \%$ of global plantation area (FAO, 2010; SFA, 2005; SFA, 2009; Peng et al., 2014). China's goal is to increase forest cover to $26 \%$ by 2050 via the largest planted forest program in the world (Wang et al., 2007). However, it has long been ignored that the new plantings may vulnerable to the changes in availability of water and nutrition (Zhao et al., 2008; Huang et al., 2003; Liu et al., 2005). In terrestrial ecosystems, the variability of water use efficiency (WUE) reflects trade-off between water loss and $\mathrm{C}$ gain, as $\mathrm{C}$ and water cycle are closely coupled during the process of photosynthetic $\mathrm{C}$ assimilation (Yu et al., 2008). This trade-off of water and $\mathrm{C}$ mechanism reflects the ecosystem adaptability to variable climate conditions, and are as well modulated by the climatic stress conditions. For example, Saleska et al. (2007) reported intact forest canopy "greenness" increased under drought stress. Huang et al. (2015) reported an increasing WUE due to effect of rising $\mathrm{CO}_{2}$, nitrogen deposition, and other climate change factors based on model simulations of the period 1982 to 2008. Keenan et al. (2013) using eddy-covariance flux measurements also found a substantial increase in WUE in mid- and high-latitude region due to rising GPP and decreasing evapotranspiration (ET) resulting from increasing ambient atmospheric $\mathrm{CO}_{2}$.

However, former studies regarding WUE at large scale generally used ET, LAI, GPP data directly from MODIS (Moderate Resolution Imaging Spectroradiometer) product, 
although these analyses were relatively coarse and inaccurate as they were based on flawed data inputs (e.g. Gao et al., 2014). These MODIS products were reported to be contaminated by various errors and rigid preprocessing procedures are required before any reasonable conclusions can be drawn (Zhao et al., 2005). Especially for investigations at fine scale such as the planted forest in China, which are mainly fragmented afforested, the errors and noises could overwhelmed the useful information if raw MODIS data were used without preprocessing. Additionally, there is a lack of studies assessing and comparing WUE between planted forest and natural forest under different water-heat stresses. This comparison is an urgent need because of its essential implications for forest management. For China, particularly, these implications are extremely valuable since the country has launched the largest planted forest program in the world and will continue to intensify the project in the next three decades. Assessing the response of WUE to past climate change will also provide insight into how to maximize the carbon sequestration benefit from limited water resources through optimization of afforestation activities in future.

Winter snow cover dynamics and drought events are reported to be particularly important for soil-atmosphere fluxes of greenhouse gases (Groffman et al., 2006). However, the impacts of snow variation on the variation of phenological events in natural vegetation have seldom been studied, and our understanding of the impacts of snow cover change on wintertime $\mathrm{C}$ budget is very limited, with most of evidence coming from in-situ observations. Moreover, a comprehensive assessment of the droughts' impacts on global ecosystems is needed since only a few studies have examined the post-drought recovery potential of different land covers globally. These issues need to be addressed as the vegetation leaf-out and soil respiration may respond primarily to soil temperature, while ecosystem resilience should be investigated to prevent large scale ecological collapse as well. Hence, changes in 
seasonal snow cover and drought stress may contribute to variations of growing season length and carbon exchange between the biosphere and the atmosphere.

Therefore, this dissertation project mainly aims at quantifying the impacts of climate change on carbon variations and enhancing the carbon sequestration ability of the terrestrial ecosystems under the background of snow variation, drought stress, land use and land cover change (afforestation and reforestation), and limited water recourses. Specifically the objectives of this proposed project are to:

(1) Evaluate the vegetation phenology trends under changing climate during the past three decades. Assess the impacts of climate change, such as snow, temperature, precipitation, on the above ground carbon variations.

(2) Investigate the underground carbon variations under changing climate during the past three decades. Quantify climate change's impacts on underground soil respiration at regional scales, specifically focus on winter soil carbon balance in the North Hemisphere.

(3) Quantify the impacts of drought events on ecosystem productivity and water use efficiency at global scale. Evaluate the change of global carbon and water relationship during the past decades.

(4) Assess the productivity and water use efficiency changes in natural and planted forest area under the changing climate in China. Provide suggestions on afforestation activities to support continuous contribution of carbon sink and enhanced water use efficiency under the pressure of disturbances. 


\section{References}

Barnett TP, Adam JC, Lettenmaier DP. 2005. Potential impacts of a warming climate on water availability in snow-dominated regions. Nature. 438: 303-309.

Berry PM, Dawson TP, Harrison PA, and Pearson RG. 2002. Modelling potential impacts of climate change on the bioclimatic envelope of species in Britain and Ireland. Global Ecology and Biogeography 11: 453-462.

Betts RA, Cox PM, Collins M, Harris PP, Huntingford C, and Jones CD. 2004. The role of ecosystem-atmosphere interactions in simulated Amazonian precipitation decrease and forest dieback under global climate warming. Theoretical and applied climatology 78: 157-175.

Battle M, Bender ML, Tans PP, White JWC, Ellis JT, Conway T, Francey RJ. 2000. Global carbon sinks and their variability inferred from atmospheric $\mathrm{O}_{2}$ and $\delta^{13} \mathrm{C}$. Science. 287: $2467-2470$.

Bert GD, Leavitt SW, Dupouey JL. 1997. Variations of wood $\delta 13 \mathrm{C}$ and water-use efficiency of Abies alba during the last century. Ecology 78: 1588-1596

Bousquet P, Peylin P, Ciais P, Le Quere C, Firedlingstein P, Tans PP. 2000. Regional changes in carbon dioxide fluxes of land and oceans since 1980. Science. 290: 13421346.

Brown RD and Brasnett B. 2010, updated annually. Canadian Meteorological Centre (CMC) Daily Snow Depth Analysis Data. [indicate subset used]. Boulder, Colorado USA: NASA DAAC at the National Snow and Ice Data Center. 
Brown RD, Robinson DA. 2011. Northern Hemisphere spring snow cover variability and change over 1922-2010 including an assessment of uncertainty. The Cryosphere, 5: 219-229.

Chmielewski FM, Muller A and Bruns E. 2004. Climate changes and trends in phenology of fruit trees and field crops in Germany, 1961-2000. Agricultural and Forest Meteorology. 121: 69-78.

Davidson EA, Savage K, Bolstad P, et al. 2002. Belowground carbon allocation in forests estimated from litterfall and IRGA-based soil respiration measurements. Agrie. For. Meteorol. 113: 39-51.

Defila C and Clot B. 2001. Phytophenological trends in Switzerland. International Journal of Biometeorology. 45: 203-207.

Dixon RK. 1994. Carbon pools and flux of global forest ecosystems. Science. 265: 171-171.

Dorrepaal E, Toet S, van Logtestijn RSP, Swart E, van de Weg MJ, Callaghan TV, Aerts R. 2009. Carbon respiration from subsurface peat accelerated by climate warming in the subarctic. Nature. 460: U616-U679.

Dye DG. 2002. Variability and trends in the annual snow-cover cycle in northern hemisphere land areas, 1972-2000. Hydrological Processes. 16: 3065-3077.

Euskirchen ES, McGuire AD, Chapin FS. 2007. Energy feedbacks of northern high latitude ecosystems to the climate system due to reduced snow cover during 20th century warming. Global Change Biology. 13: 2425-2438. 
Fan S, Mahlman J, Pacala S, Sarmiento J, Takahashi T, Tans PP. 1998. A large terrestrial carbon sink in north America implied by atmospheric and oceanic carbon dioxide data and models. Science. 282: 442-446.

Food and Agriculture Organization of the United Nations .2010. Global Forest Resources Assessment 2010. Food and Agriculture Organization of the United Nations. Available at: http://www.fao.org/forestry/fra/fra2010/en/. Accessed February 7, 2012.

Gao Y, Zhu X, Yu G, He N, Wang Q, and Tian J. 2014. Water use efficiency threshold for terrestrial ecosystem carbon sequestration in China under afforestation. Agricultural and Forest Meteorology 195: 32-37.

Giardina CP, Ryan MG, Binkley D and Fownes JH. 2003. Primary production and carbon allocation in relation to nutrient supply in a tropical experimental forest. Global Change Biology. 9: 1438-1450

Goulden ML, Munger JW, Fan SM, Daube BC and Wofsy SC. 1996. Measurements of carbon sequestration by long-term eddy covariance: methods and a critical evaluation of accuracy. Global Change Biology. 2: 169-182.

Groffman PM, Driscoll CT, Fahey TJ, Hardy JP, Fitzhugh RD, Tierney GL. 2001. Colder soils in a warmer world: A snow manipulation study in a northern hardwood forest ecosystem. Biogeochemistry. 56: 135-150.

Heumann BW, Seaquist JW, Eklundh L, and Jönsson P. 2007. AVHRR derived phenological change in the Sahel and Soudan, Africa, 1982-2005. Remote Sensing of Environment.108: 385-392. 
Huang M, Piao S, Sun Y, Ciais P, Cheng L, Mao J, Poulter B, Shi X, Zeng Z, and Wang Y. 2015. Change in terrestrial ecosystem water - use efficiency over the last three decades. Global Change Biology.

Houghton RA. 2007. Balancing the global carbon budget. Annu. Rev. Earth Planet. Science. 35: 313-347.

Huang MB, Zhang L, Gallichand J. 2003. Runoff responses to afforestation in a watershed of the Loess Plateau, China. Hydrological Processes, 17, 2599-2609.

Hubbard RM, Ryan MG, Elder K and Rhodes CC. 2005. Seasonal patterns in soil surface $\mathrm{CO}_{2}$ flux under snow cover in 50 and 300 year old subalpine forests. Biogeochemistry $73,93-107$.

Huxman TE, Smith MD, Fay PA, Knapp AK, Shaw MR, Loik ME, Smith SD et al. 2004. Convergence across biomes to a common rain-use efficiency. Nature 429, no. 6992: 651-654.

IPCC (Intergovernmental Panel on Climate Change). 2007. Climate Change 2007. The Physical Science Basis. Cambridge University Press, Cambridge.

Ito A, and Inatomi M. 2012. Water-use efficiency of the terrestrial biosphere: a model analysis focusing on interactions between the global carbon and water cycles. Journal of Hydrometeorology 13: 681-694.

Jentsch A, Kreyling J, Boettcher-Treschkow J, and Beierkuhnlein C. 2009. Beyond gradual warming: extreme weather events alter flower phenology of European grassland and heath species. Global Change Biology. 15: 837-849. 
Janssens IA, Freibauer A, and Ciais P, et al. 2003. Europe's terrestrial biosphere absorbs 7 to 12\% of European anthropogenic $\mathrm{CO}_{2}$ emissions. Science. 300: 1538-1542.

Jung M, Reichstein M, Ciais P, Seneviratne SI, Sheffield J, Goulden ML, Bonan G et al. 2010. Recent decline in the global land evapotranspiration trend due to limited moisture supply. Nature 467: 951-954.

Keenan TF., Hollinger DY, Bohrer G et al. 2013. Increase in forest water-use efficiency as atmospheric carbon dioxide concentrations rise. Nature 499: 324-327.

King DA. 2004. Climate Change Science: Adapt, Mitigate, or Ignore, Science, 303: 176-177.

Korzoun VI, and Sokolov AA. 1978. World water balance and water resources of the earth. Water Development, Supply and Management (UK) (USA) (Canada) (Australia) (France) (Germany, FR).

Laternser M, Schneebeli M. 2003. Long-term snow climate trends of the Swiss Alps (193199). Int. J. Climatol. 23: 733-750.

Law BE, Falge E, Gu L, et al. 2002. Environmental controls over carbon dioxide and water vapor exchange of terrestrial vegetation. Agricultural and Forest Meteorology. 113: 97-120.

Law BE, Ryan MG and Anthoni PM. 1999. Seasonal and annual respiration of a ponderosa pine ecosystem. Global Change Biology. 5: 169-182.

Liu YH, Wang D, Gao J, Deng W, 2005. Land Use/Cover Changes, the Environment and Water Resources in Northeast China, Environmental Management, 36, 691-701. 
Lucht W, Prentice I, Myneni R, et al. 2002. Climatic control of the high-latitude vegetation greening trend and Pinatubo effect. Science. 296: 687-1689.

L'vovich MI, White GF, Belyaev AV et al. 1990. Use and transformation of terrestrial water systems. The Earth as transformed by human action: global and regional changes in the biosphere over the past 300. 235-252.

Menzel A. 2000. Trends in phenological phases in Europe between 1951 and 1996. International Journal of Biometeorology. 44: 76-81.

Monson RK, Lipson DL, Burns SP, Turnipseed AA, Delany AC, Williams MW, Schmidt SK. 2006. Winter forest soil respiration controlled by climate and microbial community composition. Nature. 439: 711-714.

Monson RK, Sparks JP, Rosenstiel TN, et al. 2005. Climatic influences on net ecosystem C02 exchange during the transition from wintertime carbon source to springtime carbon sink in a high-elevation, subalpine forest. Oecologia. 146:130-147.

Mote PW, Hamlet AF, Clark MP, Lettenmaier DT. 2005. Declining mountain snowpack in Western North America. Bull. Am. Meteorol. Soc., 86: 39-49.

Mu Q, Heinsch FA, Zhao M, and Running SW. 2007. Development of a global evapotranspiration algorithm based on MODIS and global meteorology data. Remote Sensing of Environment 111: 519-536.

Mu Q, Zhao M, and Running SW. 2011. Improvements to a MODIS global terrestrial evapotranspiration algorithm. Remote Sensing of Environment 115: 1781-1800. 
Niu S, Xing X, Zhang ZHE, et al. (2011). Water use efficiency in response to climate change: from leaf to ecosystem in a temperate steppe. Global Change Biology 17(2): 1073-1082.

Pacala SW, Hurtt GC, and Baker D, et al. 2001. Consistent land- and atmosphere-based US carbon sink estimates. Science, 292: 2316-2320.

Peng S, Piao S, Ciais P. et al. 2010. Change in winter snow depth and its impacts on vegetation in China. Global Change Biology. 16: 3004-3013.

Peng S, Piao S, Zeng Z. et al. 2014. Afforestation in China cools local land surface temperature. Proceedings of the National Academy of Sciences 111: 2915-2919.

Piao SL, Friedlingstein $\mathrm{P}$, and Ciais $\mathrm{P}$, et al. 2006. Effect of climate and $\mathrm{CO}_{2}$ changes on the greening of the Northern Hemisphere over the past two decades. Geophysical Research Letter. 33: 1-6.

Pietsch SA, Hasenauer H. 2002. Using mechanistic modeling within forest ecosystem restoration. For Ecolo Manage 159(1):111-131.

Pan YD, Birdsey RA, Fang JY, et al. 2011. A large and persistent carbon sink in the world's forests. Science. 333: 988-993.

Parmesan C, Root TL, and Willig MR. 2000. Impacts of extreme weather and climate on terrestrial biota. Bulletin of the American Meteorological Society. 81: 443-450.

Parmesan C. 2007. Influences of Species, Latitudes and Methodologies on Estimates of Phenological Response to Global Warming. Global Change Biology. 13:1860-1872. 
Puettmann KJ. 2011. Silvicultural challenges and options in the context of global change:

"simple" fixes and opportunities for new management approaches. Journal of Forestry. 109 (6): 321-331.

Raich JW and Nadelhoffer KJ. 1989. Belowground carbon allocation in forest ecosystems: global trends. Ecology. 70: 1346-1354.

Raich JW, Potter C, Bhagawati D. 2002. Interannual variability in global soil respiration, 1980-94. Global Change Biology. 8: 800-812.

Rawlins MA, Willmott CJ, Shiklomanov A, Linder E, Frolking S, Lammers RB, Vorosmarty CJ. 2006. Evaluation of trends in derived snowfall and rainfall across Eurasia and linkages with discharge to the Arctic Ocean. Geophysical Research Letters. 33, L07403.

Richard AK. 2007. Global warming is changing the world. Science. 316: 188-190.

Ryan MG, Law BE. 2005. Interpreting, measuring, and modeling soil respiration. Biogeochemistry. 73: 3-27.

Ryan MG, Binkley D, Fownes JH, Giardina CP and Senock RS. 2004. An experimental test of the causes of forest growth decline with stand age. Ecol. Monog. 74: 393-414.

State Forestry Administration of the People's Republic of China. 2005. Sixth National Forest Resource Inventory Report (1999-2003) (State Forestry Administration of the People's Republic of China, Beijing).

State Forestry Administration of the People's Republic of China. 2009. Seventh National 
Forest Resource Inventory Report (2004-2008) (State Forestry Administration of the People's Republic of China, Beijing).

Saleska SR, Didan K, and Huete AR, et al. 2007. Amazon forests green-up during 2005 drought. Science. 318: 612.

Saurer M, Siegwolf RTW, and Schweingruber FH. 2004. Carbon isotope discrimination indicates improving water - use efficiency of trees in northern Eurasia over the last 100 years. Global Change Biology 10: 2109-2120.

Scherrer SC, Appenzeller C, Laternser M. 2004. Trends in Swiss alpine snow days-The role of local and large-scale climate variability. Geophys. Res. Lett. 31, L13215.

Schwartz MD, and Reiter BE, 2000, Changes in North American spring. International Journal of Biometeorology. 20: 929-932.

Solomon S, Qin D, and Manning M, et al. 2007. Climate Change 2007: The Physical Science Basis. Contribution of Working Group I to the Fourth Assessment Report of the Intergovernmental Panel on Climate Change, Cambridge Univ. Press.

Sturm M, Schimel J, Michaelson G, et al. 2005. Winter biological processes could help convert arctic tundra to shrubland. Bioscience. 55: 17-26.

Schwarz MD, and Reiter BE, 2000. Changes in North American spring. International Journal of Biometeorology. 20: 929-932.

Sun OJ, Campbell J, Law BE and Wolf V. 2004. Dynamics of carbon storage in soils and detritus across chronosequences of different forest types in the Pacific Northwest, 
USA. Global Change Biology. 10: 1470-1481

Tans PP, Fung IY, Takahashi T, 1990, Observational constraints on the global atmospheric $\mathrm{CO}_{2}$ budget. Science. 247: 1431-1438.

Tan B, Morisette JT, Wolfe RE, Gao F, Ederer GA, Nightingale J and Pedelty JA. 2011. An enhanced TIMESAT algorithm for estimating vegetation phenology metrics from MODIS data. IEEE Journal of Selected Topics in Applied Earth Observations and Remote Sensing. 4: 361-371.

Trenberth KE, Fasullo JT, and Kiehl J. 2009. Earth's global energy budget. Bulletin of the American Meteorological Society 90: 311-323.

Valentini R, Matteucci G, Dolman AJ, et al. 2000. Respiration as the main determinant of carbon balance in European forests. Nature. 404, 861-865.

Wahren CHA, Walker MD, Bret-Harte MS. 2005. Vegetation responses in Alaskan arctic tundra after 8 years of a summer warming and winter snow manipulation experiment. Global Change Biology. 11: 537-552.

Wang G, Innes JL, and Lei J, et al. 2007. China's forestry reforms. Science. 318: 1556-1557.

White MA, Running SW, and Thornton PE, 1999. The impact of growing-season length variability on carbon assimilation and evapotranspiration over 88 years in the eastern US deciduous forest. International Journal of Biometeorology. 42: 139-145.

Xiao XM, Hagen S., Zhang QY, Keller M, and Moore B. 2006. Detecting leaf phenology of seasonally moist tropical forests in South America with multi-temporal MODIS 
images. Remote Sensing of Environment. 103: 465-473.

Xu L, and Hsiao TC. 2004. Predicted versus measured photosynthetic water-use efficiency of crop stands under dynamically changing field environments. Journal of Experimental Botany 55: 2395-2411.

Yu G, Song X, Wang Q et al. 2008. Water-use efficiency of forest ecosystems in eastern China and its relations to climatic variables. New Phytologist 177: 927-937.

Zhao MX, Zhou JB, Kalbitz K, 2008. Carbon mineralization and properties of waterextractable organic carbon in soils of the south Loess Plateau in China. European Journal of Soil Biology 44, 158-165.

Zhao M, Heinsch FA, Nemani RR, and Running SW. 2005. Improvements of the MODIS terrestrial gross and net primary production global data set. Remote sensing of Environment 95: 164-176.

Zhu Q, Jiang H, Peng C, et al. 2011. Evaluating the effects of future climate change and elevated $\mathrm{CO} 2$ on the water use efficiency in terrestrial ecosystems of China. Ecological Modelling 222(14), 2414-2429. 


\section{Effects of seasonal snow on the growing season of temperate vegetation in China*}

"Published in Global Change Biology 


\section{Abstract}

Variations in seasonal snowfall regulate regional and global climatic systems and vegetation growth by changing energy budgets of the lower atmosphere and land surface. We investigated the effects of snow on the start of growing season (SGS) of temperate vegetation in China. Across the entire temperate region in China, the winter snow depth increased at a rate of $0.15 \mathrm{~cm} \cdot \mathrm{yr}^{-1}(\mathrm{p}=0.07)$ during the period 1982-1998, and decreased at a rate of 0.36 $\mathrm{cm}^{\circ} \mathrm{yr}^{-1}(\mathrm{p}=0.09)$ during the period 1998-2005. Correspondingly, the SGS advanced at a rate

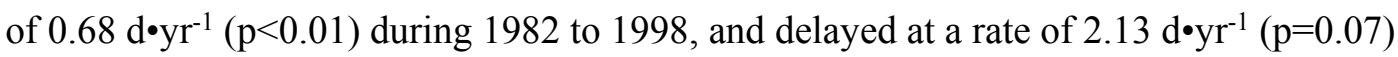
during 1998 to 2005, against a warming trend throughout the entire study period of 19822005. Spring air temperature strongly regulated the SGS of both deciduous broad-leaf and coniferous forests; whilst the winter snow had a greater impact on the SGS of grassland and shrubs. Snow depth variation combined with air temperature contributed to the variability in the SGS of grassland and shrubs, as snow acted as an insulator and modulated the underground thermal conditions. Additionally, differences were seen between the impacts of winter snow depth and spring snow depth on the SGS; as snow depths increased, the effect associated went from delaying SGS to advancing SGS. The observed thresholds for these effects were snow depths of $6.8 \mathrm{~cm}$ (winter) and $4.0 \mathrm{~cm}$ (spring). The results of this study suggest that the response of the vegetation's SGS to seasonal snow change may be attributed to the coupling effects of air temperature and snow depth associated with the underground thermal conditions. 


\subsection{Introduction}

Phenological variation has potential impacts on global vegetation's net primary productivity; carbon, water, and nitrogen cycles; the duration of pollination season; and the spread of diseases (Lucht et al. 2002, Schwartz 2000, White et al. 1999, Menzel 2000). Warming has been considered to be a major factor resulting in the advance of the start of growing season (SGS) trend, that has been witnessed, in the northern hemisphere during the past three decades (Menzel \& Fabian, 1999; Vitasse et al., 2009; Wang et al., 2010; Piao et al., 2006; Zeng et al., 2011, Yu et al., 2010b). However, increased air temperature, accompanied with reduced snow-cover, may lead to increased water stress and ultimately constrain the growth of vegetation (IPCC, 2007; Sun et al., 2012). For most temperate tree species, phenological events are primarily, but not solely, dictated by air temperature (Körner \& Basler, 2010); variations in seasonal snow cover may interact with air temperature to affect plant growth. For instance, winter warming could reduce snowfall, or shorten the duration of snow cover, thereby increasing soil freezing (Hardy et al., 2001) and root mortality (Peng et al., 2010; Wahren et al., 2005), which in turn leads to a delayed growing season and reduced vegetation growth (Bilbrough et al., 2000; Grippa et al., 2005; Bonan, 1992). In addition, increased spring snow may delay the warming of soil into the growing season and increase the possibility of soil freezing (Venalainen et al., 2001), and dramatically shorten the growing length of trees in terms of sap flow (Mellander et al., 2004) and net carbon assimilation (Strand et al., 2002).

In January, snow covers about 45 million $\mathrm{km}^{2}$, or nearly one-half of the land of the Northern Hemisphere (Stephen \& Ross, 2007). In western China, the snow depth has nearly 
doubled, increasing 92\% from 1957 to 1998 (Qin et al., 2006). This change in snow depth and snow cover may have potential impacts on global warming and water circulation by increasing the albedo of land surface (Yasunari et al., 2011). At mid- and high-northern latitudes, seasonal thawing and snowmelt are closely linked to the potential growing season length and vegetation productivity (Walker et al., 1999). As an effective insulator, snow protects soil from exposure to both wind and low temperature extremes, leading to higher soil temperature in snow-covered areas than in snow-free areas (Peng et al., 2010). Therefore, variations in seasonal snow cover may regulate plant growth through impacts on soil freezing and thawing (Cooper et al., 2011; Euskirchen et al., 2006).

Temperate China is covered by forests, shrubs and grasslands along the thermal and moisture gradients from semi-arid and low altitude northeast plain to humid and high elevation Tibetan Plateau. The whole study area has persistent, insulated snow cover through much of the winter season (Peng et al., 2010). Changes in the winter air temperature may have different impacts on soil temperature depending on the depth of this snow cover. The Tibetan Plateau specifically plays a vital role in the formation of Asian monsoon climate and the water supply of major Asian rivers (Liu \& Yin, 2002; Immerzeel et al., 2008). This is especially true where seasonal snowpack variation is critical to regional and global water and carbon cycles (Wang et al., 2008; Qiu, 2008). In addition, winter snow cover dynamics is reported to be particularly important for soil-atmosphere fluxes of greenhouse gases (Groffman et al., 2006). However, the impacts of snow variation on the variation of phenological events in natural vegetation have seldom been studied. Most previous field experiments and studies focused primarily on the influences of aboveground warming and the 
impacts of underground thermal condition were often ignored (Rollinson \& Kaye, 2012), but this apparently needs to be addressed as the leaf-out may respond primarily to soil temperature for annual plants (Yu et al., 2010a). Hence, changes in seasonal snow cover may contribute to variations of growing season length, which in turn affects carbon exchange between the biosphere and the atmosphere.

In this study, we examined the potential effects of snow depth variations on the leafout of different temperate vegetation in China from 1982 to 2005, using remote sensing data and ground meteorological observation data. This study was designed specifically to test the following hypotheses: 1) temperate vegetation phenology are constrained by interactive effects of seasonal air temperature and snow depth, and 2) effects of seasonal snow on temperate vegetation phenology vary with snow depth, vegetation types and locations. 


\subsection{Materials and methods}

\subsubsection{Study area}

Temperate regions in China, which frequently experience seasonal snow, were chosen as the study area, while subtropical and tropical areas were excluded (Figure 2-1). The snow duration in the temperate regions from winter (December-February) to spring (March-May) varies with air temperature and elevation. The study area, which is cold and dry in winter and warm and humid in summer, covers the cold temperate, middle temperate, warm temperate, alpine and subalpine zones (Chen et al., 2005). Based on the digitized 1:1,000,000 vegetation map (Institute of Botany, Chinese Academy of Sciences, 2001), twelve vegetation types in temperate China were designated to assess the effect of snow depth variations on vegetation growth (Figure 2-1). 


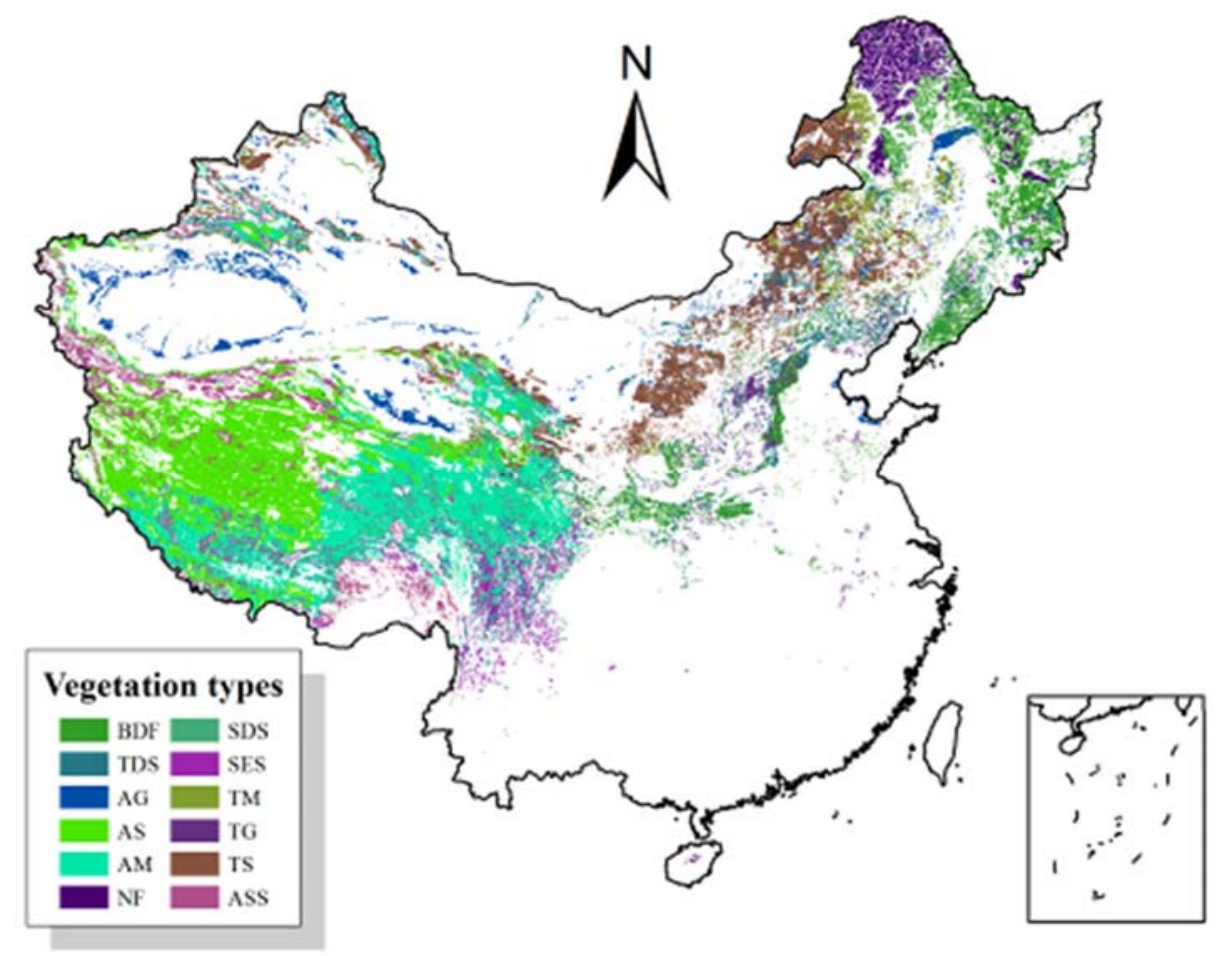

Figure 2-1 Spatial distribution of vegetation types in temperate China (BDF, broad-leaf deciduous forests; TDS, temperate deciduous shrubs; AG, alpine grasslands; AS, alpine steppes; AM, alpine meadows; NF, needle-leaf forests; SDS, subalpine deciduous shrubs; SES, subalpine evergreen shrubs; TM, temperate meadows; TG, temperate grasslands; TS, temperate steppes; ASS, alpine sparse shrubs).

\subsubsection{NDVI and climate data}

Biweekly Normalized Difference Vegetation Index (NDVI) data from 1982 to 2005 were obtained from the Global Inventory Modeling and Mapping System (GIMMS) at the NASAs Goddard Space Flight Center. The NDVI data were derived from the Advanced Very High Resolution Radiometer (AVHRR) sensor aboard NOAA polar orbiting satellites, which was calculated from AVHRR bands as: 


$$
N D V I=\frac{R_{n i r}-R_{r}}{R_{n i r}+R_{r}}
$$

Where $R_{r}$ is the spectral reflectance in visible bands $(550-700 \mathrm{~nm})$ and $R_{n i r}$ is the spectral reflectance in near infrared bands (730-1000 nm) (Sun et al., 2012). The original NDVI data were calibrated to minimize the effects of sensor degradation. In addition, the maximum value composite (MVC) algorithm was applied on the NDVI data set to reduce the effects of cloud contamination and stratospheric aerosol loadings from volcanic eruptions (Piao et al., 2006; Holben 1986).

The air temperature data were collected from 752 standard observations across China and interpolated into $8 \times 8 \mathrm{~km}$ resolution using the thin plate smoothing splines method (Hutchinson \& Gessler, 1994) provided by Anusplin software package (Ver. 4.1, Australian National University, Center for Resources and Environmental Studies, Canberra, Australia). The Anusplin package has been widely used in the interpolation of climatic factors (McVicar et al., 2007). This package was used to perform a quart-variate partial thin plate spline incorporating a bi-variate thin plate spline as a function of longitude, latitude and constant linear dependences on elevation was used in simulating surfaces of monthly air temperature.

\subsubsection{Snow data}

The detection of snow information using visible wavelength data is restricted by the requirement for clear sky conditions, and has limits and defects. In addition, snow depth information cannot be extracted from the visible-band data (Armstrong \& Brodzik, 1995). By contrast, passive microwave remote sensing is advantageous in the dark and under nearly all weather conditions (Armstrong \& Brodzik, 1995). Passive microwave sensing also provides 
the potential to compute snow water equivalent and to detect snowmelt (Kunzi et al., 1982; Foster et al., 1984; Rott, 1987). These additional variables comprise important input factors in energy budget, hydrologic and global circulation models, and therefore enhance the capability to evaluate climate change (Goodlson \& Walker, 1993).

Monthly snow depth data were provided by the Environmental \& Ecological Science Data Center for the Western China and the National Natural Science Foundation of China with spatial resolution of $25 \times 25 \mathrm{~km}^{2}$ (Che, 2006), which can be freely download at http://westdc.westgis.ac.cn. The long-term snow depth dataset of China was derived from passive microwave remote sensing data of Scanning Multichannel Microwave Radiometer (SMMR, 1978-1987) and Special Sensor Microwave/Image (SSM/I, 1987-2005). The SMMR is the first multi-frequency space-borne microwave sensor offering a surface resolution of $<60 \mathrm{~km}$ in the frequency range $(18-37 \mathrm{GHz})$ of interest in snow research (Kunzi et al., 1982). The SSM/I is carried on a spacecraft in a circular sun-synchronous, near-polar orbit at an altitude of $833 \mathrm{~km}$. With a swath width of almost $1400 \mathrm{~km}$, the SSM/I provides nearly global coverage every day (Armstrong \& Brodzik, 1995).

\subsubsection{Start of growing season}

Declining snow-cover may be, partially, responsible for the higher NDVI value associated with the greening trend (Shabanov et al., 2002), thus we assigned the minimum NDVI value to 0 , to avoid any sharply increased effects of the NDVI induced by snowmelt. A double logistic approach of Timesat software (v3.1) was applied to smooth and reconstruct the NDVI time series dataset, since this algorithm is more suitable than other algorithms at 
high latitude, such as Savitzky-Golay and asymmetric Gaussian (Zeng et al., 2011). The basic function of the algorithm is expressed as:

$$
g\left(t ; x_{1}, \ldots, x_{4}\right)=\frac{1}{1+\exp \left(\frac{x_{1}-t}{x_{2}}\right)}-\frac{1}{1+\exp \left(\frac{x_{3}-t}{x_{4}}\right)}
$$

where $x_{1}$ determines the position of the left inflection point while $x_{2}$ gives the rate of change. Similarly, $x_{3}$ determines the position of the right inflection point while $x_{4}$ gives the rate of change at this point (Eklundh \& Jonsson, 2010).

\subsubsection{Statistical analysis}

Seasonal (December-February = winter, March-May = spring) snow depth were computed by calculating the mean of daily data within a season and multiplying by days of the season. Simple linear regressions were applied to analyze the trends of seasonal temperature, snow depth, and vegetation SGS dates. Stepwise regressions were specifically conducted to examine the significance of the four scaled-predictors (winter snow, spring snow, winter temperature, and spring temperature) and their potential interactions, and to reveal the contributions of these variables to the SGS dates. The generalized model is expressed as:

$$
f\left(S W, S S, W T, S T, S W^{2}, S S^{2}, W T \times W S, S T \times S S\right)
$$

where WT represents winter temperature; ST is spring temperature; WS is winter snow depth; $S S$ is spring snow depth; $W S^{2}$ is the quadratic term of winter snow depth; and $S S^{2}$ is the quadratic term of spring snow depth. $W T \times W S$ and $S T \times S S$ are the interactive terms of winter 
temperature and snow, and spring temperature and snow, respectively. Quadratic fittings were used to identify the seasonal snow depth thresholds in different vegetation types.

Correlation coefficients between variables were explored using Pearson's correlations. The image data processing and statistical analyses were performed on Matlab (vR2011b, the MathWorks Inc.), ENVI/IDL (v4.5, the EXELIS Inc.), and R (v2.14.1) platforms. 


\subsection{Results}

\subsubsection{Patterns of air temperature, snow depth and start of growing season}

Annual mean air temperature ranged from about $15^{\circ} \mathrm{C}$ in central China to about $5^{\circ} \mathrm{C}$ in the Northeast and to $-10^{\circ} \mathrm{C}$ in the Tibetan Plateau (Figure 2-2a). Annual mean snow depth ranged from $1 \mathrm{~cm}$ in the central Tibetan Plateau and the northern China, to approximately 5 $\mathrm{cm}$ in the Southeast Tibetan Plateau, the Northwest, and the Northeast of China (Figure 2$2 b)$. The spatial pattern of SGS showed great variation over the temperate China during the period of 1982 to 2005 (Figure 2-2c). In general, the SGS's date decreased from about 150180 days of the year (DOY) (May to June) in the Tibetan Plateau to about 90-120 DOY (April) in the Northeast and Northwest of China.
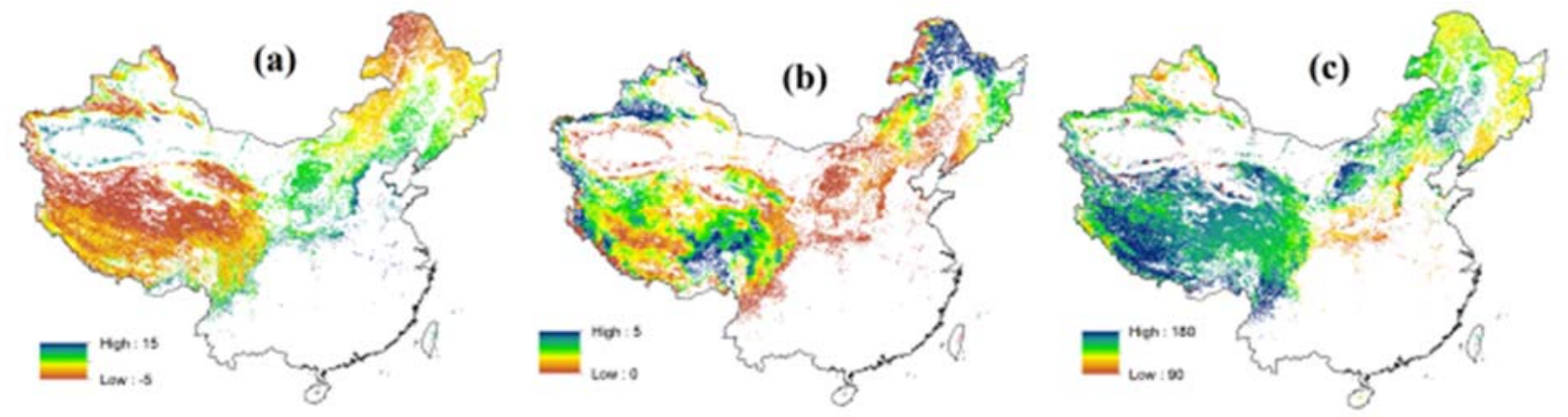

Figure 2-2 Spatial patterns of annual mean air temperature $\left(a,{ }^{\circ} \mathrm{C}\right)$, snow depth $(b, \mathrm{~cm})$, and start of growing season (c, day of the year).

Most of the study area experienced an intensive warming during 1982 to 2005 (Figure 2-3). The most pronounced warming was observed in the Tibetan Plateau, with the increase in temperature ranging from 0.03 to $0.10{ }^{\circ} \mathrm{C} \cdot \mathrm{yr}^{-1}$ (Figure 2-3a). In contrast, snow depth showed a positive trend at a rate from $0.20-0.90 \mathrm{~cm}^{\bullet} \mathrm{yr}^{-1}$ in the west of Tibetan Plateau; 
whereas the negative trends at a rate from $0.02--0.10 \mathrm{~cm} \bullet \mathrm{yr}^{-1}$ occurred in the east of Tibetan Plateau (Figure 2-3b).
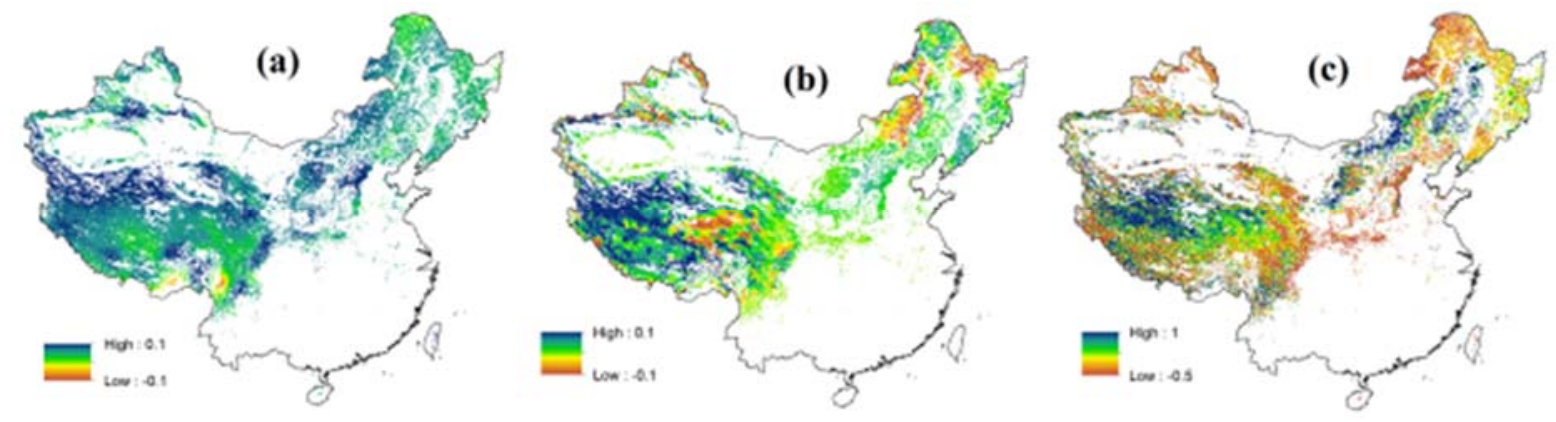

Figure 2-3 Spatial distributions of the trends of annual mean temperature $\left(a, \times{ }^{\circ} \mathrm{C} \mathrm{yr}^{-1}\right)$, snow depth $\left(b, \times c m y^{-1}\right)$, and start of growing season $\left(c, \times\right.$ day $\left.y^{-1}\right)$.

Temperate zone of China exhibited great spatial variations in vegetation types. The SGS was delayed at a magnitude of 0.50- 2.0 days $\bullet \mathrm{yr}^{-1}$ in the north of Tibetan Plateau and the east of Inner-Mongolia (Figure 2-3c). In contrast, an advance of the SGS mainly occurred in the east and south of Tibetan Plateau and the northeastern China.

Two distinct trends in SGS were observed before and after 1998 over the period 19822005 (Figure 2-4a). The SGS of temperate vegetation in China advanced significantly by 0.68 $\mathrm{d} \cdot \mathrm{yr}^{-1}(\mathrm{p}<0.01)$ from 1982 to 1998 , and then delayed by $2.13 \mathrm{~d} \bullet \mathrm{yr}^{-1}(\mathrm{p}=0.07)$ from 1998 to 2005. Similarly, the winter snow depth showed a marginally increasing trend $(p=0.07)$ at a

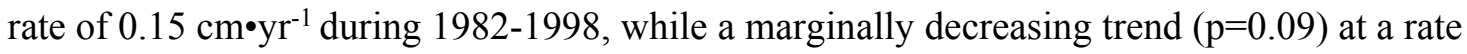

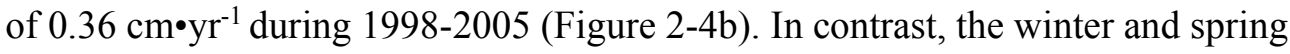
temperatures had been increasing at a rate of $0.071(\mathrm{p}<0.001){ }^{\circ} \mathrm{C} \cdot \mathrm{yr}^{-1}$ and $0.078{ }^{\circ} \mathrm{C} \cdot \mathrm{yr}^{-1}$ $(\mathrm{p}<0.001)$ during 1982 to 2005 , respectively (Figure 2-4c). 

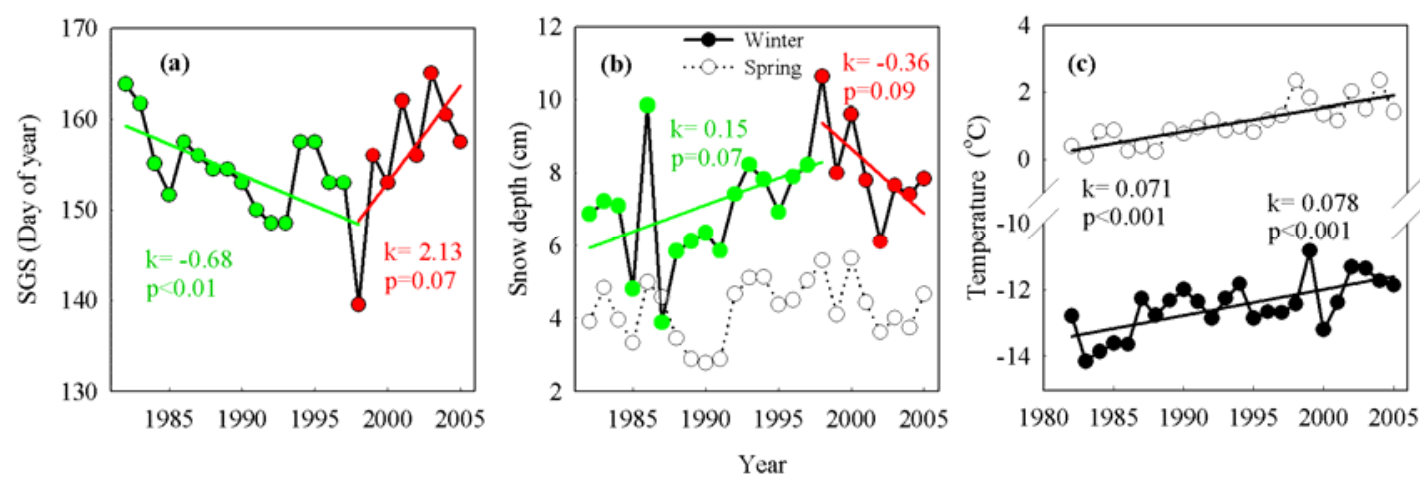

Figure 2-4 Inter-annual variations of the start of growing season (SGS), seasonal snow depth, and air temperature in the temperate China. (a: SGS trend; b: winter and spring snow depth trends; c: winter and spring temperature trends; green, red, and black dots represent the periods of 1982-1998, 1998-2005 and 1982-2005, respectively; $k$ denotes the slope of linear regression).

\subsubsection{Trends of air temperature and SGS in different vegetation types}

All temperate vegetation types experienced a significant warming (Figure 2-5). Both winter and spring temperatures of the areas classified by vegetation type: Temperate Deciduous Shrubs (TDS), Subalpine Deciduous Shrubs (SDS), Subalpine Evergreen Shrubs (SES), (Alpine Grasslands (AG), Alpine Steppes (AS), Alpine Meadows (AM), Alpine Sparse Shrubs (ASS), Temperate Grasslands (TG), Temperate Steppes (TS); showed an increasing temperature trend ranging from 0.045 to $0.100{ }^{\circ} \mathrm{C} \cdot \mathrm{yr}^{-1}$, especially in the areas of alpine and subalpine.

For the entire period from 1982 to 2005 , a delayed trend of SGS was demonstrated in AG at a rate of $0.08 \mathrm{~d} \cdot \mathrm{yr}^{-1}(\mathrm{p}<0.01)$, while an advancing trend was observed in TDS and TG at a rate of $0.03 \mathrm{~d} \cdot \mathrm{yr}^{-1}(\mathrm{p}=0.06)$ and $0.05 \mathrm{~d} \cdot \mathrm{yr}^{-1}(\mathrm{p}<0.05)$, respectively. Despite the positive 
trends of both winter and spring temperatures that were detected in the AG vegetation, a delayed trend was observed for the SGS's date from 1982 to 2005.
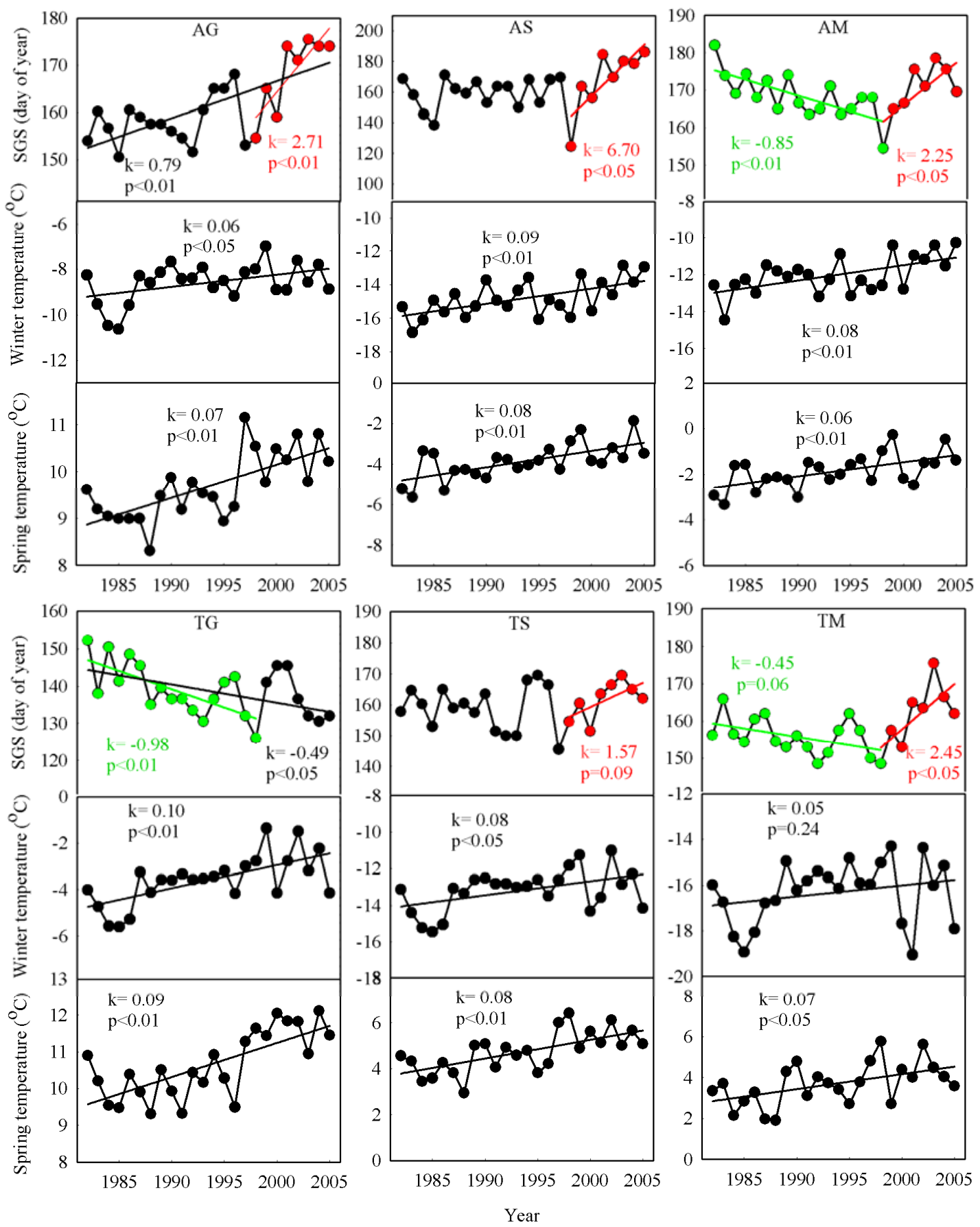

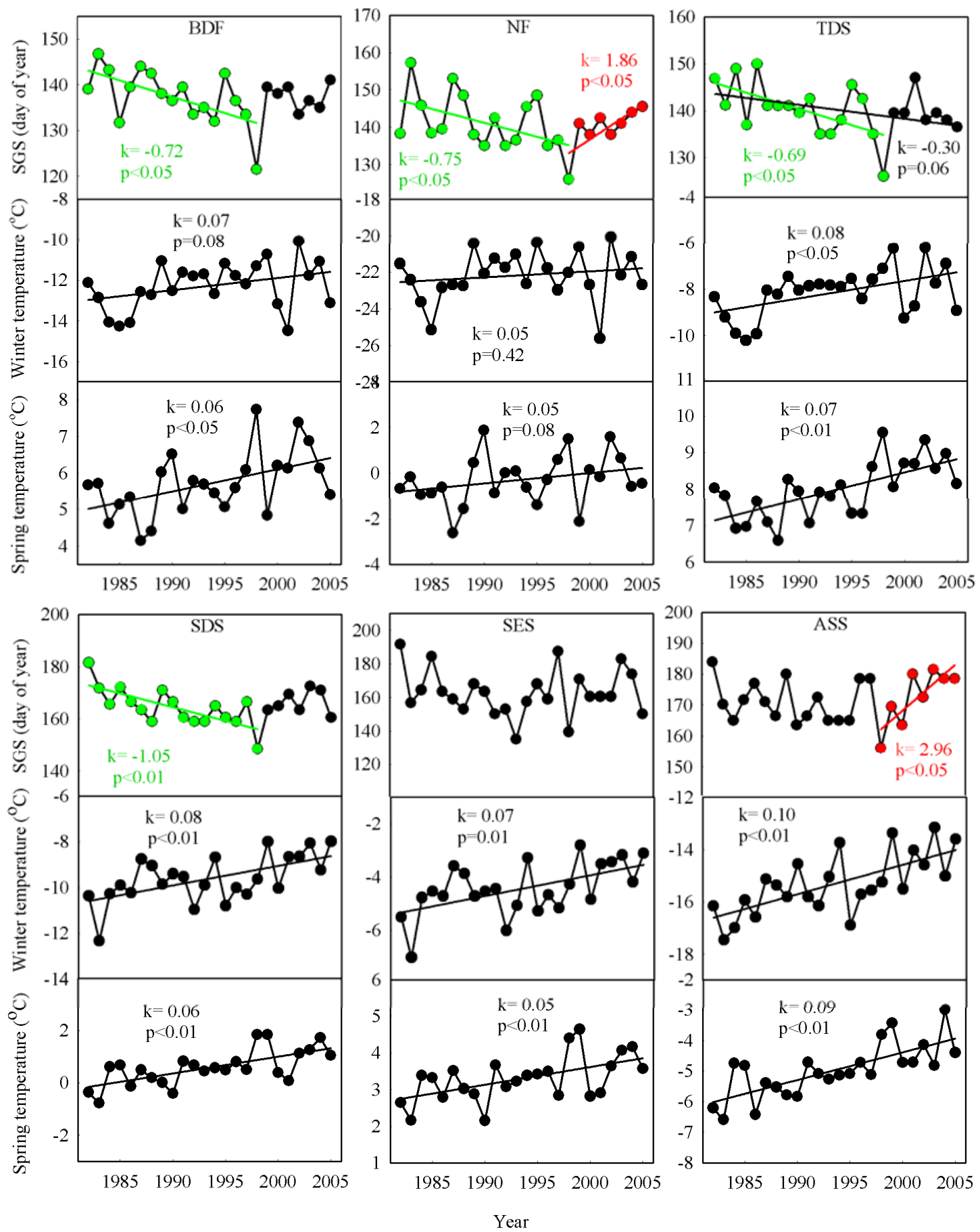

Figure 2-5 Trends of the winter and spring temperatures and the start of growing season (SGS) of different vegetation types (green red and black dots indicate the periods of 19821998, 1998-2005, and 1982-2005, respectively; $k$ denotes the slope of linear regression;

For the SGS trend, the period only with significant trend is presented). 
During 1982 to 1998, the advanced trends were found in the Broad-leaf Deciduous Forests (BDF) and Needle-leaf Forests (NF)), the shrubs (TDS and SDS), and grasslands (AM, TM, and TG). In the period of 1998 to 2005, however, the delayed trends of SGS were primarily exhibited in the grasslands (AG, AS, AM, TM, and TS), and some in shrubs and forests (ASS and NF).

\subsubsection{Correlations between snow depth, air temperature and SGS}

From 1982 to 1998, an advancing trend of the SGS was observed in a vast area of temperate vegetation zones (71\%) in China (Figure 2-6a), particularly in the areas to the east of the Tibetan Plateau, at a rate ranging from 1.0 to $2.5 \mathrm{~d} \cdot \mathrm{yr}^{-1}$. An advancing trend of the SGS was also observed in the northeastern China at a rate of 0.5 to $1.0 \mathrm{~d} \cdot \mathrm{yr}^{-1}$, while a delaying trend ranging from 1.0 to $3.0 \mathrm{~d} \bullet \mathrm{yr}^{-1}$ occurred in the central Inner-Mongolia.

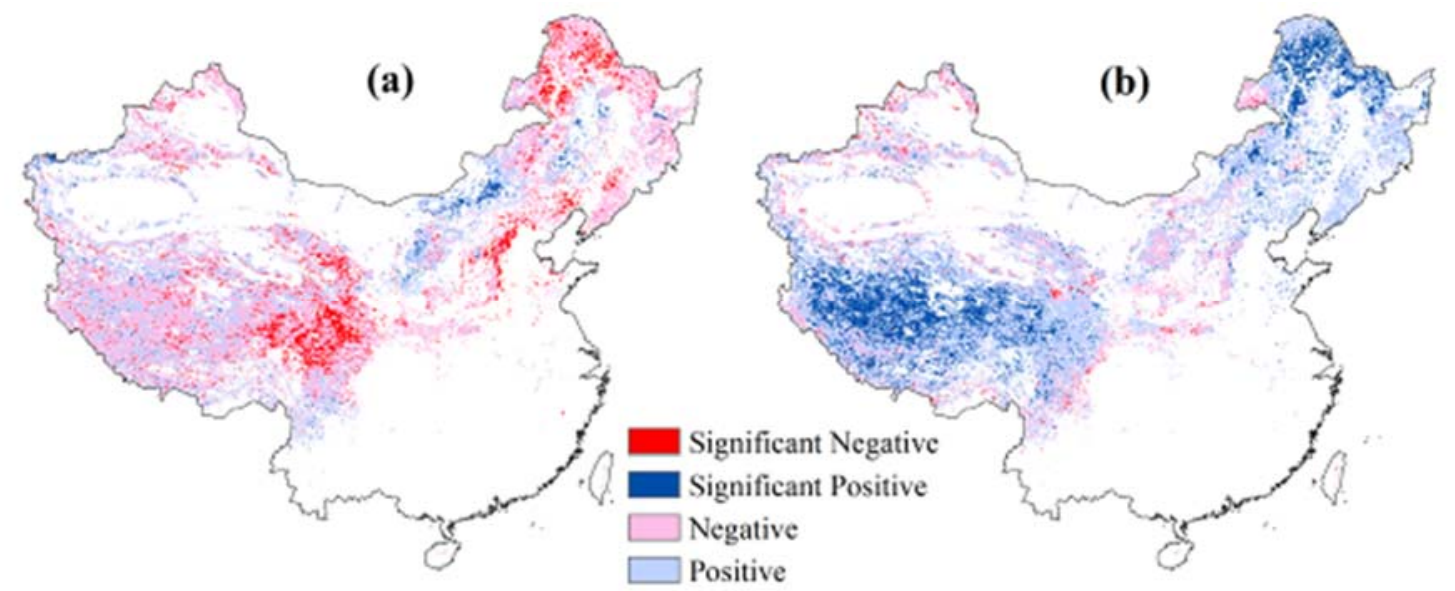

Figure 2-6 Change trends of the start of growing season during time periods of [19821998 (a) and 1998-2005 (b)].

By contrast, during 1998-2005, approximately $79 \%$ of the temperate vegetation zones demonstrated a delayed SGS (Figure 2-6b). The most significant, temporal delays of the SGS 
were observed in the Tibetan Plateau $\left(2.0-9.0 \mathrm{~d} \cdot \mathrm{yr}^{-1}\right)$ and also in the northeastern China (2.0 - $\left.3.0 \mathrm{~d} \cdot \mathrm{yr}^{-1}\right)$. In part of central China and the west of northeastern China, a negative trend of the SGS occurred at rates ranging from 0.5 to $2.0 \mathrm{~d} \cdot \mathrm{yr}^{-1}$.

During the period from 1982 to 2005, a significant negative correlation existed between spring temperature and the SGS in the vegetation of forest types $(\mathrm{BDF}, \mathrm{p}<0.05$; NF, $\mathrm{p}<0.05$ ) and the shrub types (TDS, $\mathrm{p}<0.05$; SES, $\mathrm{p}<0.05$ ) (Table 1). Like spring temperature, winter snow also had an advancing effect on the SGS of AM $(p=0.07)$ and TG $(p<0.05)$. In comparison, during 1982-1998, a negative correlation between spring temperature and the SGS also existed in most vegetation types, except for few types of grassland and shrubs (AG, SES, TG and TS). During the time period of 1998 to 2005, however, a significantly negative correlation between spring temperature and the SGS was found in the BDF. Both the winter and spring snow depths were negatively correlated with the SGS in most of the shrub types $(\mathrm{SDS}, \mathrm{p}<0.01$; SES, $\mathrm{p}<0.05$; ASS, $\mathrm{p}<0.05)$ and a few of grassland types (AS, $\mathrm{p}<0.01$; AM, $\mathrm{p}<0.05)$. 
Table 2-1 Correlations and significance levels between seasonal snow depth, air temperature and the SGS in different time periods and

vegetation types*

\begin{tabular}{|c|c|c|c|c|c|c|c|c|c|c|c|c|c|c|c|c|c|c|c|c|c|c|c|c|}
\hline & \multicolumn{8}{|c|}{$1982-2005$} & \multicolumn{8}{|c|}{$1982-1998$} & \multicolumn{8}{|c|}{$1998-2005$} \\
\hline & \multicolumn{2}{|c|}{ SWS } & \multicolumn{2}{|c|}{ SSS } & \multicolumn{2}{|c|}{ SWT } & \multicolumn{2}{|c|}{ SST } & \multicolumn{2}{|c|}{ SWS } & \multicolumn{2}{|c|}{ SSS } & \multicolumn{2}{|c|}{ SWT } & \multicolumn{2}{|c|}{ SST } & \multicolumn{2}{|c|}{ SWS } & \multicolumn{2}{|c|}{ SSS } & \multicolumn{2}{|c|}{ SWT } & \multicolumn{2}{|c|}{$\mathrm{SST}$} \\
\hline & $\mathrm{r}$ & $p$ & $\mathrm{r}$ & $p$ & $\mathrm{r}$ & $p$ & $\mathrm{r}$ & $p$ & $\mathrm{r}$ & $p$ & $\mathrm{r}$ & $p$ & $\mathrm{r}$ & $p$ & $\mathrm{r}$ & $p$ & $\mathrm{r}$ & $p$ & $\mathrm{r}$ & $p$ & $\mathrm{r}$ & $p$ & $\mathrm{r}$ & $p$ \\
\hline $\mathrm{BDF}$ & & & 0.47 & 0.02 & & & -0.7 & 0.01 & & & 0.47 & 0.06 & & & -0.73 & 0.001 & & & 0.62 & 0.10 & & & -0.79 & 0.0 \\
\hline TDS & & & 0.35 & 0.09 & -0.4 & 0.03 & -0.5 & 0.02 & & & & & -0.53 & 0.03 & -0.60 & 0.01 & & & & & & & & \\
\hline $\mathrm{AG}$ & 0.49 & 0.01 & & & & & & & 0.51 & 0.04 & 0.46 & 0.06 & & & & & & & & & & & & \\
\hline AS & & & & & 0.54 & 0.01 & & & & & & & & & -0.54 & 0.03 & -0.92 & 0.001 & -0.90 & 0.002 & 0.82 & 0.01 & & \\
\hline $\mathrm{AM}$ & -0.40 & 0.07 & & & & & & & & & & & & & -0.58 & 0.01 & -0.83 & 0.01 & -0.68 & 0.06 & & & & \\
\hline $\mathrm{NF}$ & & & & & & & -0.6 & 0.01 & & & & & & & -0.70 & 0.001 & & & & & & & & \\
\hline SDS & & & & & & & & & & & & & & & -0.74 & 0.001 & -0.85 & 0.007 & -0.71 & 0.05 & & & & \\
\hline SES & & & & & & & -0.4 & 0.03 & & & & & & & & & & & -0.76 & 0.03 & & & & \\
\hline $\mathrm{TM}$ & & & & & & & & & & & & & & & -0.49 & 0.04 & & & & & & & & \\
\hline TG & -0.50 & 0.02 & & & -0.4 & 0.04 & & & -0.54 & 0.03 & & & -0.60 & 0.01 & & & & & & & & & & \\
\hline TS & & & & & & & & & & & & & & & & & & & & & & & & \\
\hline ASS & & & & & & & & & & & & & & & -0.50 & 0.04 & -0.79 & 0.02 & -0.62 & 0.10 & 0.63 & 0.09 & & \\
\hline
\end{tabular}

*Significant levels of higher than $\mathrm{p}<0.10$ are shown; $\mathrm{r}=$ correlation coefficient; $p=$ significant level; SWS = correlation between SGS and winter snow; SSS

$=$ correlation between SGS and spring snow; SWT = correlation between SGS and winter temperature; SST = correlation between SGS and spring temperature. 
The stepwise multiple regression models were fitted at significance level of $\alpha=0.05$

(Table 2). After elimination process, the terms of snow-temperature interactions were preserved in the best fitted models of BDF, TDS, AM, AS, SDS, and SES ( $p<0.05)$. In contrast, the fitted models of AG, TG, and ASS only include the factors of spring and winter snow depth.

Specifically, all the fitted models contain the quadratic terms of seasonal snow depth.

Table 2-2 Models of best fit stepwise multiple regression analysis in AS and AM areas

\begin{tabular}{cccc}
\hline Species & Models & Adjusted & $\mathrm{p}$ \\
\hline BDF & $-0.33 \times W S^{2}-0.64 \times S T-0.38 \times W S \times W T+0.17$ & 0.49 & $<0.001$ \\
TDS & $-0.27 \times W S^{2}-0.47 \times W S+0.22 \times S S^{2}+0.64 \times S S+0.47 \times S S \times S T+0.16$ & 0.38 & $<0.05$ \\
AG & $-0.26 \times S S^{2}+0.48 \times W S+0.25$ & 0.29 & $<0.05$ \\
AM & $-0.39 \times S S^{2}-0.34 \times S S-0.41 \times S T-0.34 \times S S \times S T+0.27$ & 0.35 & $<0.05$ \\
AS & $-0.32 \times W S^{2}+0.40 \times W T+0.36 \times S S \times S T+0.18$ & 0.63 & $<0.001$ \\
NF & $0.37 \times W S^{2}-0.61 \times S T-0.35$ & 0.49 & $<0.05$ \\
SDS & $-0.29 \times S S^{2}-0.27 \times S S-0.55 \times S T+0.39 \times W S \times W T-0.54 \times S S \times S T+0.29$ & 0.53 & $<0.01$ \\
SES & $-0.54 \times S S^{2}-0.55 \times W S-0.51 \times W T+0.51 \times W S \times W T-0.44 \times S S \times S T+0.53$ & 0.47 & $<0.01$ \\
TG & $0.38 \times W S^{2}-0.43 \times S S^{2}-1.06 \times W S+0.91 \times S S+0.05$ & 0.34 & $<0.05$ \\
ASS & $-0.53 \times S S^{2}-0.28 \times W S+0.51$ & 0.25 & $<0.05$ \\
\hline WT:
\end{tabular}

WT: winter temperature; ST: spring temperature; WS: winter snow depth; SS: spring snow depth. All variables are scaled before regression.

\subsubsection{Seasonal air temperature, snow depth and SGS}

A plot of the temperate SGS vs. the winter and spring snow depth indicates the effects of seasonal snow depth variations on vegetation leaf-out (Figure 2-7). Throughout the entire study area, the effects of seasonal snow on the SGS varied from a delaying effect to advancing effect when the snow layer exceeded a threshold depth (spring: $4.03 \mathrm{~cm}, \mathrm{p}<0.01$; winter: $6.81 \mathrm{~cm}$, $\mathrm{p}<0.05)$. 


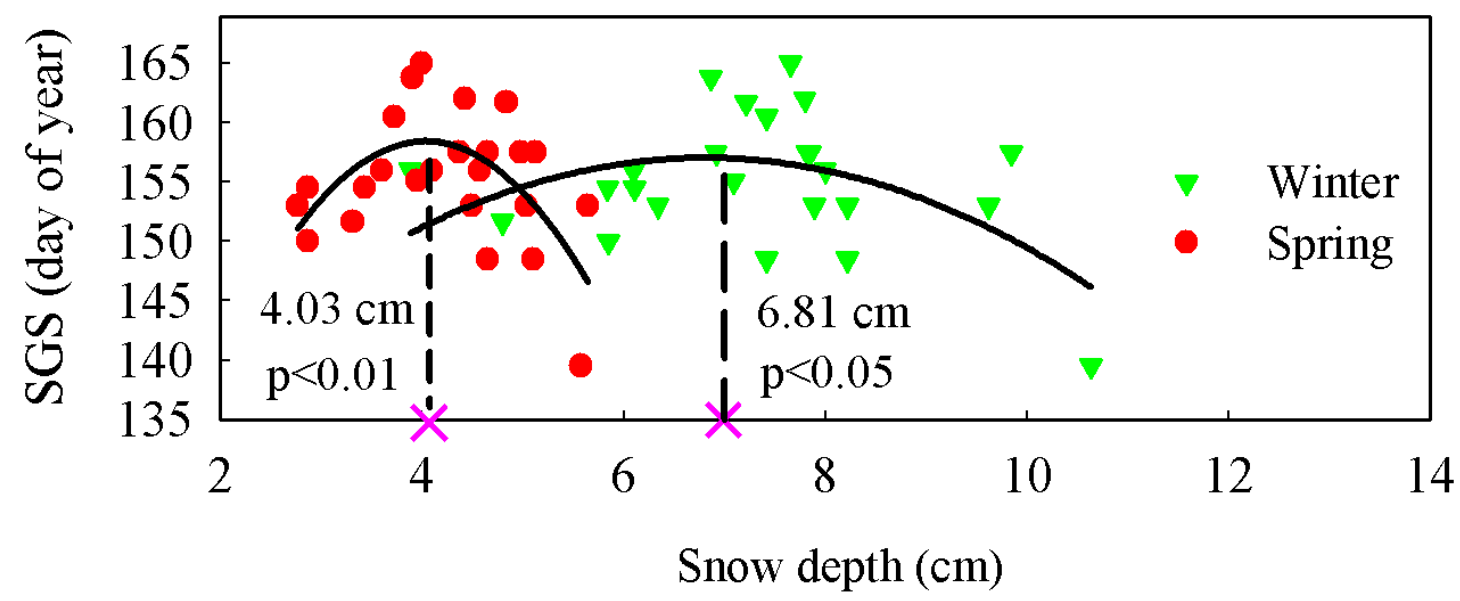

Figure 2-7 Seasonal snow depths vs. the start of growing season in the temperate China. (Red: spring; green: winter). 

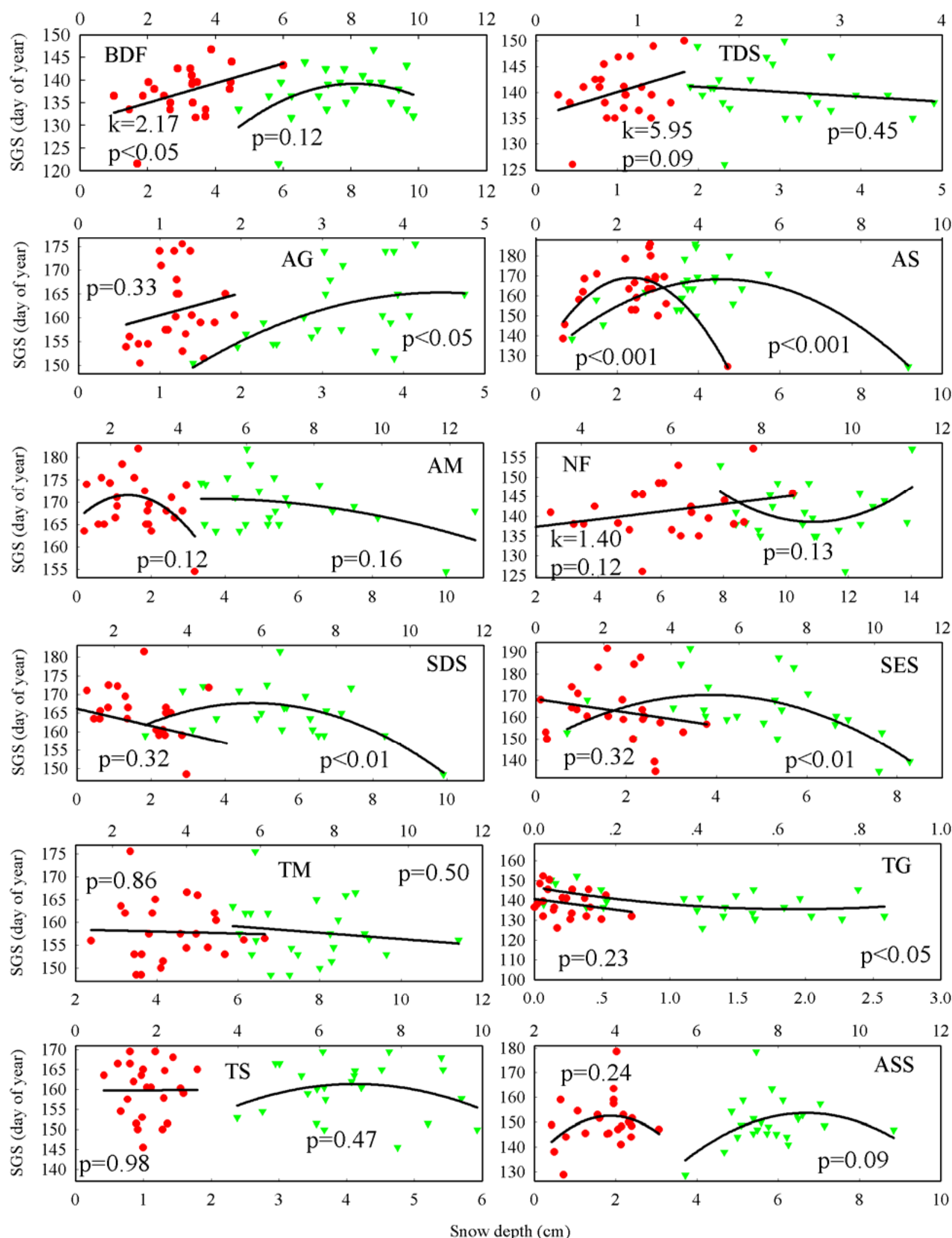
Figure 2-8 Correlations between snow depth and the start of growing season of different vegetation types. (Top axis: spring; bottom axis: winter; green: winter; red: spring; $k$ denotes the slope of linear regression).

The relationship of the SGS of each vegetation type with the winter/spring snow depth was analyzed to further identify effects of seasonal snow depth variations on inter-vegetation growth (Figure 2-8). The winter and spring snow depths affected the SGS in a different manner for different vegetation types when the snow layer exceeded a certain depth (Table 3).

Table 2-3 Snow depth thresholds of different vegetation types

\begin{tabular}{ccccc}
\hline & \multicolumn{2}{c}{ Winter } & \multicolumn{2}{c}{ Spring } \\
Vegetation types & Threshold depth $(\mathrm{cm})$ & $p$ & Threshold depth $(\mathrm{cm})$ & $p$ \\
\cline { 2 - 4 } & 4.45 & $<0.05$ & - & - \\
AG & 4.57 & $<0.001$ & 2.34 & $<0.001$ \\
AS & 4.75 & $<0.01$ & - & - \\
SDS & 3.87 & $<0.01$ & - & - \\
SES & 6.68 & 0.09 & - & \\
ASS & 1.92 & $<0.05$ & & \\
TG & & & \\
\hline
\end{tabular}

For most of the alpine and subalpine vegetation areas (except for AM), the SGS changed from delayed to advanced when the snow depth exceeded a threshold (Table 3). For example, the winter snow postponed the SGS in the grassland and shrub types of AG, AS, SDS, SES, and ASS areas when the snow depth was less than $4.57 \mathrm{~cm}(\mathrm{p}<0.001), 4.45 \mathrm{~cm}(\mathrm{p}<0.05), 4.75 \mathrm{~cm}$ $(\mathrm{p}<0.01), 3.87 \mathrm{~cm}(\mathrm{p}<0.01)$ and $6.68 \mathrm{~cm}(\mathrm{p}=0.09)$, respectively. On the contrary, the SGS was 
advanced in TG when the winter snow depth was under $1.92 \mathrm{~cm}$, while a delayed SGS occurred when the winter snow depth was greater than this threshold $(1.92 \mathrm{~cm})(\mathrm{p}<0.05)$.

The effect of seasonal snow depth on the SGS varied by regions and vegetation types with different snow depth thresholds across the study area (Figure 2-9). The greater snow depth thresholds were primarily distributed in the east of Tibetan Plateau $(20-30 \mathrm{~cm})$, followed by the northeastern China $(10-20 \mathrm{~cm})$, and the northern regions while the lower threshold values (1-10 $\mathrm{cm})$ were observed in the west of Tibetan Plateau.

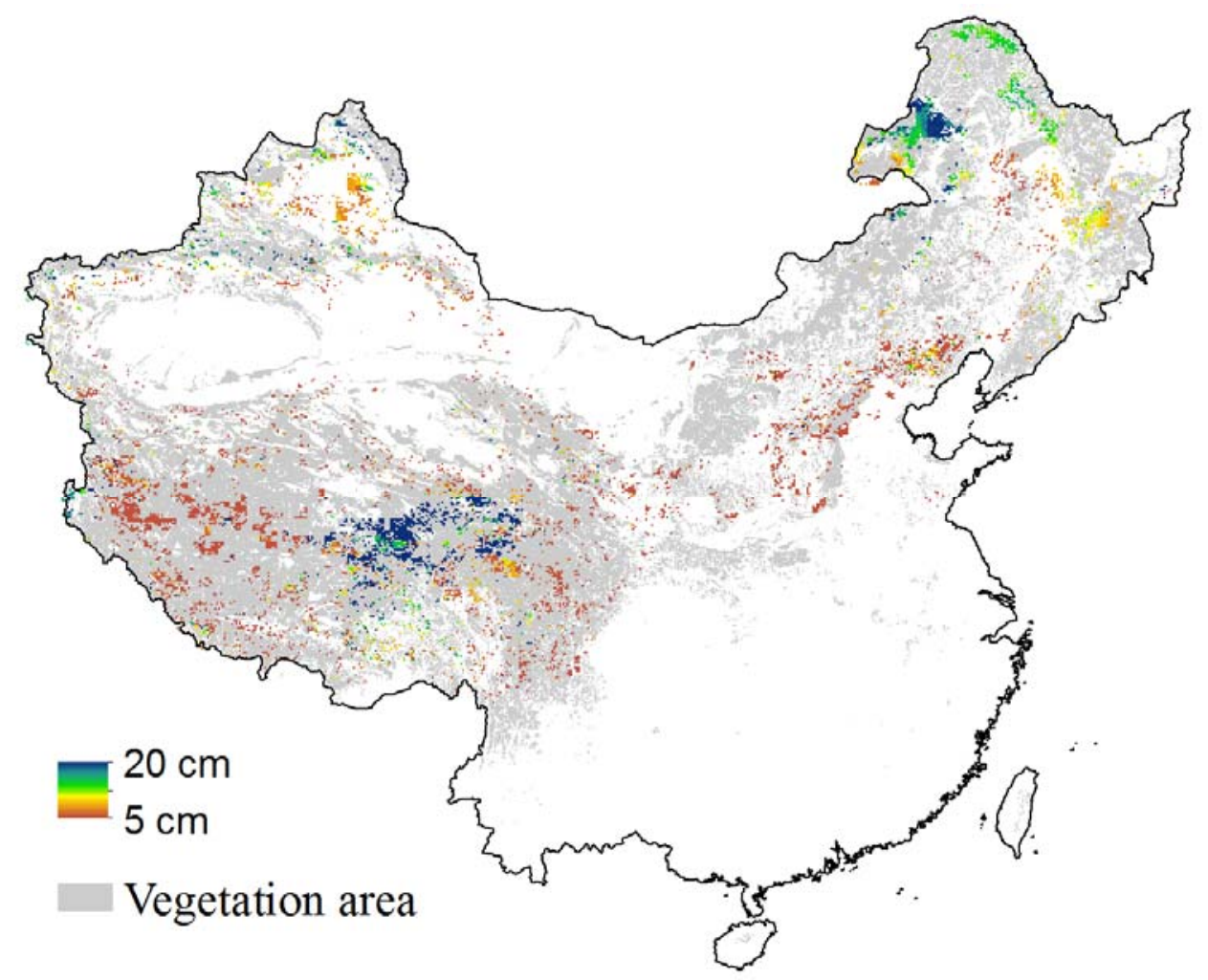

Figure 2-9 Distribution of winter snow depth thresholds (gray region denotes vegetation area, other color region denotes area with snow depth thresholds significant at level $P<0.05$ ). 


\subsection{Discussion}

\subsubsection{Temperature, snow depth and vegetation phenology}

During the past few decades, intensive warming has occurred across the temperate zones of China (Qian et al., 2007; Piao et al., 2006, Piao et al., 2010). This is especially true in the Tibetan Plateau, where the spring air temperature increased at a rate of $0.072{ }^{\circ} \mathrm{C} \cdot \mathrm{yr}^{-1}(\mathrm{p}<0.001)$ from 1982 to 2005 . However, vegetation growth did not respond in parallel with the warming during the same time period. Piao et al. $(2006,2011)$ reported that the growing season NDVI showed opposite trends during the periods of 1982-1997 and 1997-2006 in temperate and boreal regions of the Eurasia. Similarly, in this study, the two distinct periods with opposite trends of the SGS were also identified before and after 1998 in temperate zones of China. Our results further indicated that the changes of the SGS in the Tibetan Plateau were consistent with the findings reported in the regions of Alpine Steppes (AS) and Alpine Meadows (AM) by Piao et al.( 2011), and also in a recent study by Yu et al. (2010a) that reported a delay of leaf-out in both meadow and steppe vegetation during 1998-2006.

For all of temperate China, the SGS showed an advancing trend at a rate of $0.68 \mathrm{~d} \cdot \mathrm{yr}^{-1}$

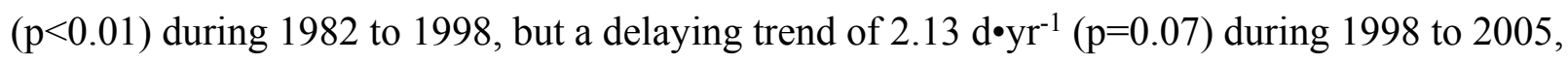
despite a strong warming trend throughout the entire period of 1982-2005. The SGS change ($\left.0.68 \mathrm{~d} \cdot \mathrm{yr}^{-1}\right)$ of our findings is close to the rate $\left(-0.79 \mathrm{~d} \cdot \mathrm{yr}^{-1}\right)$ reported by Piao et al. (2006). The change trend of the SGS found in this study is also consistent with the growing season change and NDVI variations reported in other studies (Jong et al., 2012; Jeong et al., 2011). 


\subsubsection{Impacts of snow depth and temperature on vegetation leaf-out at large scale}

It is generally assumed that warming trends prolong the growing season by advancing the leaf-out of vegetation (Piao et al., 2006; Tucker et al., 2001; Stockli et al., 2004; Julien \& Sobrino, 2009; Zeng et al., 2011). In this study, the vegetation leaf-out was primarily controlled by spring air temperature during the period of 1982-1998. However, the spring air temperature alone could not explain the SGS variations in most of the grasslands and shrub types during the period of 1982-2005 (Table 1,2), as changes in the SGS for many vegetation types were not parallel with the warming trend across the whole study area. In comparison, a strong correlation was found between snow depth and the SGS of grasslands and shrubs, indicating that underground thermal conditions could exert a stronger impact on the leaf-out of grasses and shrubs. Körner \& Basler (2010) described that shorter-lived species, such as grasses and shrubs, are temperature-sensitive. This is also supported by the stepwise multiple regression models, which reveal the coupled effects of snow-temperature on the SGS (Table 2). Our results suggest that the air temperature could have limited impacts on the SGS of grasslands and shrubs, since the underground thermal conditions are modulated through the variations of snow depth.

Rollinson \& Kaye (2012) reported that the phenology of trees should be strongly influenced by air temperature. In contrast, Körner \& Basler (2010) argued that phenology in tree species are primarily controlled by photoperiod rather than temperatures. In this study, we found that the winter snow depth had relatively weaker effects on forests (Broad-leaf Deciduous Forests, BDF; and Needle-leaf Forests, NF) than on grasslands and shrubs in the entire study area (Figure 2-8, Table 1), while significant correlations of the SGS with spring air temperature existed in some vegetation types (1982-2005: BDF, $\mathrm{p}<0.01$; NF, $\mathrm{p}<0.01)$. This suggests that the leaf-out of trees is not only modulated by air temperature, but also partially dependent on the 
aboveground tissue that receives thermal or photoperiod signal contributing to breaking dormancy in spring.

\subsubsection{Effects of snow depth on leaf-out of warm-favored vegetation types}

In temperate China, both winter and spring snows could affect the SGS from delaying to advancing when the snow depth exceeded the threshold depth $(6.81 \mathrm{~cm}$ for winter snow, $4.03 \mathrm{~cm}$ for spring snow). However, the seasonal snow depth threshold varied with vegetation types, suggesting the different ecological adaptations of plants in terms of root depth, germination, and nutrient requirements.

The increased winter snow depth advanced the SGS in most of the shrub and grassland types (Alpine Grasslands (AG), AS, Subalpine Deciduous Shrubs (SDS), Subalpine Evergreen Shrubs (SES), and Alpine Sparse Shrubs (ASS)) when the snow layer exceeded the depth threshold ranging from 3.87 to $6.68 \mathrm{~cm}$ (Figure 2-8, Table 3). If the winter snow depth dropped below the threshold values, chilling would penetrate the snow layer to affect the underground root system. Previous studies revealed that increased snow depth could mitigate soil freezing and reduce root mortality, favoring plant growth in the growing seasons (Tierney et al., 2001; Dorrepaal et al., 2004). In this study, we found that snow depth below the threshold would be ineffective in providing thermal insulation. It was observed that below the threshold depth, as the snow depth increased there was a longer duration of low air temperatures that had potentially negative effects on root systems. Therefore, a snow depth of greater than the snow threshold depth indicates a good underground thermal condition that is beneficial to leaf-out of vegetation.

In the Tibetan Plateau, a later onset of growing seasons in AS and AM areas was detected in this study. Yu et al. (2010) postulated that the warming delayed the fulfillment of the chilling 
requirement and thus led to a postponed growing season. However, the insulation effect of the seasonal snow was ignored in their study. In this study, we found both spring snow depth and spring temperature had significant effects on leaf-out date of AM (Table 2). However, we also found that the temporal trends of both winter $\left(0.21^{\circ} \mathrm{C} \cdot \mathrm{yr}^{-1}, \mathrm{R}=0.53, \mathrm{p}=0.18\right)$ and spring $(-0.01$ ${ }^{\circ} \mathrm{C} \cdot \mathrm{yr}^{-1}, \mathrm{R}=0.04, \mathrm{p}=0.93$ ) air temperatures were not statistically significant in the vegetation area of AM, while the SGS was delayed for about $2.25 \mathrm{~d} \bullet \mathrm{yr}^{-1}(\mathrm{R}=0.72, \mathrm{p}<0.05)$. Noticeably, the advanced leaf-out trends were accompanied with a decline in winter snow depth $\left(-0.56 \mathrm{~cm}^{\bullet} \mathrm{yr}^{-1}\right.$, $\mathrm{R}=0.66, \mathrm{p}=0.08$ ). Therefore, the major factor attributing to the delayed leaf-out of AM could be the increased chilling in soil due to thinner snow depth, rather than the decreased chilling induced by warming as asserted by Yu et al. (2010). On the contrary, the increased chilling in soil caused by thinner snow depth would be a major factor contributing to the delayed SGS in the AM area.

For the AS, another vegetation type distributed in the Tibetan Plateau, the model reveals significant impacts of winter snow depth, winter temperature, and coupled effect of spring snow depth and spring temperature on its SGS (Table 2). In addition, a significant decrease in winter and spring snow depth was observed during 1982 and 2005, while a mild warming also accompanied snow depth variation. During this time period, the winter snow depth had reduced from around $9.16 \mathrm{~cm}$ in 1998 to $3.92 \mathrm{~cm}$ in 2005 at a rate of $0.52 \mathrm{~cm}^{\bullet} \mathrm{yr}^{-1}(\mathrm{R}=0.71, \mathrm{p}<0.05)$. The effects of thermal insulation from winter snow was reduced due to attenuating of the snow depth (depth threshold $=4.57 \mathrm{~cm}$ ). Hence, it was the increased chilling stress in the soil layer that postponed the SGS of AS vegetation between 1998 and 2005. 


\subsubsection{Effects of snow depth on leaf-out of chilling-favored vegetation types}

Most temperate woody plants need chilling to break dormancy (Yu et al., 2010a;

Luedeling et al., 2009), but a snow layer serves as a thermal insulator to alleviate chilling from underground root systems (Cohen, 1994). This could attribute to the different effects of winter snows on the SGS depending on the snow threshold depth of $1.92 \mathrm{~cm}$ in Temperate Grasslands (TG). A snow layer exceeding this threshold depth $(1.92 \mathrm{~cm})$ could insulate the root systems from winter cold and mitigate belowground chilling accumulation, and postpone the SGS of the following year (Chen et al., 2005; Powell et al., 1986; Murray et al., 1989). In addition, alpine and subalpine vegetation might be more likely to favor warm temperatures in winter, while temperate grasslands, shrubs, and trees would be more likely to require chilling in winter for breaking dormancy (Figure 2-9).

Some tree species typically require heat accumulation to promote the leaf-out stage in spring (Luedeling et al., 2009). A thicker snow layer in spring may indicate a later snow melting date and a lower spring air temperature, and consequently delay the heating requirement in spring. Therefore, spring snow is assumed to have a postponing effect on the SGS for some vegetation types, such as BDF $(\mathrm{p}<0.05)$, Temperate Deciduous Shrubs (TDS, $\mathrm{p}=0.09)$, and NF $(p=0.12)$. In the late spring, the snow layer is saturated with melting water, which could result in the formation of relatively high density snow with increased thermal conductivity (Bernier \& Fortin, 1998). This may account for the postponing effects of spring snow on the leaf-out date of $\operatorname{BDF}\left(2.17 \mathrm{~d} \bullet \mathrm{cm}^{-1}, \mathrm{p}<0.05\right)$ and $\operatorname{TDS}\left(5.95 \mathrm{~d} \bullet \mathrm{cm}^{-1}, \mathrm{p}=0.09\right)$. When the spring snow layer loses its thermal insulation effect, a thicker snow cover implies a longer period of snow melting and lengthening of the heat accumulating process in spring, hence leading to a delayed leaf-out date. However, the delayed snow-melting process of thicker snow layer could also be beneficial to 
vegetation growth through increasing the growing season moisture and shifting the growth into a warming period (Walker et al., 1995).

Our findings suggest that temperate vegetation phenology is dependent on both seasonal air temperature and soil thermal conditions regulated by both snowfall and snow depth. The spring air temperature significantly regulated the SGS of forests, while the winter snow depth showed greater impacts on grassland and shrub types in temperate China. The responses of the SGS to snow depths are attributable to the regional environmental factors and vegetation traits. Therefore, the responses of vegetation growth to seasonal snow should be incorporated into a large scale carbon cycle modeling process to accurately simulate the carbon sequestration and carbon dynamic under global climate change scenarios. 


\section{Acknowledgement}

This study was funded by the National Natural Science Foundation of China (Grant No. 31290223), the Ministry of Finance of China (Grant No. 200804001 and 201104006), and the Ministry of Science and Technology of China (Grant No. 2012BAD22B01 and 2006BAD03A04). We gratefully acknowledge the China National Forest Ecosystem Research Network and Chinese Ecosystem Research Network (CERN) for provision of technical data, and two anonymous reviewers for constructive comments for improvement of the manuscript. 


\section{References}

Armstrong RL, Brodzik MJ (1995) An earth-gridded SSM/I data set for cryospheric studies and global change monitoring. Advances in Space Research, 16, 155-163.

Bernier M, Fortin, J-P (1998) The potential of times series of C-band SAR data to monitor dry and shallow snow cover, IEEE Transactions on Geoscience and Remote Sensing, 36, 226-243.

Bilbrough CJ,Welker JM, Bowman WD (2000) Early-spring N uptake by snow covered plants: a comparison of arctic and alpine plant function under snowpack. Arctic, Antarctic and Alpine Research, 32, 404-411.

Bonan, G.B (1992) Soil temperature as an ecological factor in boreal forests. In: Shugart, H.H., Leemans, R., Bonan, G.B. (Eds.), A Systems Analysis of the Global Boreal Forest. Cambridge University Press, Cambridge, ISBN: 0521405467, 126-143.

Che T (2006) Cold and Arid Regions Environmental and Engineering Research Institute, Chinese Academy of Science.

Chen XQ, Hu B, Yu R (2005) Spatial and temporal variation of phenological growing season and climate change impacts in temperate eastern China. Global Change Biology, 11, 1118-1130.

Cohen J (1994) Snow cover and climate, 49, 150-156.

Compiling Committee of Vegetation Maps of 1:1,000,000 in China, 2001, Atlas of Vegetation Maps of 1:1,000,000 in China. (Beijing: Science Press).

Cooper EJ, Dullinger S, Semenchuk P (2011) Late snowmelt delays plant development and results in lower reproductive success in the High Arctic. Plant science, 180, 157-167. 
Dorrepaal E, Aerts R, Cornelissen JHC, Callaghan TV, van Logtestijn RSP (2004) Summer warming and increased winter snow cover affect Sphagnum fuscum growth, structure and production in a sub-arctic bog. Global Change Biology, 10, 93-104.

Eklundh L, Jönsson P (2010) TIMESAT 3.0 - Software Manual. Lund University, 74 pp.

Euskirchen ES, McGUIRE a D, Kicklighter DW, Zhuang Q, Clein JS, Dargaville RJ, Dye DG, Kimball JS, McDonald KC, Melillo JM, Romanovsky VE, Smith NV (2006) Importance of recent shifts in soil thermal dynamics on growing season length, productivity, and carbon sequestration in terrestrial high-latitude ecosystems. Global Change Biology, 12, $731-750$.

Foster JL, Hall DK, Chang ATC, Goddard N (1984) An overview of passive microwave snow research and results, Reviews of Geophysics and Space Physics, 22, 195-208.

Goodlson BE, Walker AE (1993) Use of snow cover derived from satellite passive microwave data as an indicator of climate changes, Annuls of Glaciology, 17, 137-142.

Grippa M, Kergoat L, Le Toan T, Mognard NM, Delbart N, L'Hermitte J, Vicente-Serrano SM (2005) The impact of snow depth and snowmelt on the vegetation variability over central Siberia. Geophysical Research Letters, 32, 1-4.

Groffman PM, Hardy JP, Driscoll CT, Fahey TJ (2006) Snow depth, soil freezing, and fluxes of carbon dioxide, nitrous oxide and methane in a northern hardwood forest. Global Change Biology, 12, 1748-1760.

Hardy JP, Groffman PM, Fitzhugh RD, Henry KS, Welman AT, Demers JD, Fahey TJ, Driscoll CT, Geraldine L, Nolan S (2001) Snow depth manipulation and its influence on soil frost and water dynamics in a northern hardwood forest. Biogeochemistry, 56, 151-174. 
Holben BN, (1986) Characteristics of maximum-value composite images from temporal AVHRR data. International Journal of Remote Sensing, 7, 1417-1434.

Hutchinson MF, Gessler PE (1994) Splines - more than just a smooth interpolator, Geoderma, $62,45-67$.

Immerzeel WW, Droogers P, de Jong SM, Bierkens MFP (2009) Large-scale monitoring of snow cover and runoff simulation in Himalayan river basins using remote sensing. Remote Sensing of Environment, 113, 40-49.

IPCC (2007) IPCC Climate change 2007: The scientific basis Cambridge University Press, Cambridge.

Jeong S-J, Ho C-H, Gim H-J, Brown ME (2011) Phenology shifts at start vs. end of growing season in temperate vegetation over the Northern Hemisphere for the period 1982-2008. Global Change Biology, 17, 2385-2399.

Jong R, Verbesselt J, Schaepman ME, Bruin S (2012) Trend changes in global greening and browning: contribution of short-term trends to longer-term change. Global Change Biology, 18, 642-655.

Julien Y, Sobrino J A (2009) Global land surface phenology trends from GIMMS database. International Journal of Remote Sensing, 30, 3495-3513.

Körner C, Basler D (2010) Phenology under global warming, Science, 327, 1461-1462.

Kunzi KF, Patil S, Rott H (1982) Snow-cover parameters retrieved from Nimbus-7 Scanning Multichannel Microwave Radiometer (SMMR) data, IEEE Transactions on Geoscience and Remote Sensing, 20, 452-467.

Liu XD, Yin ZY (2002) Sensitivity of East Asian monsoon climate to the uplift of the Tibetan Plateau. Palaeogeography, Palaeoclimatology, Palaeoecology, 183, 223-245. 
Luedeling E, Zhang MH, Girvetz EH (2009) Climatic changes lead to declining winter chill for fruit and nut trees in California during 1950-2099. PLOS ONE, 4: 1-10.

Luedeling E, Zhang MH, McGranahan G, Leslie C (2009) Validation of winter chill models using historic records of walnut phenology. Agricultural and Forest Meteorology, 149: $1854-1864$.

McVicar TR, Van Niel TG, Li LT, Hutchinson MF, Mu XM, Liu ZH (2007). Spatially distributing monthly reference evapotranspiration and pan evaporation considering topographic influences. Journal of Hydrology, 338, 196-220.

Mellander P-E, Bishop K, Lundmark T (2004) The influence of soil temperature on transpiration: a plot scale manipulation in a young Scots pine stand. Forest Ecology and Management, 195, 15-28.

Menzel A, Fabian P (1998) Growing season extended in Europe. Nature, 1996.

Murray MB, Cannell MGR, Smith RI (1989) Date of budburst of fifteen tree species in Britain following climatic warming. Journal of Applied Ecology, 26, 693-700.

Peng SS, Piao SL, Ciais P, Fang JY, Wang, XH (2010) Change in winter snow depth and its impacts on vegetation in China. Global Change Biology, 16, 3004-3013.

Piao SL, Ciais P, Huang Y et al. (2010) The impacts of climate change on water resources and agriculture in China. Nature, 467, 43-51.

Piao SL, Fang JY, Zhou LM, Ciais P, Zhu B (2006) Variations in satellite-derived phenology in China's temperate vegetation. Global Change Biology, 12, 672-685.

Piao SL, Wang XH, Ciais P, Zhu B, Wang T, Liu J (2011) Changes in satellite-derived vegetation growth trend in temperate and boreal Eurasia from 1982 to 2006. Global Change Biology, 17, 3228-3239. 
Powell LE, Swartz HJ, Pasternak G, Maybee CG (1986) Time of flowering in spring: its regulation in temperate zone woody plants. Biologia Plantarum (PRAHA), 28, 81-84.

Qian WH, Fu JL, Yan ZW (2007) Decrease of light rain events in summer associated with a warming environment in China during 1961-2005. Geophysical Research Letters, 34, 15.

Qin DH, Liu SY, Li PJ (2006) Snow Cover Distribution, Variability, and Response to Climate Change in western China. Journal of Climate, 19, 1820-1833.

Qiu J (2008) China: The third pole, Nature, 454, 393-396.

Rollinson CR, Kaye MW (2012) Experimental warming alters spring phenology of certain plant functional groups in an early successional forest community, Global Change Biology, 18, 1108-1116.

Rott H (1987) Remote sensing of snow, Large Scale Effects of Seasonal Snow Cover. International Association of Hydrological Sciences Press, Institute of Hydrology, Wallingford, Oxfordshire UK. IAHS Publication No. 166, 1987. 279-290.

Shabanov NV, Zhou LM, Knyazikhin Y, Myneni RB, Tucker CJ (2002) Analysis of interannual changes in northern vegetation activity observed in AVHRR data from 1981 to 1994, IEEE Transactions on Geoscience and Remote Sensing, 40, 115-130.

Stadler D, Wunderli H, Auckenthaler A, Brundl M (1996) Measurement of frost-induced snowmelt runoff in a forest soil. Hydrological Processes. 10, 1293-1304.

Stockli R, Vidale P L (2004) European plant phenology and climate as seen in a 20-year AVHRR land-surface parameter dataset. International Journal of Remote Sensing. 25, 3303-3330. 
Sun PS, Yu Z, Liu SR, Wei XH, Wang JX \& Zegre N (2012) Climate change, growing season water deficit and vegetation activity along the north-south transect of Eastern China from 1982 through 2006. Hydrology and Earth System Sciences Discussions, 9, 6649-6688.

Tierney GL, Fahey TJ, Groffman PM, Hardy JP, Fitzhugh RD, Driscoll CT (2001) Soil freezing alters fine root dynamics in a northern hardwood forest. Biogeochemistry, 56, 175-190.

Tucker C J, Slayback D A, Pinzon J E, Los S O, Myneni R B, Taylor M G (2001) Higher northern latitude NDVI and growing season trends from 1982 to 1999. International Journal of Biometeorology. 45, 184-190.

Venäläinen A, Tuomenvirta H, Heikinheimo M, Kellomäki S, Peltola H, Strandman H, Väisänen H (2001) Impact of climate change on soil frost under snow cover in a forested landscape. Climate Research. 17, 63-72.

Vitasse Y, Porté AJ, Kremer A, Michalet R, Delzon S, (2009) Responses of canopy duration to temperature changes in four temperate tree species: relative contributions of spring and autumn leaf phenology. Oecologia, 161, 187-198.

Wahren CHA, Walker MD, Bret-Harte MS (2005) Vegetation responses in Alaskan arctic tundra after 8 years of a summer warming and winter snow manipulation experiment. Global Change Biology, 11, 537-552.

Walker DA, Auerbach NA, Shippert MM (1995) NDVI, biomass, and landscape evolution of glaciated terrain in northern Alaska, Polar record. 31,169-178.

Walker MD, Walker DA, Welker JM, Arft AM, Bardsley T, Brooks PD, Fahnestock JT, Jones MH, Losleben M, Parsons AN, Seastedt TR, Turner PL (1999) Long-term experimental manipulation of winter snow regime and summer temperature in arctic and alpine tundra. Hydrological Processes, 13, 2315-2330. 
Wang GX, Li YH, Wang YB, Wu QB (2008) Effects of permafrost thawing on vegetation and soil carbon pool losses on the Qinghai-Tibet Plateau, China. Geoderma, 143, 143-152.

Wang XH, Piao SL, Ciais P, Li JS, Friedlingstein P, Koven C, Chen AP (2011) Spring temperature change and its implication in the change of vegetation growth in North America from 1982 to 2006. Proceedings of the National Academy of Sciences of the United States of America, 108, 1240-1245.

Yasunari TJ, Koster RD, Lau K-M, Aoki T, Sud YC, Yamazaki T, Motoyoshi H, Kodama Y (2011) Influence of dust and black carbon on the snow albedo in the NASA Goddard Earth Observing System version 5 land surface model. Journal of Geophysical Research, $116,1-15$

Yu HY, Luedeling E, Xu JC (2010a) Winter and spring warming result in delayed spring phenology on the Tibetan Plateau. Proceedings of the National Academy of Sciences of the United States of America, 107, 22151-22156.

Yu Z, Sun PS, Liu SR, (2010b), Phenological change of main vegetation types along a NorthSouth Transect of Eastern China. Chinese Journal of Plant Ecology. 34, 316-329.

Zeng HQ, Jia GS, Epstein H (2011) Recent changes in phenology over the northern high latitudes detected from multi-satellite data, Environtal Research Letter, 6, 1-11. 
3. Decrease in winter respiration explains $25 \%$ of annual northern forest carbon sink enhancement over the last 30 years ${ }^{\dagger}$

$\dagger$ Published in Global Ecology and Biogeography 


\section{Abstract}

Winter snow has been suggested to regulate terrestrial carbon (C) cycling by modifying microclimate, but the impacts of snow cover change on the annual $\mathrm{C}$ budget at the large scale are poorly understood. Our aim is to quantify the $\mathrm{C}$ balance under changing snow depth. Here, we used site-based eddy covariance flux data to investigate the relationship between snow cover depth and ecosystem respiration (Reco) during winter. We then used the Biome-BGC model to estimate the effect of reductions in winter snow cover on $\mathrm{C}$ balance of Northern forests in nonpermafrost region. According to site observations, winter net ecosystem C exchange (NEE) ranged from $0.028-1.53 \mathrm{gC} \cdot \mathrm{m}^{-2} \cdot \mathrm{day}^{-1}$, accounting for $44 \pm 123 \%$ of the annual $\mathrm{C}$ budget. Model simulation showed that over the past 30 years, snow driven change in winter $\mathrm{C}$ fluxes reduced non-growing season $\mathrm{CO}_{2}$ emissions, enhancing the annual $\mathrm{C}$ sink of northern forests. Over the entire study area, simulated winter ecosystem respiration ( $R_{\text {eco }}$ ) significantly decreased by 0.33 $\mathrm{gC} \cdot \mathrm{m}^{-2} \cdot \mathrm{day}^{-1} \cdot \mathrm{yr}^{-1}$ in response to decreasing snow cover depth, which accounts for approximately $25 \%$ of the simulated annual C sink trend from 1982 to 2009 . Soil temperature was primarily controlled by snow cover rather than by air temperature as snow served as an insulator to prevent chilling impacts. A shallow snow cover has less insulation potential, causing colder soil temperatures and potentially lower respiration rates. Both eddy covariance analysis and modelsimulated results showed that both Reco and NEE were significantly and positively correlated with variation in soil temperature controlled by variation in snow depth. Overall, our results highlight that a decrease in winter snow cover restrains global warming through emitting less $\mathrm{C}$ to the atmosphere. 


\subsection{Introduction}

Net ecosystem carbon exchange (NEE) is regulated by the net difference between photosynthetic carbon uptake and ecosystem respiration ( $\left.\mathrm{R}_{\mathrm{eco}}\right)$ (Mahecha et al., 2010; Running et al., 2009). Most studies have focused on $\mathrm{CO}_{2}$ exchange during the growing season, whereas winter $\mathrm{CO}_{2}$ fluxes are generally ignored due to a much lower emission rate during cold time periods (Monson et al., 2006). However, small but persistent changes in the magnitude of winter Reco impact the $\mathrm{C}$ budget of large areas (Monson et al., 2005), and Reco, the sum of aboveground (plant) respiration and belowground (soil) respiration, is strongly correlated with temperature (Wang et al., 2007; Raich \& Schlesinger, 1992). Increased air temperature in winter may promote soil respiration by warming the soil at greater depths (Raich \& Schlesinger, 1992; Jenkinson et al., 1991; Brooks et al., 2005; Melillo et al., 2011; Dorrepaal et al., 2009; Natali et al., 2011) but the response of decomposition will depend both on biotic factors (microbial activity and its response to temperature and moisture) and on physical factors (insulation of soil organic matter by snow or mosses, soil freezing, and soil thermal conductivity). In regions affected by snowfall, increased air temperature, accompanied by reduced snowfall, or shortened duration of snow-cover (Euskirchen et al., 2007), may lead to deeper soil freezing (Hardy et al., 2001). This type of feedback would result in suppressed soil respiration and hence reduced $R_{\text {eco, }}$ and reduced vegetation growth (Goulden et al., 1996; Grippa et al., 2005).

Winter snow covers about 45 million $\mathrm{km}^{2}$, or nearly one-half of the land mass in the Northern Hemisphere (Déry \& Brown; 2007; Sommerfeld et al., 1993). Recent climate analyses have shown a widespread decline in winter and spring snow cover in the western USA and Europe (Karl et al., 1993; Ye et al., 1998; Mote et al., 2005; Laternser \& Schneebeli, 2003; Scherrer et al., 2004), and over Eurasia (Brown \& Robinson, 2011; Zuo et al., 2011). This 
change may be critical to regional and global carbon cycling in the context of $\mathrm{CO}_{2}$ and $\mathrm{CH}_{4}$ exchange between the ecosystem and atmosphere (Wang et al., 2011; Groffman et al., 2006; Wania et al., 2010). In non-permafrost areas, snow serves as an insulator and protects soil from exposure to low air temperature, leading to warmer soil temperatures in snow-covered areas than in snow-free areas (Peng et al., 2010). However, our understanding of the impacts of snow cover change on wintertime $\mathrm{C}$ budget is very limited, with most of evidence coming from in-situ observations. Manipulation experiments suggest snow addition could increase winter Reco by 0.5 1.5 times (Larsen et al., 2007; Nobrega \& Grogan et al., 2007; Schimel et al., 2004).

Furthermore, the thermal insulation effects of snow are imperfectly considered in most of current global carbon cycle models due to systematic model errors for snow thickness, conductivity (Gouttevin et al., 2012) and soil thermodynamics (Wang et al., 2015). In this study, we aimed to test the hypothesis that winter snow decline has led to reduced ecosystem respiration and temporarily suppressed C efflux. We specifically examined the effects of variation of snow cover depth on the winter $\mathrm{C}$ efflux in non-permafrost regions of northern forests at both site and regional scales using observational data from eddy covariance flux sites, and the Biome-BGC biogeochemical model. Using this approach, we quantified the spatial and temporal change of winter ecosystem carbon flux and its contribution to regional and global carbon budgets. 


\subsection{Materials and methods}

\subsubsection{Flux sites data descriptions and analysis}

Flux data from Fluxnet (http://fluxnet.ornl.gov/) were collected and analyzed to investigate the responses of $\mathrm{C}$ efflux to regional snow dynamics at site level (Table 1). The Fluxnet data includes the observations of C flux recorded at 125 flux sites, 110 of which were excluded from analysis due to lack of 3-year consecutive observations in winters. Snow cover depth observations were discontinuously performed at 13 flux sites listed in Table 1 . The 21 flux sites selected for analysis in this study are mainly from the Canadian Carbon Program (CCP) and AmeriFlux research networks. In total, the analyses were based on 114 years of measured Reco and 112 years of measured NEE (net ecosystem exchange) performed at the site level.

The eddy covariance technique was used to measure the fluxes of $\mathrm{CO}_{2}$ and $\mathrm{H}_{2} \mathrm{O}$ between the ecosystem and the atmosphere at each flux site. The winter $\mathrm{NEE}\left(\mathrm{CO}_{2}\right.$ flux between ecosystem and atmosphere) can be expressed as:

$$
\mathrm{NEE}=\mathrm{R}_{\mathrm{eco}}-\mathrm{GPP}
$$

where, Reco is the ecosystem respiration and GPP is the gross primary productivity of the ecosystem. A negative NEE indicates an uptake of $\mathrm{CO}_{2}$ by the ecosystem while a positive value indicates a loss of $\mathrm{CO}_{2}$ from the ecosystem. Missing flux data were filled by the Fluxnet-Canada Data Policy and Management Working Group and AmeriFlux Network group. The detail of the gap-filling methods can be found in Barr et al., (2004), Kljun et al. (2006), and Papale \& Valentini (2003). 
Table 3-1 Descriptions of flux sites used in this study.

\begin{tabular}{|c|c|c|c|c|c|c|}
\hline \multirow{2}{*}{ Site code } & \multirow{2}{*}{ Biome } & \multirow{2}{*}{ Longitude } & \multirow{2}{*}{ Latitude } & \multicolumn{3}{|c|}{ Uses of analyses } \\
\hline & & & & $\mathrm{BGC}$ & Snow & Anomaly \\
\hline CA-Gro & $\mathrm{MF}$ & -82.16 & 48.22 & $x$ & $x$ & $x$ \\
\hline CA-TP4 & ENF & -80.36 & 42.71 & $x$ & $x$ & $x$ \\
\hline CA-Qc2 & ENF & -74.57 & 49.76 & $x$ & $x$ & \\
\hline CA-Qcu & ENF & -74.04 & 49.27 & & $x$ & $x$ \\
\hline CA-Qfo & ENF & -74.34 & 49.69 & $x$ & $x$ & $x$ \\
\hline $\mathrm{CA}-\mathrm{SJ} 2$ & ENF & -104.65 & 53.94 & & & $x$ \\
\hline CA-Oas & $\mathrm{DBF}$ & -106.20 & 53.63 & $x$ & $x$ & $x$ \\
\hline CA-Ojp & ENF & -104.69 & 53.92 & $x$ & $\times$ & $\times$ \\
\hline CA-Obs & ENF & -105.12 & 53.99 & $x$ & $x$ & $x$ \\
\hline CA-TP2 & MF & -80.71 & 42.77 & & & $x$ \\
\hline $\mathrm{CA}-\mathrm{Na} 1$ & MF & -67.10 & 46.47 & & $x$ & \\
\hline CA-SJ3 & ENF & -104.65 & 53.88 & & $x$ & \\
\hline US-UMB & $\mathrm{DBF}$ & -84.71 & 45.56 & $x$ & & $x$ \\
\hline US-GLE & ENF & -106.24 & 41.36 & & $\times$ & \\
\hline CA-Ca1 & ENF & -125.33 & 49.87 & $x$ & & $\times$ \\
\hline US-Ha1 & $\mathrm{DBF}$ & -72.17 & 42.54 & & & $x$ \\
\hline US-MMS & DBF & -86.41 & 39.32 & & & $\times$ \\
\hline US-Bar & DBF & -71.29 & 44.06 & $x$ & & $\times$ \\
\hline US-WCr & $\mathrm{DBF}$ & -90.08 & 45.81 & $\times$ & & $\times$ \\
\hline CA-SJ1 & ENF & -104.66 & 53.91 & & $\times$ & \\
\hline CA-FEN & ENF & -104.62 & 53.80 & & $x$ & \\
\hline
\end{tabular}

ENF: evergreen needle leaf forest; DBF: deciduous broadleaf forest; MF: mixed forest; " $\times$ " denotes the site was used in analyses of BGC (Biome-BGC model validation), SNOW (snow products validation), and Anomaly 
(anomaly analyses with meteorological factors), respectively. The sites not used in BGC analysis were due to intensive disturbances occurred during the study period. For sites not used in SNOW and anomaly analyses were due to lacked of observational data.

\subsubsection{Snow data in non-permafrost region}

All permafrost areas, including continuous (90\%-100\%), discontinuous (50\%-90\%), sporadic $(10-50 \%)$, and isolated patches $(0-10 \%)$ were excluded from analysis due to its different mechanistic response to snow variation. The permafrost map was obtained from National Snow and Ice Data Center (NSIDC, http://nsidc.org/; Brown et al., 2001). Two snow data products were used to extract the snow depth of non-permafrost region in this study. Both snow data sets provide global coverage, but with different spatial scales and temporal ranges. The first set of snow data is the Canadian Meteorological Centre's (CMC) snow depth analysis data, which has relatively high resolution (24 km resolution) and covers from August 1998 to December 2012. This data set was used to explore the relationships between snow and C fluxes at site level. The CMC's snow data were generated from surface synoptic observations, meteorological aviation reports, and special aviation reports acquired from the World Meteorological Organization (WMO) information system (http://nsidc.org/data/docs/; Brasnett, 1999; Brown \& Brasnett, 2010). The second set was obtained from the NCEP/CFSR (National Centers for Environmental Prediction / Climate Forecast System Reanalysis) with relatively low spatial resolution of 0.3125 $\times 0.3122$ degrees but a long-term coverage of from 1982 to 2010 . The data were generated by the U.S. National Weather Service's NCEP Global Forecast System (Saha et al., 2010; Fuka et al., 2014). Both snow datasets were validated to be good quality for analysis (see Appendix S1 in Supporting Information). 


\subsubsection{Carbon exchange modeling}

To quantify spatial and temporal trends of carbon balance, Biome-BGC (v4.1.2), a process-based mechanistic model of terrestrial ecosystems, was used to simulate the $\mathrm{C}$ flux in the study area. Previous studies reported that many of the currently used global C cycle models based on average daily temperature neglect the key process of asymmetrical response of terrestrial ecosystems to daytime versus nighttime temperature (Peng et al., 2013). The BGC models, using daily or sub-daily average, maximum and minimum temperature as inputs, partially take the asymmetric effects of daily temperature fluctuations into account.

We modified the BGC model to allow the use of the soil temperature from NCEP/CFSR as input. In the original BGC model, an empirical algorithm was used for soil temperature calculation, which was derived from an eleven-day running, weighted average of daily average temperatures with a minor correction for the presence of snow. This simplification cannot account for the insulation effects of snow during winter, and hence resulted in a lower soil temperature in winter than in NCEP/CFSR. Therefore, daily soil temperatures from the NCEP/CFSR were used as input for the modified BGC model. In CFSR, the energy transmission model (the four-layer Noah Land Surface Model) was used to simulate soil heat fluxes under snowpack (Ek et al., 2003) and to reflect the snow effects and generate more accurate soil temperature outputs.

Due to a lack of spatial initialization variables, an equilibrium spin-up was performed to initialize soil and plant C/N pools (Pietsh \& Hasenauer, 2002; Pietsh \& Hasenauer, 2006). In the Biome-BGC model, a spin-up run develops natural vegetation within an undisturbed forest ecosystem or a quasi-equilibrium state (Pietsh \& Hasenauer, 2002; Chiesi et al., 2007). However, the actual forest could have been disturbed to some extent by both human activities and/or 
climate change. To address this issue, a "clear-cut" harvest was applied to remove aboveground biomass after a steady state was achieved by spin-up run. Then we simulated the establishment of forest ecosystem based on forest age map (Poulter et al. in prep) using averaged daily climatic data from 1982 to 2010 . This process was to arrive at a final initialization state for the simulation run using $\mathrm{CO}_{2}$ concentration data, nitrogen deposition map, and daily climatic data from 1982 to 2010.

Other climatic variables required for the modified BGC model, including daily maximum, minimum, and average temperature, precipitation, short wave radiation, and vapor pressure deficit, were based on the NCEP/CFSR project in the CISL Research Data Archive (RDA) with spatial resolution of $0.3125 \times 0.3122$ degrees (http://rda.ucar.edu/). These data have been widely used and validated in related climate analyses (Mueller \& Seneviratne, 2012; Eichler \& Londoño, 2013; Fuka et al., 2014). Nitrogen deposition and atmospheric $\mathrm{CO}_{2}$ data were obtained from the Oak Ridge National Laboratory Distributed Active Archive Center for Biogeochemical Dynamics (ORNL DAAC) and the Mauna Loa Observatory (http://co2now.org/) to integrate nitrogen deposition and $\mathrm{CO}_{2}$ fertilization into the simulation (Dentener, 2006). Four types of forests, including deciduous broadleaf forest (DBF), mixed forest (MF), evergreen needle leaf forest (ENF), and deciduous needle leaf forest (DNF), were modeled based on the CFSR land cover maps. The forest age map was provided by Poulter et al., assuming that the youngest, newly planted forest is 5 years old. The winter Reco was modeled with default parameters and then validated by comparing the model simulation results with all observed Reco available from flux sites $\left(\mathrm{R}^{2}=0.73, p<0.0001\right.$; Appendix S2), indicating the default model is suitable for simulation in the study area. 


\subsubsection{Statistical analysis}

Winter season was defined from December to March, because most of the flux sites: 1) have snow cover during this time period each year; 2) have snow melt occurring in late March, which releases $\mathrm{CO}_{2}$ trapped in the snow layer. Winter snow depth was computed by multiplying the mean of daily data within the time period by the number of days of the season. Simple linear regressions were applied to analyze the trends of air temperature, soil temperature, snow depth, and carbon change. 


\subsection{Results and Discussion}

\subsubsection{Wintertime carbon flux at site level}

From the 15 flux tower sites, wintertime (December-March) NEE ranged from $0.028-1.53 \mathrm{gC} \cdot \mathrm{m}^{-}$ 2. $\mathrm{day}^{-1}$ (3.39 to $185.13 \mathrm{gC} \cdot \mathrm{m}^{-2} \cdot \mathrm{yr}^{-1}$, accounting for $44 \pm 123 \%$ of annual NEE on average), a positive value indicating a source of carbon to the atmosphere. Winter ecosystem respiration (Reco) at flux sites ranged from about $0.028-1.87 \mathrm{gC} \cdot \mathrm{m}^{-2} \cdot \mathrm{day}^{-1}\left(3.39\right.$ to $\left.226.27 \mathrm{gC} \cdot \mathrm{m}^{-2} \cdot \mathrm{yr}^{-1}\right)$ with an average of $0.63 \mathrm{gC} \cdot \mathrm{m}^{-2} \cdot \mathrm{day}^{-1}\left(65.53 \mathrm{gC} \cdot \mathrm{m}^{-2} \cdot \mathrm{yr}^{-1}\right)$, which is within the range of $45-152 \mathrm{gC} \cdot \mathrm{m}^{-}$ 2. $\mathrm{yr}^{-1}$ reported by other studies (Wang et al., 2007; Sommerfeld et al., 1993; Wang et al., 2011; Monson et al., 2002; Brooks et al., 1997; Winston et al., 1997). Thus, winter NEE is dominated by winter Reco (assuming suppressed or minimum photosynthetic activity in winter). Winter Reco do not appear to be spatially correlated with winter air temperature (Figure 3-1a), but it is positively and significantly correlated with observed soil temperature across the flux sites ( $p<0.0001$; Figure 3-1b), suggesting that belowground thermal conditions rather than air temperature controls the winter ecosystem respiration rate. In comparison, winter NEE negatively correlated with air temperature ( $p<0.0001$; Figure $3-1 \mathrm{c})$, but positively correlated with soil temperature ( $p<0.0001$; Figure 3-1d), implying net carbon flux was modulated by both soil temperature (respiration of belowground biota) and air temperature (photosynthesis of aboveground flora). 

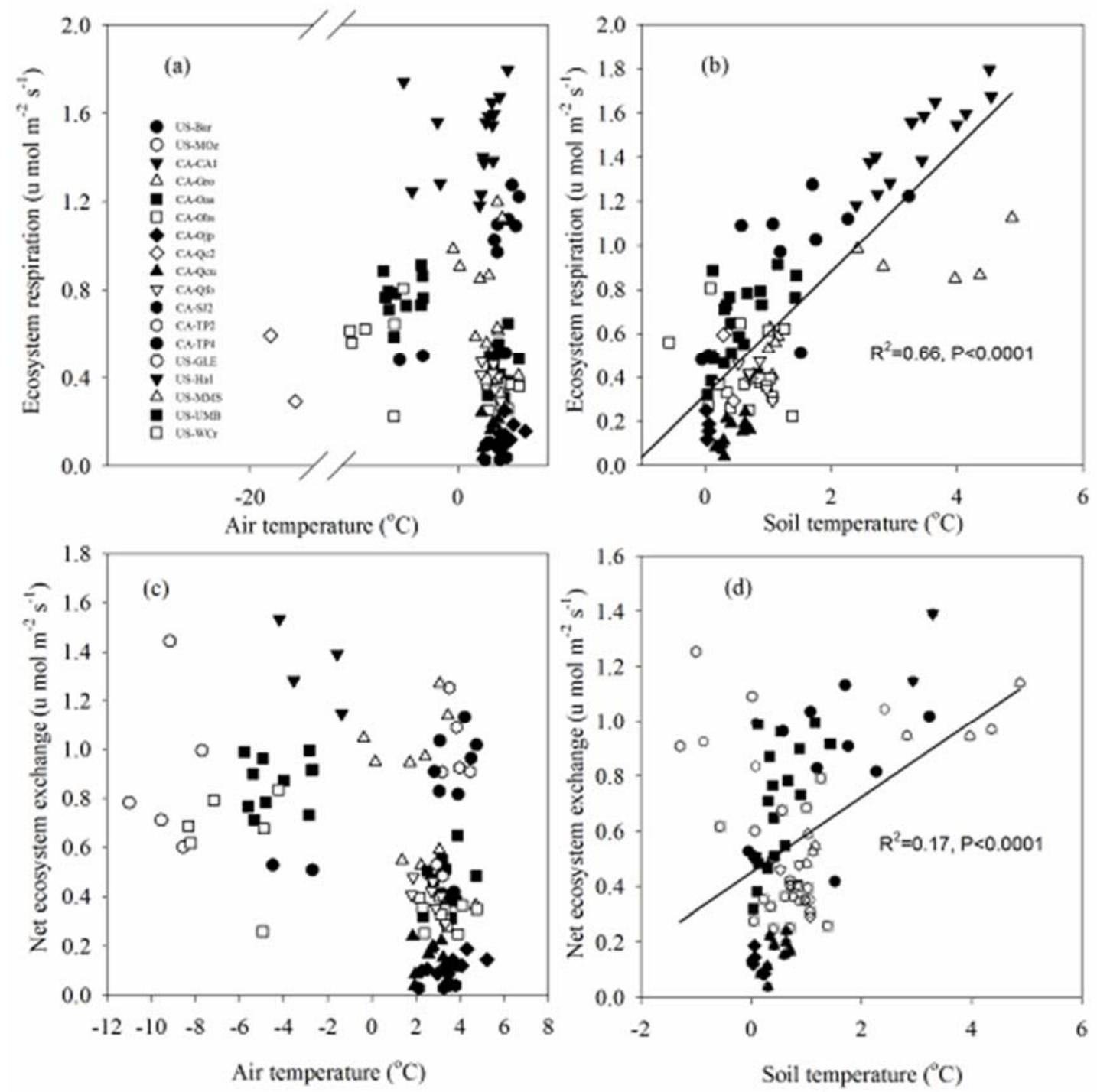

Figure 3-1 Correlations between air temperature and ecosystem respiration $(a, p=0.20)$; soil temperature and ecosystem respiration (b, $p<0.0001)$; air temperature and net ecosystem exchange (c, $p<0.0001)$; and soil temperature and net ecosystem exchange $(d, p<0.0001)$ in winter derived from measurements at 15 flux sites. The CA-Ca1 flux site, a coastal forest with negative NEE during winter was not shown in Fig.1c, d. 

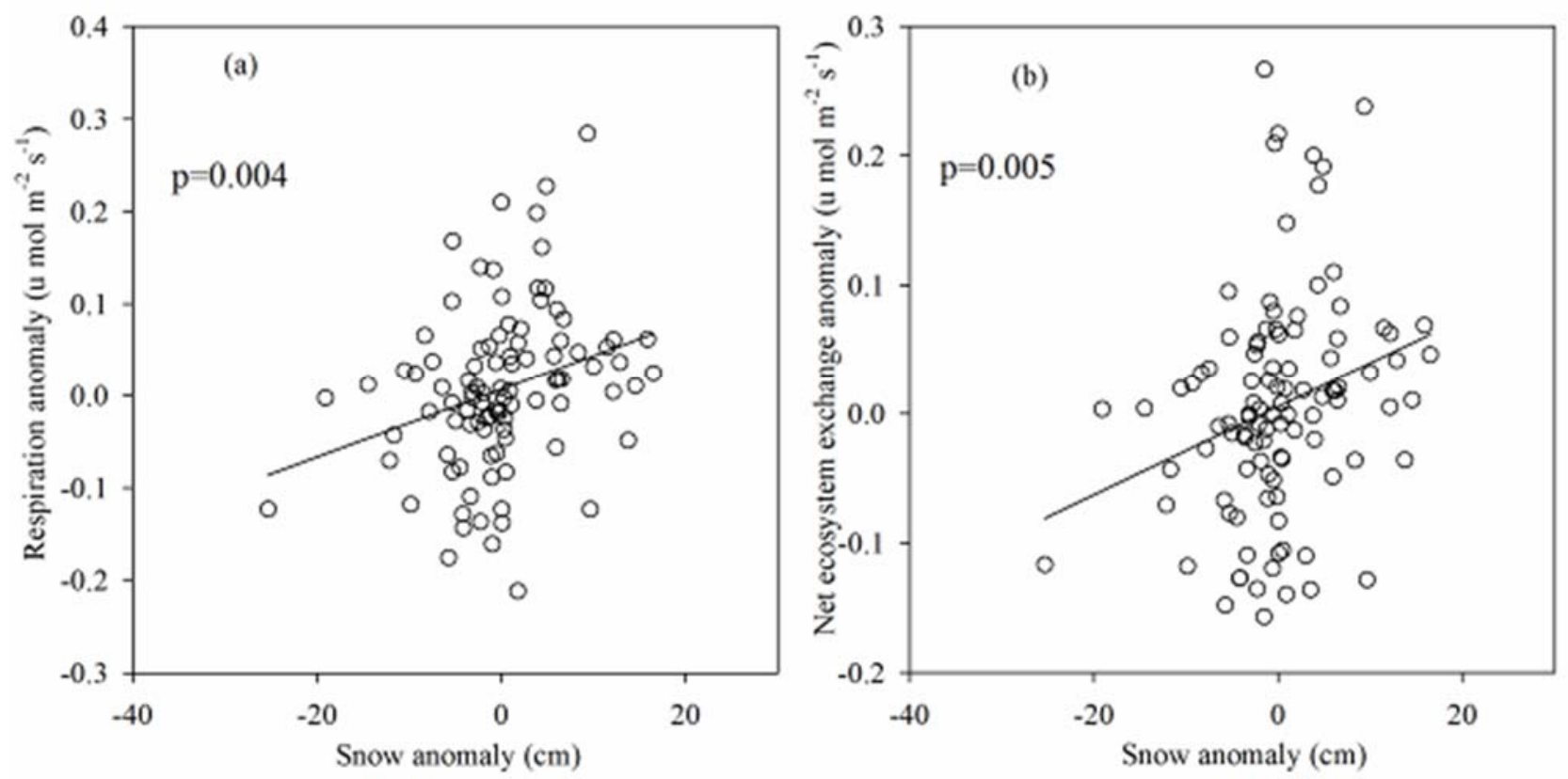

Figure 3-2 Correlation between ecosystem respiration anomaly and snow anomaly (a); and the correlation between anomalies of net ecosystem exchange and snow depth (b). The respiration and net ecosystem exchange data were observational data obtained from 15 flux sites; snow data of each flux sites were extracted from CMC snow data.

In order to fill gaps of snow depth measurements at flux sites, we used the Canadian Meteorological Centre (CMC) daily snow depth analysis as substitution (Appendix S1) for residual analyses. This product was validated at the flux site locations where snow was measured (56 observations from 12 sites; $\mathrm{R}^{2}=0.47, p<0.0001$, Appendix S1). We found winter snow depth anomalies to be significantly and positively correlated with $\mathrm{R}_{\mathrm{eco}}$ anomalies $\left(\mathrm{R}^{2}=0.09 ; p<0.05\right.$; Figure 3-2a) and NEE anomalies $\left(\mathrm{R}^{2}=0.07 ; p<0.01\right.$; Figure $\left.3-2 \mathrm{~b}\right)$, which suggests enhanced $\mathrm{R}_{\text {eco }}$ under higher snow cover depth. This positive relationship between snow depth and $\mathrm{R}_{\text {eco }}$ provides an empirical basis for linking snow depth in controlling $R_{\text {eco. }}$ These results are consistent with results reported by other studies (Goulden et al., 1996; Brooks et al., 1997; Yu et al., 2013), 
which found that higher snow depth acts as an effective insulator of soil, promoting belowground decomposition. Conversely, reduced snow depth may result in decreased respiration.

\subsubsection{Climatic factors and carbon flux change at regional scale}

We analyzed the long-term air temperature, soil temperature, and snow depth from the NCEP/CFSR (National Centers for Environmental Prediction / Climate Forecast System Reanalysis). Different patterns were observed for air temperature. Increased winter air temperature was detected in northern North America (Figure 3-3a; $0.0483{ }^{\circ} \mathrm{C} \cdot \mathrm{yr}^{-1}, p=0.06$, Figure 3-3d) while air temperature remained relatively constant in Eurasia (Figure 3-3a; $0.0271^{\circ} \mathrm{C} \mathrm{yr}^{-1}$, $p=0.38$, Figure 3-3d). However, decreasing trends of soil temperature occurred in Eurasia (Fig. $3 \mathrm{~b} ;-0.0384{ }^{\circ} \mathrm{C} \cdot \mathrm{yr}^{-1}, p=0.01$, Figure $3-3 \mathrm{e}$ ) while remaining relatively constant in North America (Figure 3-3b; $p=0.71$, Figure 3-3e). These changes of soil temperature were accompanied by a reduction of snow cover (Figure 3-3c; Figure 3-3f). Furthermore, these interannual variations of soil temperature were significantly correlated with snow change ( $p<0.01$, Appendix S3), but not air temperature change ( $p=0.56$, Appendix S3), indicating that soil temperature is primarily controlled by snow cover rather than air temperature. Therefore, an increase in air temperature may not necessarily result in a warmer soils (Natali et al., 2011; Heimann \& Reichstein, 2008), such as the non-permafrost North America region in this study. 

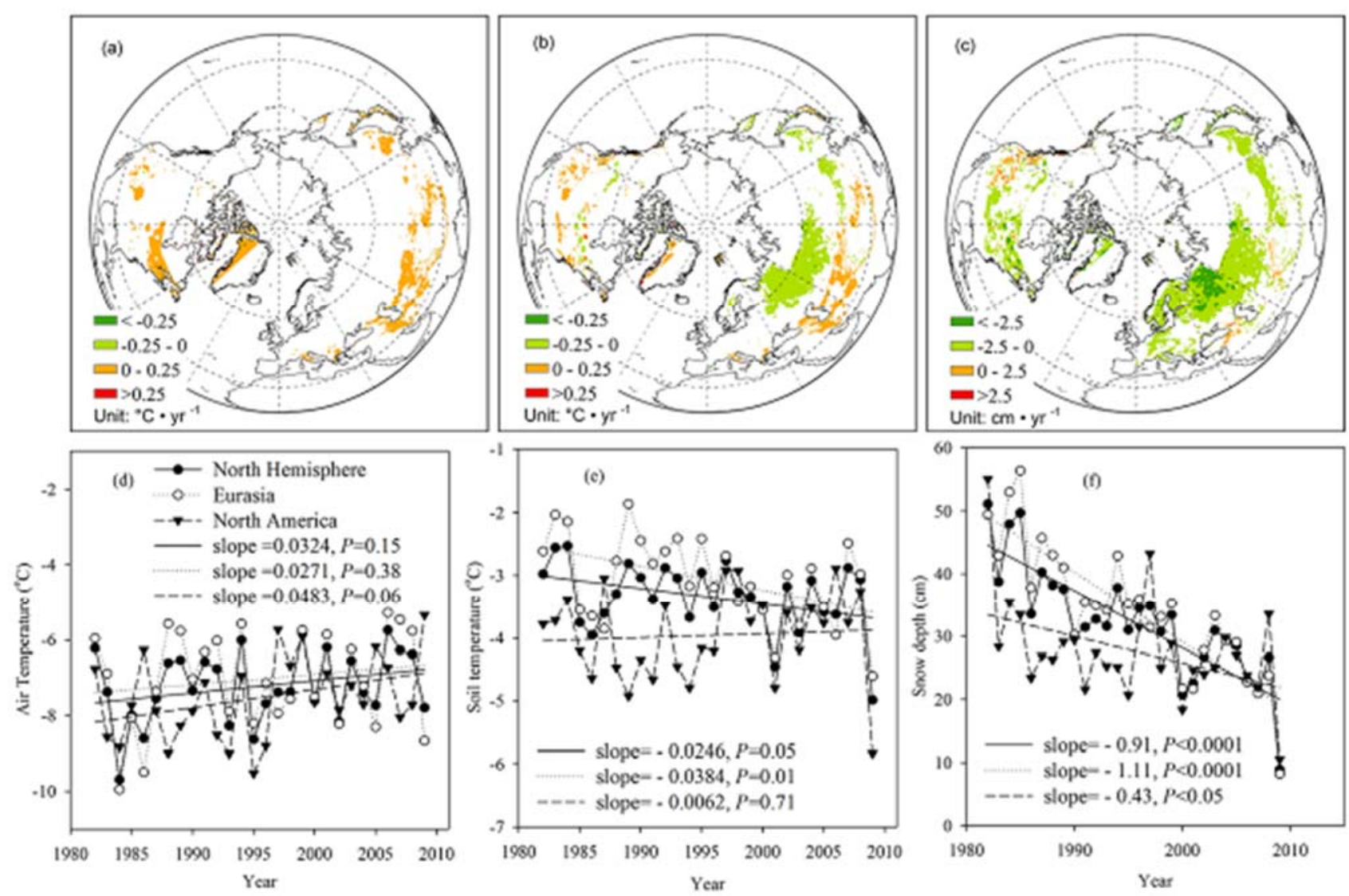

Figure 3-3 Spatial patterns of winter (a,d) change trend of air temperature $\left({ }^{\circ} \mathrm{C} \mathrm{yr} r^{-1}\right),(b, e)$ change trend of soil temperature $\left({ }^{\circ} \mathrm{C} \mathrm{yr}^{-1}\right)$, and $(\mathrm{c}, f)$ change trend of snow depth $\left(\mathrm{cm} \mathrm{yr}{ }^{-1}\right)$ from 1982-2009 based on NCEP/CFSR (National Centers for Environmental Prediction / Climate Forecast System Reanalysis) data. (Figure a, $b$ and $c$ are spatial patterns; and Figure d, e and fare regional trends) 


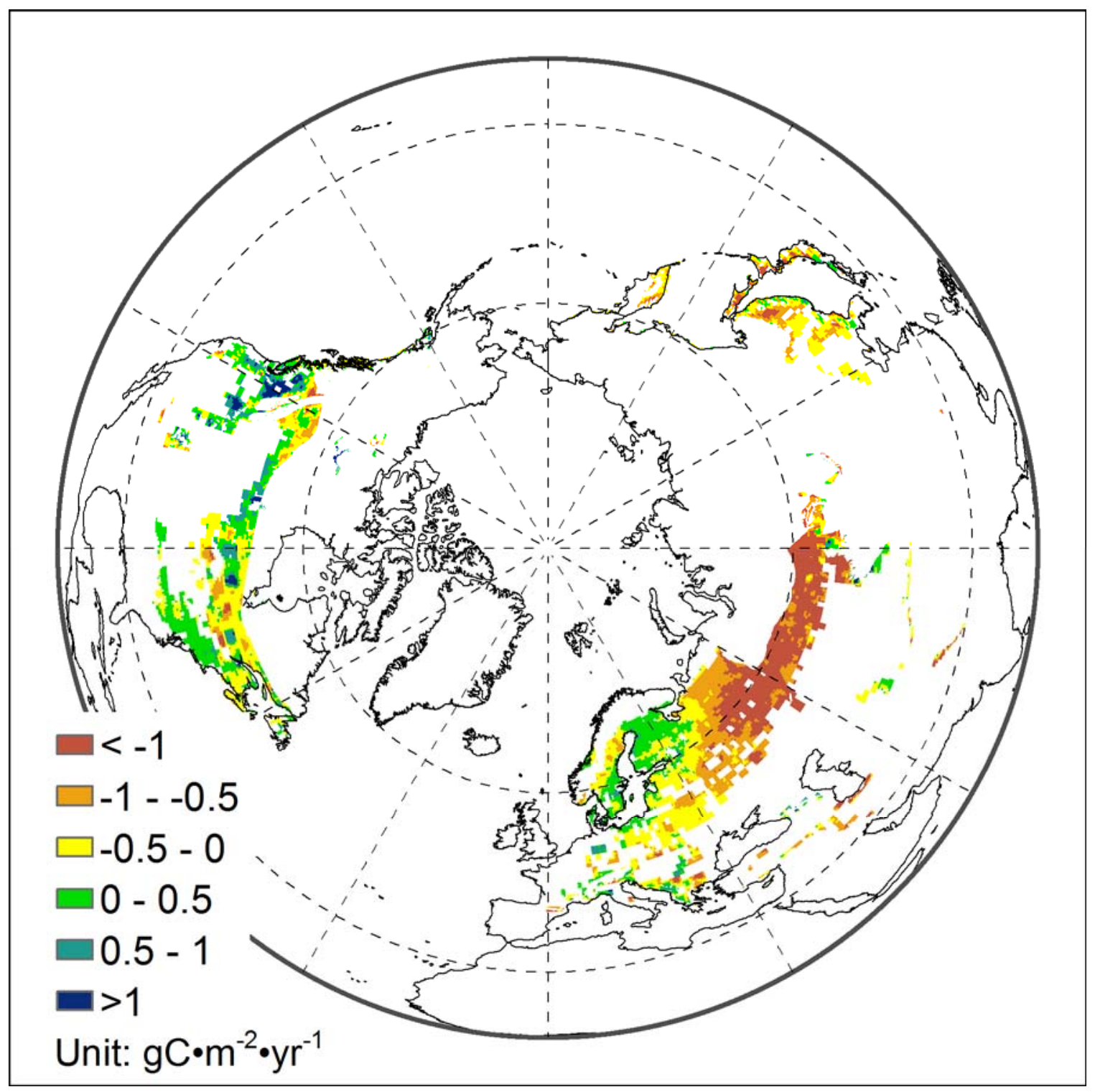

Figure 3-4 Spatial trends of winter $R_{\text {eco }}\left(g C \cdot m^{-2} \cdot \mathrm{yr}^{-1}\right)$ in the non-permafrost region of Northern forest area from 1982 to 2009. The results were derived from Biome-BGC modeling simulations. 

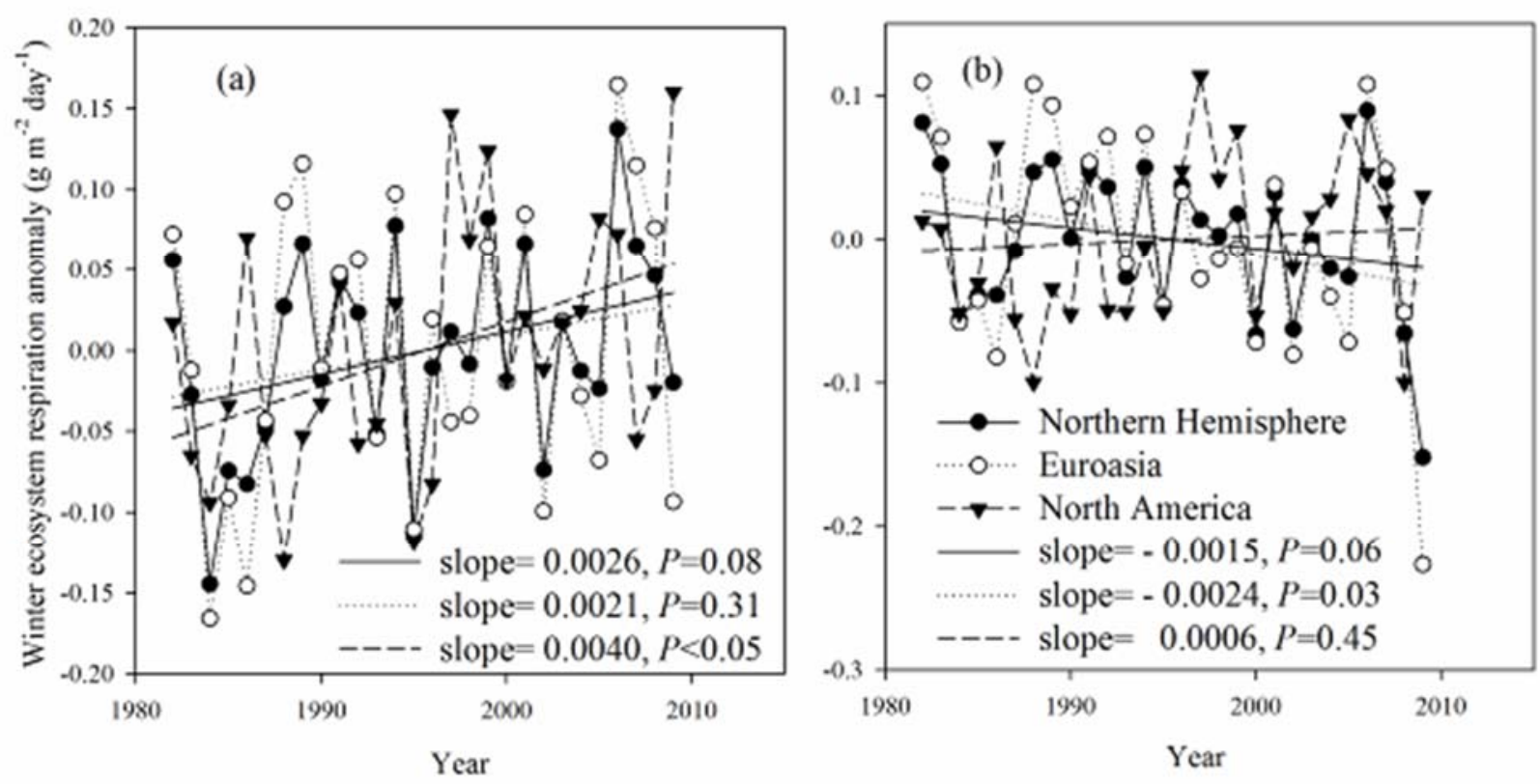

Figure 3-5 Ecosystem respiration of different regions under snow-free (a) and snow-cover (b) scenarios from 1982 to 2009. The results were derived from Biome-BGC modeling simulations.

Table 3-2 $\mathrm{CO}_{2}$ flux and changes in the non-permafrost region of Northern forest area by Biome-BGC modeling from 1982 to 2009.

\begin{tabular}{ccccc}
\hline \multirow{2}{*}{ Season } & \multicolumn{2}{c}{ Average C flux } & \multicolumn{2}{c}{ Change trend of C flux } \\
& $\mathrm{gC} \cdot \mathrm{m}^{-2} \cdot \mathrm{yr}^{-1}$ & $\mathrm{Pg} \mathrm{C}^{-\mathrm{yr}^{-1}}$ & $\mathrm{gC} \cdot \mathrm{m}^{-2} \cdot \mathrm{yr}^{-1}$ & $\mathrm{Pg} \mathrm{C} \cdot \mathrm{yr}^{-1}$ \\
\hline Winter & 54.53 & 0.58 & $-0.33^{* *}$ & -0.0035 \\
Non-winter & -155.25 & -1.65 & $-0.97^{* *}$ & -0.0103 \\
Annual & -100.72 & -1.07 & $-1.30^{* *}$ & -0.0138 \\
\hline
\end{tabular}

* Significant at $p<0.01$ level; ** Significant at $p<0.001$ level; Negative indicates a carbon sink; Positive means a carbon source. 
To quantify how air temperature, soil temperature, and snow depth influenced the soil carbon efflux at the scale of the northern Hemisphere, we applied the Biome-BGC (v4.2) process model. We used observational data from the 21 flux sites to compare with the model results for winter $R_{e c o}$, and found a good agreement between observational and simulated results $\left(R^{2}=0.73\right.$, $p<0.0001$; Appendix S2). As shown in Table 2, model-simulated winter NEE is positive in the non-permafrost Northern forest region $\left(>45^{\circ} \mathrm{N}\right)$ and this winter source offsets $32 \%(44 \pm 123 \%$ across sites) of the total $\mathrm{C}$ uptake during growing season. The large magnitude of the winter respired $\mathrm{CO}_{2}$ suggests that small but persistent changes of winter NEE could alter annual C budgets. The modeled, average winter and annual NEE were approximately 0.58 and $-1.05 \mathrm{Pg}$ $\mathrm{C} \cdot \mathrm{yr}^{-1}$ in the mid- and high-latitude forest area of Northern Hemisphere, respectively (Table 2). The uncertainty of the carbon sink at continental scale remains large using inverse model, forward model, and inventory-based estimates (Fan et al., 1998; Hayes et al., 2012). The North American forest sink has a reported range of $0.21-0.25 \mathrm{Pg} \mathrm{yr}^{-1}$ (Fan et al., 1998; Hayes et al., 2012; King et al., 2012; Pacala et al., 2007), while the Eurasian forest sink ranges from 0.817 $0.915 \mathrm{Pg} \mathrm{yr}^{-1}$, respectively (Luyssaert et al., 2012; Dolman et al., 2012; Goodale et al., 2002). Our estimation of annual NEE is close to these estimates, which reported the Northern forest ecosystem to be a sink of about $1.096 \mathrm{Pg} \mathrm{C} \mathrm{yr}^{-1}$.

In total, the winter $\mathrm{CO}_{2}$ emissions in Northern forest areas have decreased by approximately $-3.5 \mathrm{Tg} \mathrm{C} \cdot \mathrm{yr}^{-1}(1 \mathrm{Tg}=0.001 \mathrm{Pg})$ from 1982 to 2009 , with the most dramatic decrease occurring in Siberia at the rate of $0.61-1.21 \mathrm{gC} \cdot \mathrm{m}^{-2} \cdot \mathrm{yr}^{-1}$. This reduction of Reco accounts for $6.74 \%$ of the total increased global carbon uptake (Ballantyne et al., 2012). In total, the reduced winter $\mathrm{C}$ emission temporarily contributed approximately $25 \%$ of the increased annual $\mathrm{C}$ uptake in the study area (Table 2). Winter Reco trends are not spatially uniform, with an increase 
in the coastal western North America, and a decrease in Siberia (Figure 3-4). Overall, about 71\% of the study area showed a decrease of winter Reco (Figure 3-4). Piao et al. (2008) reported an abnormal $0.2 \mathrm{Pg} \mathrm{C}$ loss from northern terrestrial ecosystems for a $1{ }^{\circ} \mathrm{C}$ warming in autumn. In comparison, we found that a $1 \mathrm{~cm}$ decrease of winter snow depth reduced Reco by $3.5 \mathrm{Tg}$ (Appendix S4a), while air temperature had no significant effect on the interannual changes of winter NEE ( $p=0.19$; Appendix S4b). These results indicate that reduced snow depth may therefore account for part of the net uptake of $\mathrm{CO}_{2}$ in forest ecosystems (Goulden et al., 1996).

We performed a model sensitivity test assuming snow free conditions and observed airtemperatures, and found a significantly increasing trend in the Reco anomaly of entire study area ( $p=0.08$; Figure 3-5a), which contrasts with the simulated results with snow cover effects ( $p=0.06$; Figure 3-5b). Therefore, the spatial pattern of the interannual trend in winter Reco are primarily driven by the spatial patterns of change in snow cover. Goulden et al. (1996)'s study also revealed that snow insulation help to produce a higher than normal soil temperature and respiration rates despite colder than normal air temperature in a deciduous forest in New England. Their further estimation projected a $0.1-0.8 \mathrm{Pg} \mathrm{C} \cdot \mathrm{yr}^{-1}$ shifting in Reco due to snow cover variation (Goulden et al., 1996). Our results indicate that the Reco in mid- and high-latitude montane forests are sensitive to snow dynamics, which are consistent with Goulden et al. (1996) and Monson et al.(2006)'s studies but unlike previous results obtained from low latitude temperate forest site (Schindlbacher et al., 2014). 


\subsection{Conclusions}

Our results showed that the aboveground warming could result in attenuated snow cover, which would consequently increase the freezing potential of soil, and offset the enhanced aboveground $\mathrm{C}$ emission from temporarily suppressed underground respiration. In this study, we focused on $\mathrm{CO}_{2}$ emission due to the limited data availability. However, the different feedbacks of greenhouse gases (e.g. $\mathrm{CO}_{2}, \mathrm{~N}_{2} \mathrm{O}$, and $\mathrm{CH}_{4}$ ) aggravate the uncertainty in quantifying the effects of snow on global climate change, which needs to be further studied through eddy-covariance flux measurements and manipulation experiments. Further investigation is certainly needed in order to comprehensively understand and assess the impact of snow dynamics on global C cycling and balancing.

\section{Acknowledgement}

The authors would like to thank all the PIs of the Eddy Covariance sites of Canadian Carbon Program (CCP) and AmeriFlux for providing the flux data. This study was financially supported in part by China National Science Foundation (No. 31290223), Sino-US cooperative project (No. 2015DFA31440), and United States Department of Agriculture National Institute of Food and Agriculture (2012-67009-19660). 


\section{Reference}

Ballantyne AP, Alden CB, Miller JB, Tans PP, White JWC (2012) Increase in observed net carbon dioxide uptake by land and oceans during the past 50 years. Nature, 488(7409):70-72.

Barr AG, Black TA, Hogg EH, Kljun N, Morgenstern K, Nesic Z (2004) Inter-annual variability in the leaf area index of a boreal aspen-hazelnut forest in relation to net ecosystem production. Agricultural and forest meteorology, 126(3):237-255.

Brasnett B (1999) A global analysis of snow depth for numerical weather prediction. Journal of Applied Meteorology and Climatology, 38(6):726-740.

Brooks PD, McKnight D, Elder K (2005) Carbon limitation of soil respiration under winter snowpacks: potential feedbacks between growing season and winter carbon fluxes. Global Change Biology, 11(2):231-238.

Brooks PD, Schmidt SK, Williams MW (1997) Winter production of $\mathrm{CO}_{2}$ and $\mathrm{N}_{2} \mathrm{O}$ from alpine tundra: environmental controls and relationship to inter-system $\mathrm{C}$ and $\mathrm{N}$ fluxes. Oecologia, 110:403-413.

Brown J, Ferrians OJ, Heginbottom JA, Melnikov ES (2001) Circum-arctic map of permafrost and ground ice conditions. Boulder, CO: National Snow and Ice Data Center. http://nsidc.org/. Accessed 20 Sep 2015.

Brown RD, Brasnett B (2010) Canadian Meteorological Centre (CMC) Daily Snow Depth Analysis Data. Boulder, Colorado USA: NASA DAAC at the National Snow and Ice Data Center. http://nsidc.org/. Accessed 10 Feb 2014. 
Brown RD, Robinson DA (2011) Northern Hemisphere spring snow cover variability and change over 1922-2010 including an assessment of uncertainty. The Cryosphere, 5(1):219-229.

Chiesi M, Maselli F, Moriondo M, Fibbi L, Bindi M, Running SW (2007) Application of BIOME-BGC to simulate Mediterranean forest processes. Ecological Modelling, 206(1):179-190.

Dentener FJ (2006) Global Maps of Atmospheric Nitrogen Deposition, 1860, 1993, and 2050. Data set. Available on-line [http://daac.ornl.gov/] from Oak Ridge National Laboratory Distributed Active Archive Center, Oak Ridge, Tennessee, USA.

Déry SJ, Brown RD (2007) Recent Northern Hemisphere snow cover extent trends and implications for the snow-albedo feedback. Geophysical Research Letters, 34(22).

Dolman AJ, Shvidenko A, Schepaschenko D et al. (2012) An estimate of the terrestrial carbon budget of Russia using inventory-based, eddy covariance and inversion methods. Biogeosciences, 9(12):5323-5340.

Dorrepaal E, Toet S, van Logtestijn RS, Swart E, van de Weg MJ, Callaghan TV, Aerts R (2009) Carbon respiration from subsurface peat accelerated by climate warming in the subarctic. Nature, 460(7255):616-619.

Eichler TP, Londoño AC (2013) South American climatology and impacts of El Niño in NCEP's CFSR Data. Advances in Meteorology, 2013:1-15.

Ek, MB, Mitchell KE, Lin Y et al. (2003) Implementation of Noah land surface model advances in the National Centers for Environmental Prediction operational mesoscale Eta model. Journal of Geophysical Research: Atmospheres, 108(D22):8851.

Euskirchen ES, McGuire AD, Chapin FSIII (2007) Energy feedbacks of northern high-latitude 
ecosystems to the climate system due to reduced snow cover during 20th century warming. Global Change Biology, 13(11): 2425-2438.

Fan S, Gloor M, Mahlman J, Pacala S, Sarmiento J, Takahashi T, Tans P (1998) A large terrestrial carbon sink in North America implied by atmospheric and oceanic carbon dioxide data and models. Science, 282(5388):442-446.

Fuka DR, Walter MT, MacAlister C, Degaetano AT, Steenhuis TS, Easton ZM et al. (2014) Using the Climate Forecast System Reanalysis as weather input data for watershed models. Hydrological Processes, 28(22):5613-5623.

Goulden, ML, Munger JW, Fan SM, Daube BC, Wofsy SC (1996) Exchange of carbon dioxide by a deciduous forest: response to interannual climate variability. Science, 271: 15761578.

Goodale CL, Apps MJ, Birdsey RA et al. (2002) Forest carbon sinks in the Northern Hemisphere. Ecological Application, 12(3): 891-899.

Gouttevin I, Menegoz M, Dominé F, Krinner G, Koven C, Ciais P, Tarnocai C, Boike J (2012) How the insulating properties of snow affect soil carbon distribution in the continental pan-Arctic area. Journal of Geophysical Research: Biogeosciences, 117(G2).

Grippa M, Kergoat L, Le Toan T, Mognard NM, Delbart N, L'Hermitte J, Vicente-Serrano, SM (2005) The impact of snow depth and snowmelt on the vegetation variability over central Siberia. Geophysical Research Letters, 32:1-4.

Groffman PM, Hardy JP, Driscoll CT, Fahey TJ (2006) Snow depth, soil freezing, and fluxes of carbon dioxide, nitrous oxide and methane in a northern hardwood forest. Global Change Biology, 12:1748-1760. 
Hardy JP, Groffman PM, Fitzhugh RD et al. (2001) Snow depth manipulation and its influence on soil frost and water dynamics in a northern hardwood forest. Biogeochemistry, 56(2):151-174.

Hayes DJ, Gloor M, Mahlman J, Pacala S, Sarmiento J, Takahashi T, Tans P (2012) Reconciling estimates of the contemporary North American carbon balance among terrestrial biosphere models, atmospheric inversions, and a new approach for estimating net ecosystem exchange from inventory-based data. Global Change Biology, 18(4):12821299.

Heimann M, Reichstein M (2008) Terrestrial ecosystem carbon dynamics and climate feedbacks. Nature, 451(7176):289-292.

Jenkinson DS, Adams DE, Wild A (1991) Model estimates of $\mathrm{CO}_{2}$ emissions from soil in response to global warming. Nature, 351(6324):304-306.

Karl TR, Groisman PY, Knight RW, Heim RR Jr (1993) Recent variations of snow cover and snowfall in North America and their relation to precipitation and temperature variations. Journal of Climate, 6(7):1327-1344.

King AW, Hayes DJ, Huntzinger DN, West TO, Post WM (2012) North America carbon dioxide sources and sinks: Magnitude, attribution, and uncertainty. Frontiers in Ecology and the Environment, 10:512-519.

Kljun N, Black TA, Griffis TJ, Barr AG, Gaumont-Guay D, Morgenstern K, McCaughey JH, Nesic Z (2006) Response of net ecosystem productivity of three boreal forest stands to drought. Ecosystems, 9(7):1128-1144. 
Larsen KS, Grogan P, Jonasson S, Michelsen A (2007) Respiration and microbial dynamics in two subarctic ecosystems during winter and spring thaw: effects of increased snow depth. Arctic, Antarctic, and Alpine Research, 39(2):268-276.

Laternser M, Schneebeli M (2003) Long-term snow climate trends of the Swiss. Alps (1931-99). International Journal of Climatology, 23:733-750.

Luyssaert S, Abril G, Andres R et al. (2012) The European land and inland water $\mathrm{CO}_{2}, \mathrm{CO}, \mathrm{CH}_{4}$ and N2O balance between 2001 and 2005. Biogeosciences, 9(8):3357-3380.

Mahecha MD, Miguel D, Markus R et al. (2010) Global convergence in the temperature sensitivity of respiration at ecosystem level. Science, 329(5993):838-840.

Melillo JM, Butler S, Johnson J et al. (2011) Soil warming, carbon-nitrogen interactions, and forest carbon budgets. Proceedings of the National Academy of Sciences, 108(23):95089512.

Monson RK, Lipson DL, Burns SP, Turnipseed AA, Delany AC, Williams MW, Schmidt SK (2006) Winter forest soil respiration controlled by climate and microbial community composition. Nature, 439(7077):711-714.

Monson RK, Turnipseed AA, Sparks JP (2002) Carbon sequestration in a high-elevation subalpine forest. Global Change Biology, 8:459-478.Monson RK, Sparks JP, Rosenstiel TN et al. (2005) Climatic influences on net ecosystem $\mathrm{CO}_{2}$ exchange during the transition from wintertime carbon source to springtime carbon sink in a high-elevation, subalpine forest. Oecologia, 146:130-147.

Mote PW, Hamlet AF, Clark MP, Lettenmaier DT (2005) Declining mountain snowpack in Western North America. Bulletin of the American Meteorological Society, 86:39-49. 
Mueller B, Seneviratne SI (2012) Hot days induced by precipitation deficits at the global scale. Proceedings of the National Academy of Sciences, 109(31):12398-12403.

Natali SM, Schuur EA, Trucco C, Hicks Pries CE, Crummer KG, Baron Lopez AF (2011) Effects of experimental warming of air, soil and permafrost on carbon balance in Alaskan tundra. Global Change Biology, 17(3):1394-1407.

Nobrega S, Grogan P (2007) Deeper snow enhances winter respiration from both plantassociated and bulk soil carbon pools in birch hummock tundra. Ecosystems, 10(3):419431.

Pacala S, Birdsey RA, Bridgham SD et al. (2007) The North American carbon budget past and present, The First State of the Carbon Cycle Report (SOCCR): The North American Carbon Budget and Implications for the Global Carbon Cycle, eds King, AW, Dilling L, Zimmerman GP, Fairman DM, Houghton RA, Marland G, Rose AZ, Wilbanks TJ National Oceanic and Atmospheric Administration, National Climatic Data Center, Asheville, NC: 29-36.

Peng SS, Piao SL, Ciais P et al. (2013) Asymmetric effects of daytime and night-time warming on Northern Hemisphere vegetation. Nature, 501(7465):88-92.

Peng SS, Piao SL, Ciais P, Fang JY, Wang XH (2010) Change in winter snow depth and its impacts on vegetation in China. Global Change Biology, 16:3004-3013.

Piao SL, Ciais P, Friedlingstein P et al. (2008) Net carbon dioxide losses of northern ecosystems in response to autumn warming. Nature, 451:49-52.

Pietsch SA, Hasenauer H (2002) Using mechanistic modeling within forest ecosystem restoration. Forest Ecology and Management, 159(1):111-131. 
Pietsch SA, Hasenauer H (2006) Evaluating the self-initialization procedure for large-scale ecosystem models. Global Change Biology, 12(9):1658-1669.

Poulter et al. in prep.

Raich JW, Schlesinger WH (1992) The global carbon dioxide flux in soil respiration and its relationship to vegetation and climate. Tellus B, 44(2):81-99.

Running SW, Nemani RR, Townshend JR, Baldocchi DD (2009) Next-Generation Terrestrial Carbon Monitoring. Carbon Sequestration and Its Role in the Global Carbon Cycle, 4969.

Saha S, Moorthi S, Pan HL et al. (2010) NCEP Climate Forecast System Reanalysis (CFSR) 6hourly Products, January 1979 to December 2010. Research Data Archive at the National Center for Atmospheric Research, Computational and Information Systems Laboratory, Boulder, Colorado, USA. http://rda.ucar.edu/datasets/ds093.0. Accessed 10 Jan 2014.

Scherrer SC, Appenzeller C, Laternser M (2004) Trends in Swiss alpine snow days-the role of local and large-scale climate variability. Geophysical Research Letters, 31:L13215.

Schimel JP, Bilbrough C, Welker JM (2004) Increased snow depth affects microbial activity and nitrogen mineralization in two Arctic tundra communities. Soil Biology and Biochemistry, 36(2):217-227.

Sommerfeld RA, Mosier AR, Musselman RC (1993) $\mathrm{CO}_{2}, \mathrm{CH}_{4}$ and $\mathrm{N}_{2} \mathrm{O}$ flux through a Wyoming snowpack and implications for global budgets. Nature, 361:140-142.

Wang T, Ciais P, Piao SL et al. (2011). Controls on winter ecosystem respiration in temperate and boreal ecosystems. Biogeosciences, 8(7):2009-2025. 
Wang T, Peng S, Ciais P (2015) Spring snow cover deficit controlled by intraseasonal variability of the surface energy fluxes. Environmental Research Letters, 10(2): 024018.

Wang W, Wang T, Peng SS, Fang JY (2007) Review of winter $\mathrm{CO}_{2}$ efflux from soils: A key process of $\mathrm{CO}_{2}$ exchange between soil and atmosphere. Chinese Journal of Plant Ecology, 31(3):394-402.

Wania R, Ross I, Prentice IC (2010) Implementation and evaluation of a new methane model within a dynamic global vegetation model: LPJ-WHyMe v1. 3.1. Geoscientific Model Development, 3(2):565-584.

Winston GC, Sundquist ET, Stephens BB (1997) Winter $\mathrm{CO}_{2}$ fluxes in a boreal forest, Journal of Geophysical Research, 102:28795-28804.

Ye H, Cho HR, Gustafson PE (1998) The changes in Russian winter snow accumulation during 1936-83 and its spatial patterns. Journal of Climate, 11(5): 856-863.

Yu Z, Liu SR, Wang JX, Sun PS, Liu WG, Hartley DS (2013) Effects of seasonal snow on the growing season of temperate vegetation in China. Global Change Biology, 19(7):21822195.

Zuo Z, Yang S, Wang W, Kumar A, Xue Y, and Zhang R (2011) Relationship between anomalies of Eurasian snow and southern China rainfall in winter. Environmental Research Letters, 6(4): 045402.

\section{Supporting Information}

Appendix S1 Supplementary information describing full details of validations of the two snow datasets used in this study. 
Appendix S2 Supplementary information providing validation of the model simulation performed.

Appendix S3 Supplementary analyses of correlation between interannual winter soil temperature, snow cover depth, and air temperature in the study area.

Appendix S4 Supplementary analyses of correlation between interannual snow cover depth, winter air temperature, and model simulated net ecosystem exchange. 


\section{Global gross primary productivity and water use efficiency changes under drought stress ${ }^{\ddagger}$}

$\$$ To be submitted to Environmental Research Letters 


\section{Abstract}

Drought can affect the structure, composition and function of terrestrial ecosystems, yet the drought impacts and post-drought recovery potential of different land cover types have not been extensively studied at a global scale. Here, we evaluated drought impacts on gross primary productivity (GPP), evapotranspiration (ET), and water use efficiency (WUE) of different global terrestrial ecosystems, as well as the drought-resilience of each ecosystem type during the period of 2000 to 2011. We found the rainfall and soil moisture during drought period were dramatically lower than these in non-drought period, while air temperatures were higher than normal during drought period with amplitudes varied by land cover types. The length of recovery days (LRD) presented an evident gradient of high (> 60 days) in mid- latitude region and low (< 60 days) in low (tropical area) and high (boreal area) latitude regions. As average GPP increased, the LRD showed a significantly decreasing trend among different land covers $\left(\mathrm{R}^{2}=0.53\right.$, $p<0.0001)$. Moreover, the most dramatic reduction of the drought-induced GPP was found in the mid-latitude region of north Hemisphere (48\% reduction), followed by the low-latitude region of south Hemisphere (13\% reduction). In contrast, a slightly enhanced GPP (10\%) was showed in the tropical region under drought impact. Additionally, the highest drought-induced reduction of ET was found in the Mediterranean area, followed by Africa. The water use efficiency, however, showed a pattern of decreasing in the north Hemisphere and increasing in the south Hemisphere. 


\subsection{Introduction}

Drought is an important adverse climatic event for both ecosystems and human society (Mu et al., 2013). Previous studies using state-of-the-art models projected higher frequency and intensity of droughts in most of the southern Hemisphere and part of the northern Hemisphere in response to global climate change (IPCC, 2013; Fisher \& Knutti, 2014; Allen et al., 2014, Spinoni et al., 2014). Global air temperature has linearly increased over the 50 years from 1956 to $2005\left(0.13^{\circ} \mathrm{C}\right.$ per decade $)$, which is nearly as twice fast as the rising rate during 100 years from 1906 to 2005 (Solomon et al., 2007). While more prominently, the past decade has experienced a faster and unprecedented warming trend than the prior century as evidenced by the fact that the 10 hottest years on record have all occurred since 1998 (NASA 2011, UK-MetOffice 2011, JMA 2011), making the past decade an ideal period to examine the terrestrial ecosystems' responses to drought extremes.

Increased heating itself from global climate change may not cause droughts but it is expected to intensify droughts (Trenberth et al., 2014). Intensity is the most important dimension of drought, and its change refers to the significant reduction of water availability comparing to "normal conditions" (Tsakiris \& Vangelis, 2005). Water availability is determined by both of the

water input (precipitation) and output (evapotranspiration, runoff). Land evapotranspiration (ET), the sum of soil evaporation, canopy evaporation, and plant transpiration, is a central process in the climate system, and is also a nexus of the water, energy and carbon cycles (Jung et al., 2010; Mu et al., 2007). The ratio of GPP to ET, namely water use efficiency (WUE), is an indicator reflecting the carbon gain and water loss in terrestrial ecosystems as carbon and water cycles are closely coupled during the process of photosynthetic C assimilation (Yu et al., 2008). The trading of water and $\mathrm{C}$ mechanism is closely related to the drought stress. Under negative 
conditions, plants may increase WUE to adapt to unfavorable environment. For example, Saleska et al. (2007) reported intact forest canopy "greenness" increased under drought stress.

Various indices have been developed to represent regional- to global-scale drought stresses, including Palmer drought severity index (PDSI; Palmer, 1965; Alley, 1984), MODIS DSI (Moderate Resolution Imaging Spectroradiometer Drought Severity Index; Mu et al., 2013), Standardized Precipitation Index (SPI; McKee et al., 1993), and Evaporative Drought Index (EDI; Yao et al., 2010). Among all of these metrics, the PDSI is perhaps the best well known and commonly used drought index which is determined by monthly water supply, water outputs, and preceding soil water status. Nonetheless, the PDSI has weaknesses of lag of emerging droughts and ineffectiveness for mountainous regions or in spring (Orvos et al., 2015; Mu et al., 2013). By comparison, the MODIS DSI index developed by Mu et al. using satellite-derived ET, PET, and NDVI is advantageous in providing both simultaneous and high resolution drought information. Limitations of other commonly used drought metrics have been comprehensively summarized in Mu et al. (2013)'s study, in terms of weak representativeness, low effectiveness, and limited reliability.

Previous studies have improved our understanding of the measurement in drought intensity and mechanism underlying the ecosystem responses to drought events, which is of great importance in projecting the impacts of climate extremes on regional $\mathrm{C}$ budget and water resources in the future. Despite this, a comprehensive assessment of the droughts' impacts on global ecosystems is essentially needed. Furthermore, only a few studies have examined the post-drought recovery potential of different land covers globally. Ecosystem resilience, an indicator of the recovery potential, should be investigated to examine the large scale ecological collapse. Allen et al. (2010) reported that part of the world's forested ecosystems may become 
increasingly vulnerable to higher background tree mortality rates and die-off in response to future warming and drought, even in the environments that are not normally considered waterlimited. Examples have been well documented in local and regional scales such as in Europe (Peñuelas et al., 2001; Breda et al., 2006; Bigler et al., 2006), and western North America (van Mantgem et al., 2009). Therefore, in this study, based on MODIS data and CRU (Climate Research Unit at half-degree resolution) climate data, we identified the drought events and quantify their impacts on GPP, ET, and WUE in different, global terrestrial ecosystems during the period from 2000 to 2011 . We further addressed the length of days each ecosystem requires to recover from drought stress as well as its relationship with ecosystem productivity. Finally, we discussed the response of terrestrial ecosystems to heat extremes and the implications to enhance ecosystem carbon sequestration potential. 


\subsection{Materials and methods}

\subsubsection{Study area and data descriptions}

This study focused on the different terrestrial ecosystem types of the global land area, including Evergreen Needleleaf forest (ENF), Evergreen Broadleaf forest (EBF), Deciduous Needleleaf forest (DNF), Deciduous Broadleaf forest (DBF), Mixed forest (MF), Closed shrublands (CSHB), Open shrublands (OSHB), Woody savannas (WSAV), Savannas (SAV), Grasslands (GR), Permanent wetlands (WET), Croplands (CROP). MODIS GPP, ET (MOD16/17) and DSI (Drought Severity Index) products were used for analyses of droughts and ecosystem responses. The models implemented for developing these products were thoroughly described by Mu et al. (2007), Mu et al. (2011), Zhao et al. (2005), and Mu et al. (2013). The MODIS products were downloaded from the Numerical Terradynamic Simulation Group (NTSG) of University of Montana at an 8-day interval. All datasets were resampled and categorized from original $5 \times 5 \mathrm{~km}$ into a $0.5 \times 0.5$ degree resolution for modeling and analyses. We then evaluated water use efficiency (WUE) derived from the GPP and ET products (defined as WUE $=\mathrm{GPP} / E T)$, to detect the drought-induced changes in trade-off between $\mathrm{C}$ and water at different ecosystems.

Other climatic datasets, such as air temperature and rainfall were obtained from the Climate Research Unit at half-degree resolution (CRU, http://www.cru.uea.ac.uk/cru/data/hrg/). Global coverage daily soil moisture (SM) data were derived from the ESA Global Monitoring of Essential Climate Variables (ECV) with spatial resolution at 0.25 degree from 1978 to 2013 (http://www.esa-soilmoisture-cci.org/). The soil moisture data were then summarized, resampled, and gap-filled to 8-day time series at half-degree spatial resolution (see Supporting Information). 


\subsubsection{Drought and non-drought period}

In this study, MODIS DSI product was used to detect drought occurrence. We defined a drought event as the period which has at least one month (4 times of 8-day time series) with a consecutive DSI below -0.9 . The threshold value -0.9 refers to moderate drought defined in $\mathrm{Mu}$ et al. (2013). Air temperature, rainfall, and soil moisture of the drought period were extracted to compare with the average values of the non-drought (normal) period. The non-drought period was defined as the duration in a growing season (May to September) with all 8-day time series DSI higher than -0.9 (without drought occurrence).

\subsubsection{GPP recovery duration length}

Ecosystem GPP, a metrics of photosynthesis activity, was used to evaluate the recovery level of ecosystem vitality after drought impacts. First, the average non-drought GPP (AveGPP) was calculated at a pixel basis of 8-day interval time-scale (Equations 1 and 2). The original 8day GPP dataset was divided by the AveGPP to produce a standardized GPP time-series (StdGPP, Equation 3), which was then smoothed by a one-month window and created the final time-series data for analyses (SmhGPP, Equation 4). In this study, we also defined an ecosystem recovery from a drought event to its normal condition as once a post-drought one-month consecutive GPP achieved 95\% (negative drought impacts) or 105\% (positive drought impacts) of the average non-drought period GPP (the month when SmhGPP with the threshold value of 0.95 or 1.05$)$.

$$
\begin{aligned}
& \text { Flag }_{i}=\left\{\begin{array}{ll}
0 & \text {; if } D S I_{i}<-0.9 \\
1 & \text {; if } D S I_{i}>-0.9
\end{array} \quad(i=1,2,3 \ldots, n \times 46)(1)\right. \\
& \operatorname{AveGPP}_{i}=\left(\sum_{k=1}^{n} G P P_{i+(k-1) \times 46} \times \text { Flag }_{i}\right) /\left(\sum_{k=1}^{n} k \times F \operatorname{lag}_{i}\right) \quad(i=1,2,3 \ldots 46)
\end{aligned}
$$




$$
\begin{aligned}
\operatorname{StdGPP}_{j} & =G P P_{j} / \text { AveGPP } \\
\text { mod } 46 & (j=1,2,3 \ldots, n \times 46)(3) \\
\operatorname{SmhGPP} P_{j} & =\left(\sum_{k=1}^{4} \operatorname{StdGPP}_{j+k-1}\right) / 4 \quad(j=1,2,3 \ldots, n \times 46)(4)
\end{aligned}
$$

Where, $n$ is the number of years from 2000 to 2013 (for each year there are 46 8-day data); Flagi denotes whether drought emerges at time $i$; AveGPP is the average non-drought GPP at time $i$; StdGPP is the standardized GPP; and SmhGPP is the GPP time-series smoothed by one-monthwindow. 


\subsection{Results}

\subsubsection{Climatic factors during drought and non-drought periods}

During drought period, the rainfall and soil moisture were much lower than them in nondrought period, yet a higher than normal air temperature was detected during the drought period (Figure 4-1). The highest reduction of rainfalls ( $>50 \%)$ in drought period was found in central North America, Mediterranean, and Australia (Figure 4-1a). Extensively lower soil moisture $(<50 \%$ reduction) was also detected in most of the land areas except for part of the high latitude regions of North America, Eurasia and southern China (Figure 4-1b). In contrast, air temperature showed a pattern of higher than normal in almost the entire global land, with a few scattered pixels of slightly lower values (Figure 4-1c).
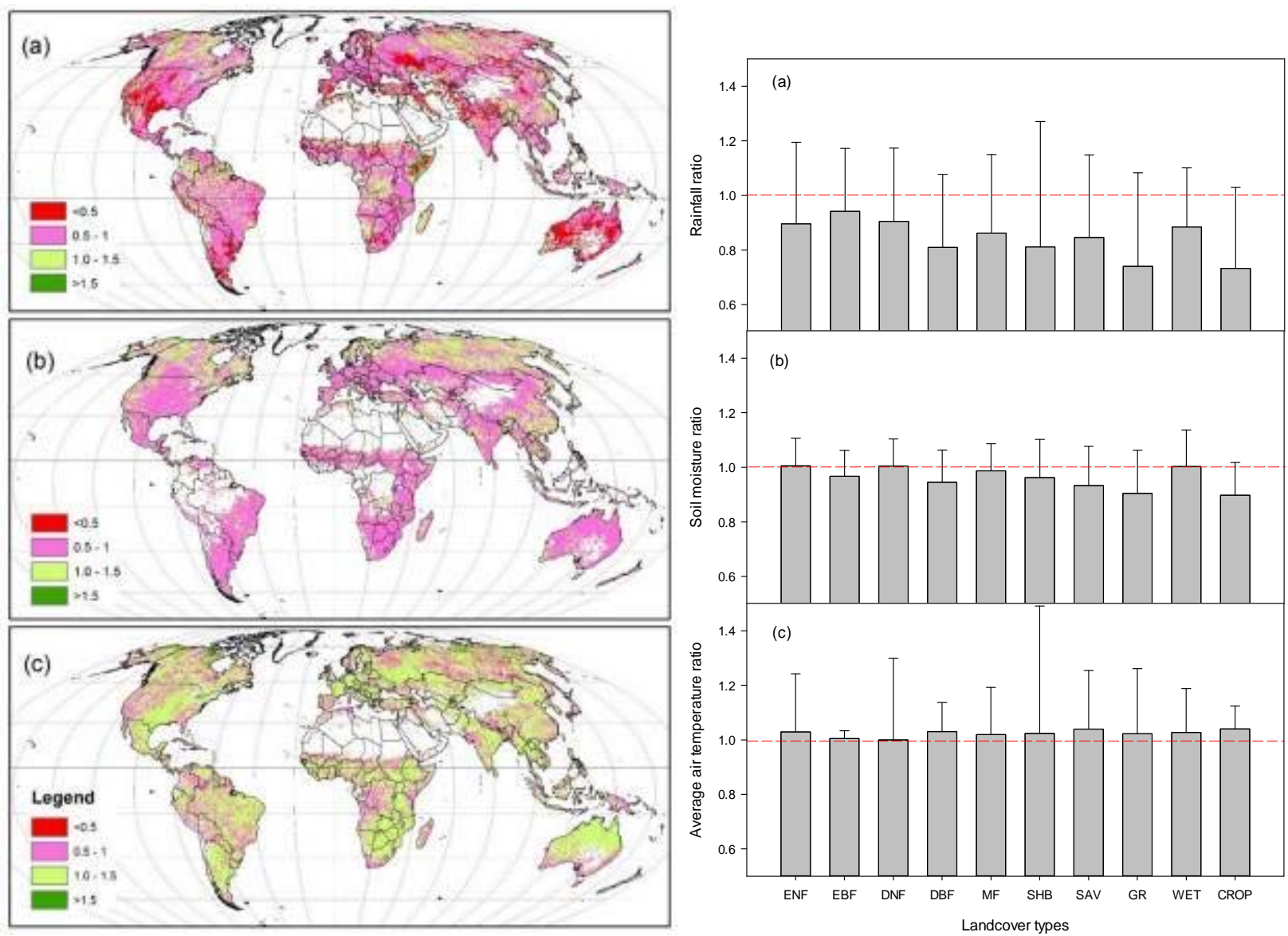
Figure 4-1 Rainfall (a), soil moisture (b) and average air temperature (c) ratio of drought period and the non-drought period; the right panel shows the average ratios of rainfall, soil moisture, and air temperature in different land covers

Table 4-1 Rainfall, soil moisture, and average air temperature difference of drought period and the non-drought period by land covers

\begin{tabular}{|c|c|c|c|c|c|c|}
\hline Type & $\begin{array}{l}\text { Rainfall } \\
\text { (mm/day) }\end{array}$ & $\begin{array}{c}95 \% \\
\text { confidence } \\
\text { interval of the } \\
\text { difference }\end{array}$ & $\begin{array}{c}\text { Volumetric } \\
\text { Soil moisture } \\
(* 0.0001 \\
\left.\mathrm{m}^{3} / \mathrm{m}^{3}\right)\end{array}$ & $\begin{array}{l}95 \% \text { confidence } \\
\text { interval of the } \\
\text { difference }\end{array}$ & $\begin{array}{l}\text { Average air } \\
\text { temperature } \\
\left({ }^{\circ} \mathrm{C}\right)\end{array}$ & $\begin{array}{c}95 \% \\
\text { confidence } \\
\text { interval of the } \\
\text { difference }\end{array}$ \\
\hline ENF & $-0.23 * *$ & $-0.20--0.26$ & $16.65 * *$ & $4.77-28.53$ & $0.34 * *$ & $0.24-0.44$ \\
\hline $\mathrm{EBF}$ & $-0.39 * *$ & $-0.44--0.33$ & $-28.62 * *$ & $-33.18--24.07$ & $0.12 * *$ & $0.10-0.13$ \\
\hline DNF & $-0.20 * *$ & $-0.24--0.16$ & 17.14 & $-1.43-35.71$ & -0.05 & $-0.27-0.17$ \\
\hline $\mathrm{DBF}$ & $-0.67 * *$ & $-0.74--0.54$ & $-97.33 * *$ & $-113.35--81.30$ & $0.56^{* *}$ & $0.45-0.67$ \\
\hline MF & $-0.36^{* *}$ & $-0.40--0.32$ & $-25.27 * *$ & $-34.94--15.61$ & $0.30 * *$ & $0.22-0.39$ \\
\hline CSHB & $-0.38 * *$ & $-0.43--0.33$ & $-91.22 * *$ & $-106.27--76.17$ & $0.29 * *$ & $0.19-0.40$ \\
\hline OSHB & $-0.26^{* *}$ & $-0.27--0.24$ & $-38.05 * *$ & $-44.45--31.65$ & $0.30 * *$ & $0.24-0.35$ \\
\hline WSAV & $-0.52 * *$ & $-0.55--0.49$ & $-73.86 * *$ & $-81.39--66.34$ & $0.56 * *$ & $0.51-0.61$ \\
\hline
\end{tabular}




\begin{tabular}{ccccccc}
\hline SAV & $-0.89 * *$ & $-0.94--0.85$ & $-243.49^{* *}$ & $-254.28--232.71$ & $0.39 * *$ & $0.35-0.43$ \\
GR & $-0.46^{* *}$ & $-0.49--0.44$ & $-159.52^{* *}$ & $-165.86--153.18$ & $0.46^{* *}$ & $0.41-0.51$ \\
WET & $-0.41^{* *}$ & $-0.51--0.31$ & 14.60 & $-9.72-38.91$ & $0.35^{* *}$ & $0.19-0.52$ \\
CROP & $-0.61 * *$ & $-0.64--0.58$ & $-209.78^{* *}$ & $-216.95--202.60$ & $0.72 * *$ & $0.68-0.76$ \\
\hline
\end{tabular}

** denotes significant at $\mathrm{p}<0.001$

On average, the drought period rainfall was less than that in the normal period with a difference ranging $0.23-0.89 \mathrm{~mm} /$ day while air temperature was higher at a difference of $0.12-$ $0.72{ }^{\circ} \mathrm{C}$. This resulted in a lower soil moisture content during drought periods under most of the land cover types except for ENF, DNF and WET areas (Table 1). The declines of rainfall and soil moisture were found to be the largest in grassland (22\%) and cropland (21\%), while the smallest rainfall decrease was observed in EBF area (5\%).

\subsubsection{Recovery duration days after droughts}

The length of recovery days (LRD) showed a general gradient of high ( $>60$ days) in midlatitude region and low ( $<60$ days) in low (tropical area) and high (boreal area) latitude regions (Figure 4-2a). In general, average LRDs were shorter in forest types than non-forest types (Figure 4-2b). Among all the land cover types, EBF had the shortest LRD ( $\sim 30$ days; Figure 4$2 b)$ and grassland showed the longest LRD ( $\sim 80$ days; Figure $4-2 b)$. With an increase of average GPP, the LRD showed a significantly decrease trend in different land cover types (Figure 4-3). 

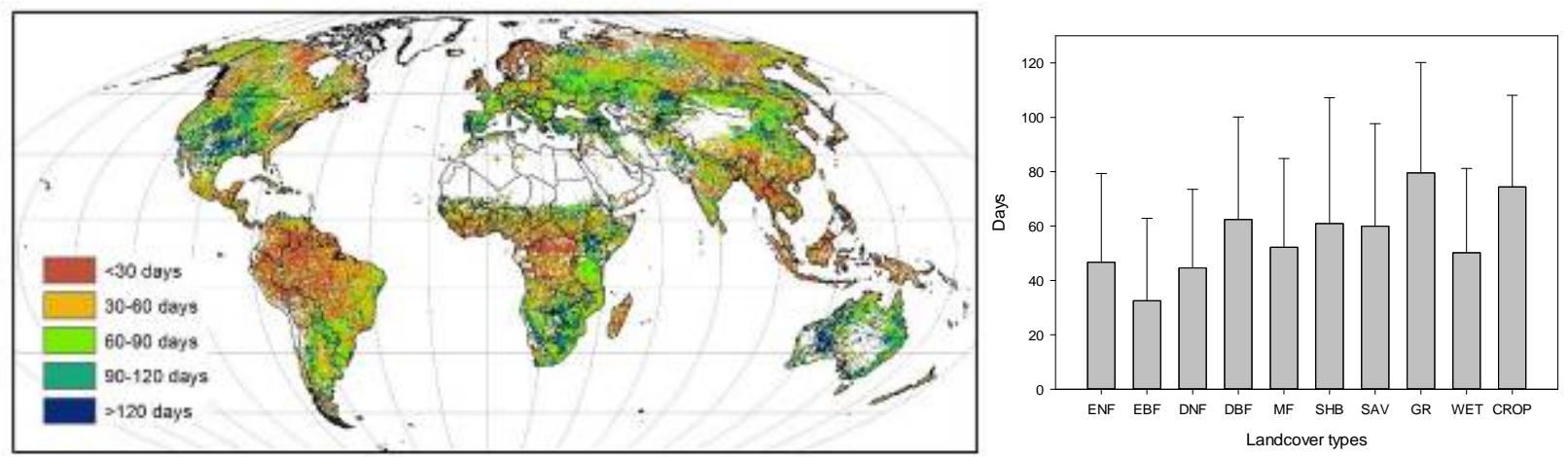

Figure 4-2 Days of GPP recovery back to normal after drought impacts

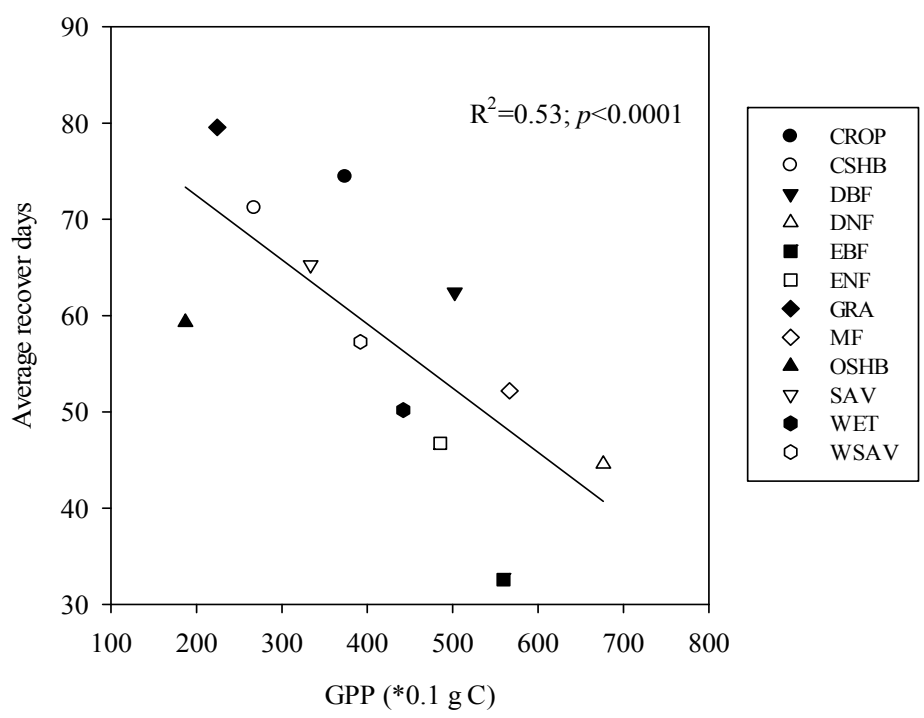

Figure 4-3 Relationship between GPP and Days recovery after droughts impacts

\subsubsection{GPP and evapotranspiration after droughts}

GPPs extensively declined in most of the terrestrial ecosystems after drought extremes, except for the tropical area (Figure 4-4a). The most intensive drought-induced GPP reduction was found in the mid-latitude region $\left(30^{\circ} \mathrm{N}-50^{\circ} \mathrm{N}\right)$ of north hemisphere (48\% reduction; Figure $4-$ 
$4 a)$, and followed by the low-latitude region $\left(15^{\circ} \mathrm{N}-30^{\circ} \mathrm{N}\right)$ of south hemisphere $(13 \%$ reduction; Figure 4-4a). In contrast, the tropical region showed a slight increase in GPP (10\%; Figure 4-4a).

Drought-induced ET decline was more extensive than GPP reduction (Figure 4-4b). The most intensive reduction of ET were detected in the Mediterranean area, followed by Africa (Figure 4-4b). The water use efficiency (WUE), however, showed a different pattern of decreasing in the north Hemisphere while increasing in the south Hemisphere (Figure 4-4c). 

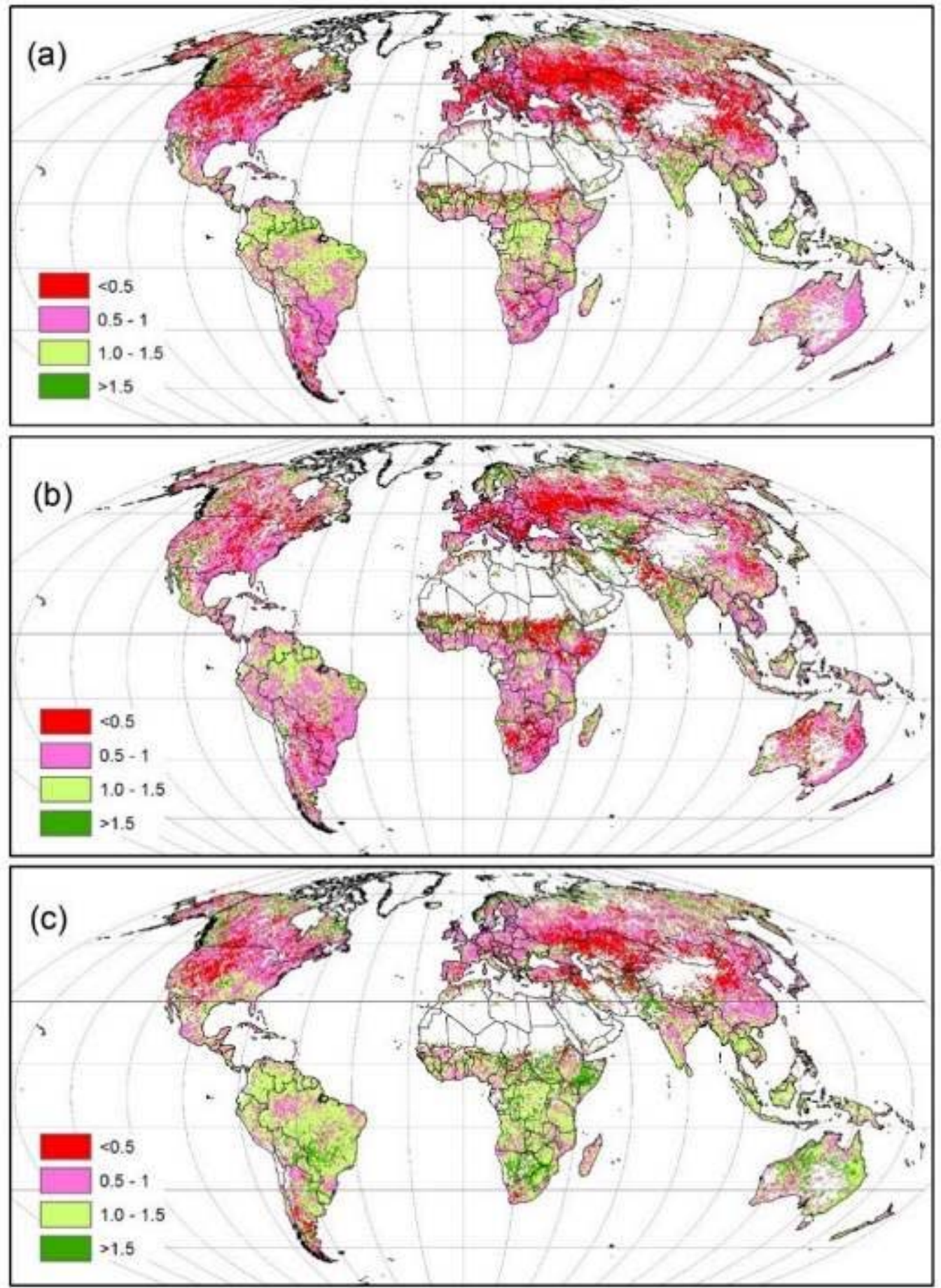

Figure 4-4 GPP (a), ET (b) and WUE (c) ratio of recovery period and the non-drought period 

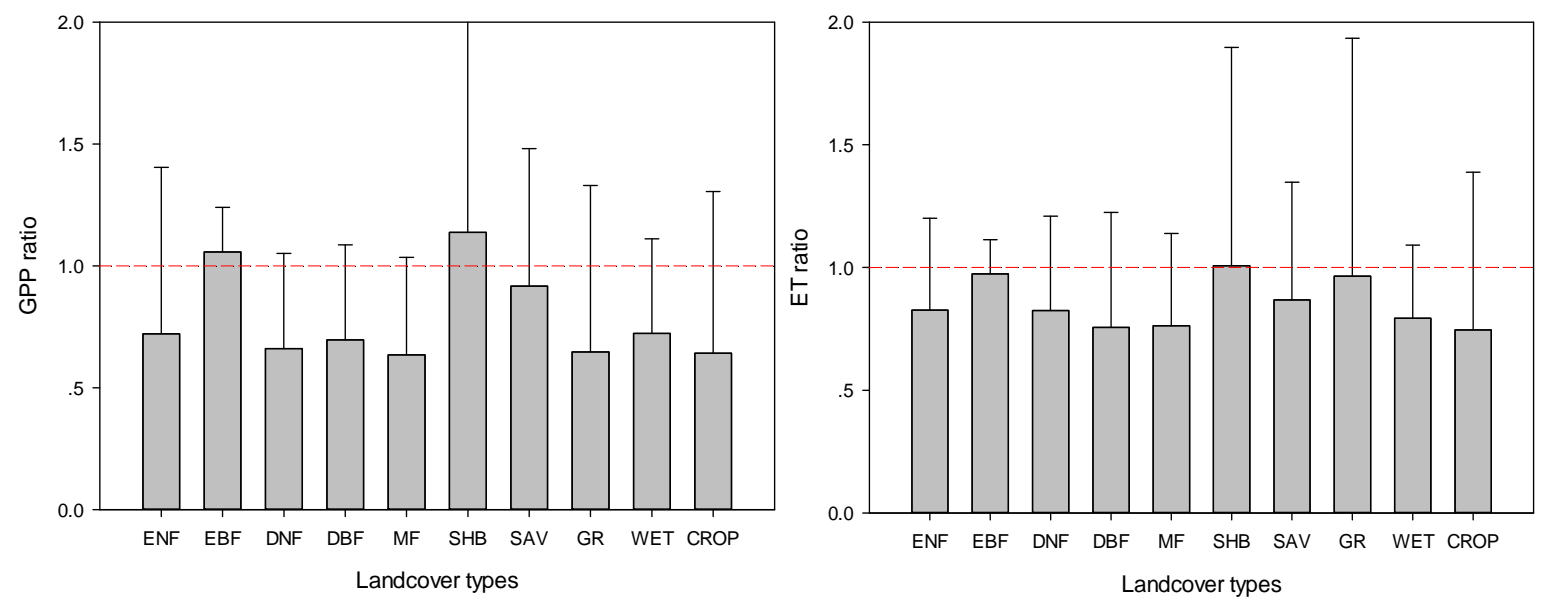

Figure 4-5 GPP and ET ratio of drought period and the non-drought period by different land covers

Latitudinal analyses showed different change patterns in GPP, ET, and WUE after drought impacts (Figure 4-6). Drought-induced reductions in GPP and ET were found in the area of south of $10^{\circ} \mathrm{S}$ and north of $20^{\circ} \mathrm{N}$ (Figure 4-6a, b). In the area north of $20^{\circ} \mathrm{N}$, however, the reduction of GPP was greater than ET, while in the area of south of $10^{\circ} \mathrm{S}$, ET decline exceeded the GPP reduction rate, which resulted in a higher WUE in the area of south of $10^{\circ} \mathrm{S}$ but a lower WUE in the area of north of $20^{\circ} \mathrm{N}$ (Figure 4-6a, b, c). The higher WUE in the region of $10^{\circ} \mathrm{S}-20$ ${ }^{\circ} \mathrm{N}$ was due to a slightly enhanced GPP and marginally reduced ET. 


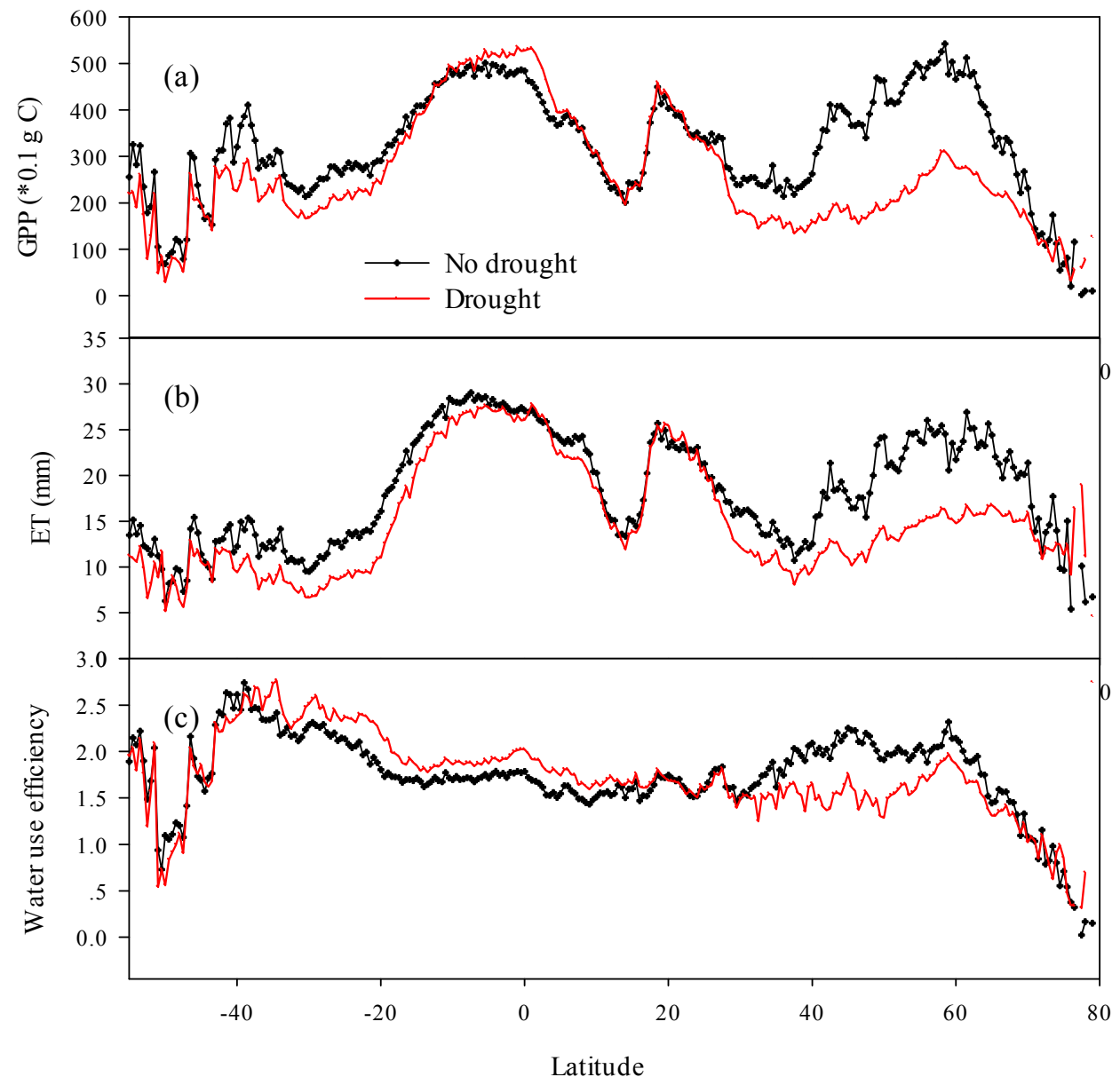

Figure 4-6 GPP, ET and WUE during recovery period and the non-drought period (average of 8-days sum) 


\subsection{Discussion}

\subsubsection{Direct concurrent impacts of droughts}

Drought can have manifold impacts on terrestrial ecosystems, including direct concurrent impacts, direct lagged impacts, and indirect lagged impacts (Frank et al., 2015). These impacts may influence the vegetation physiology, phenology, growth in the following year, pest outbreak, and fire occurrence. In this study, we evaluated the drought's direct impacts with focus on quantifying the changes of climate factors during the drought period of the last decades.

Based on the MODIS drought severity index (DSI), Orvos et al. (2015) reported 17\% of the land area exhibited significant trend of either drying or wetting, and most of such locations were joined to large, geographically correlated areas. Our study found significant reductions of rainfall and soil moisture in drought period, while higher than normal air temperatures were detected during drought period in most of the land covers. In particular, the largest decline of rainfall was found in savanna area $(-0.89 \mathrm{~mm} /$ day, $\mathrm{p}<0.0001)$, and the smallest reduction was in DNF area $(-0.20 \mathrm{~mm} /$ day, $\mathrm{p}<0.0001)$. These changes also contributed to the largest drop of soil moisture in savanna area $\left(-0.024349 \mathrm{~m}^{3} / \mathrm{m}^{3}, \mathrm{p}<0.0001\right)$ and an insignificant change of soil moisture in DNF $\left(0.001714 \mathrm{~m}^{3} / \mathrm{m}^{3}, \mathrm{p}>0.10\right)$. It is known that soil moisture is determined by water inflow (rainfall, snow melt) and discharge (runoff, evapotranspiration). If rainfall decreases, a lower soil moisture can be expected in most of the terrestrial ecosystems. In this study, particularly, we found that DNF and wetland soil moisture did not show significant differences between drought and non-drought periods, albeit a significant decline of rainfall $(\mathrm{p}<0.0001)$ existed in both of the regions (Table 1). For the DNF area, this may be explained by water 
compensation from snow melt, while wetland soil was closely related to abundant underground water supply.

Furthermore, significantly higher air temperatures were detected in all land cover types (Table 1, p $<0.001$ ) except for DNF, suggesting the DNF droughts were more closely related to moisture stress (rainfall) than heat stress (warming). During the period of 2000 to 2011, the largest drought-induced increase of air temperature was found in CROP $\left(0.72{ }^{\circ} \mathrm{C}, \mathrm{p}<0.0001\right)$ while the lowest existed in $\operatorname{EBF}\left(0.12^{\circ} \mathrm{C}, \mathrm{p}<0.0001\right)$. This inter-correlated changes of rainfall and air temperature led to conspicuously concurrent and lagged impacts on terrestrial ecosystems. Hence, we found extensive and intensive reductions of GPP in mid- and highlatitude regions of the north Hemisphere (Figure 4-4a), which is consistent with Teixeira et al. (2011)'s study revealing a high risk of crop yield damage due to drought for high latitudes continental lands, particularly in the $40-60^{\circ} \mathrm{N}$ region. Piao et al. (2010) also reported that drought affected $25 \pm 7$ Mha cropland per year (17 $\pm 5 \%$ of sown area) and contributed to harvest failure of 5 Mha per year during 2000-2007 in China. Lobell \& Gourdji (2012) alleged that -5\% decline of global crop yields occurred due to each $1^{\circ} \mathrm{C}$ of warming, as well as the average decline of crop yield was at $-3.6 \%$ due to warming impacts in the past decades. Nonetheless, the estimated reduction of GPP in our study (36\%, Figure 4-5a) is much higher than other estimations, suggesting a much severe impact of transient drought extremes than chronic warming. Similarly, Ciais et al. (2005) also reported a 20\% drop in Europe-wide NPP caused by the heat and drought in 2003. Climate model simulations also showed that drought disaster-affected area will increase from $15.4 \%$ to $44.00 \%$ by 2100 (Li et al., 2009), which signifies the essential needs of adaptation strategies to avoid aggravated drought-disaster risks. 


\subsubsection{Lagged impacts of droughts}

Barber et al. (2000)'s study revealed that drought stress has disproportionately affected the most rapidly growing white spruce, implying drought may have been an essential limiting factor restraining carbon uptake in a large portion of the North American boreal forest. The largest decline of rainfall and soil moisture were found in grassland (22\%) and cropland (21\%), and the smallest rainfall decrease existed in EBF area (5\%). Accordingly, the length of recovery days (LRD) after drought was the longest in grassland (79.56 days, Figure 4-2b) while the shortest was in EBF (32.58 days, Figure 4-2b). These results suggested that grassland and cropland were the most vulnerable to drought extremes while EBF had higher resilience to drought stress. A negative, significant relationship between GPP and LRD implies a positive relation in GPP and ecosystem resilience (Figure 4-3, $\mathrm{p}<0.0001$ ). The studies by van Mantgem et al. (2009) and Raffa et al. (2008) reported that tree mortality rate was increased in the western North America forests during the past decade. The causal factor of these tree moralities has been attributed to elevated warming and/or water stress, raising the possibility of world's forests being increasingly responsive to ongoing droughts (Allen et al., 2010). Therefore, trees with lower resilience to drought stress will be more likely to die under global warming. In this study, we also found longer LSD in North America, central Eurasia, South Africa, and Australia (Figure 43a) than in other regions of the world, indicating a more intensive influences of drought stress in these areas.

Drought can alter the structure, composition and functioning of terrestrial ecosystems; and can thereby change regional carbon cycle, with the potential to shift ecosystems from net carbon sink to carbon source (Frank et al., 2015). Here, we found drought-induced GPP was intensively reduced in DNF (34\%), MF (36\%), GR (35\%) and CROP (36\%), while slightly 
enhanced GPP was also identified in EBF (6\%) and SHB (18\%) (Figure 4-5a). A large reduction of GPP found in North America (>50\%, Figure 4-4a) is consistent with Schwalm et al (2012)'s study that reported net carbon uptake was reduced by $51 \%$ during the $2000-2004$ drought in western North America. Studies have also revealed that drought extremes often lead to decreased ET, cooling effect, and thereby intensified warming effect (Teuling et al., 2010; Mueller \& Seneviratne, 2012). Our study showed drought-induced ET reductions were widely found in most of the land cover types with amplitudes ranging from 3\%-25\% (Figure 4-5b). This resulted in a reduction of water use efficiency (WUE) ranging from $-0.96 \%$ to $-27.67 \%$ in most of the land cover types. While particularly, for EBF and savanna, an increase of WUE by $7.09 \%$ and $9.88 \%$, respectively, was found under drought stress. Noticeably, we also found a slightly enhancement of GPP in tropical regions, including Amazon, central Africa, Indonesia, and south India (Figure 4-4a, Figure 4-6a). Similarly, Saleska et al. (2007) reported intact forest canopy "greenness" was increased under drought stress. This drought-induced enhancement of ecosystem activity might be attributed to increased availability of sunlight (due to decreased cloudiness). In their situation, water was not a limiting factor and trees were able to utilize deep waters during dry extremes, even though precipitation was slightly declined (Saleska et al., 2007). Thus, root system and water table should be appropriately represented in global ecosystem modeling. 


\subsection{Conclusions}

This study evaluated the drought impacts on gross primary productivity (GPP), evapotranspiration (ET), and water use efficiency (WUE) in different land covers, as well as the resilience that each ecosystem recovered from drought stress during the period of 2000 to 2011. We found the rainfall and soil moisture during drought period were dramatically lower than these in non-drought period, while air temperatures were higher than normal during drought period with amplitudes varied by land cover types. The length of recovery days (LRD) presented an evident gradient of high in mid- latitude region and low in low (tropical area) and high (boreal area) latitude regions. As average GPP increased, the LRD showed a significantly decreasing trend among different land covers. Moreover, the drought-induced GPP reduction was found in the mid-latitude region, but a slightly enhanced GPP was found in the tropical region under drought impact. The water use efficiency, however, showed a pattern of decreasing in the north Hemisphere and increasing in the south Hemisphere. The findings underline the importance of direct concurrent impacts and direct lagged impacts of droughts. More works are required to fully quantify the direct and indirect impacts of drought extremes to terrestrial ecosystems. 


\section{References}

Allen CD, Macalady AK, Chenchouni H, Bachelet D, McDowell N, Vennetier M, Kitzberger T, Rigling A, Breshears DD, Hogg ET, Gonzalez P (2010) A global overview of drought and heat-induced tree mortality reveals emerging climate change risks for forests. Forest ecology and management, 259(4), 660-684.

Allen SK, Plattner GK, Nauels A, Xia Y, Stocker TF (2014) Climate Change 2013: The Physical Science Basis. An overview of the Working Group 1 contribution to the Fifth Assessment Report of the Intergovernmental Panel on Climate Change (IPCC). In EGU General Assembly Conference Abstracts (Vol. 16, p. 3544).

Alley WM (1984) The Palmer drought severity index: limitations and assumptions. Journal of climate and applied meteorology, 23(7), 1100-1109.

Barber VA, Juday GP, Finney BP (2000) Reduced growth of Alaskan white spruce in the twentieth century from temperature-induced drought stress. Nature, 405(6787), 668-673.

Bigler C, Bräker OU, Bugmann H, Dobbertin M, Rigling A (2006) Drought as an inciting mortality factor in Scots pine stands of the Valais, Switzerland. Ecosystems, 9(3), 330343.

Bréda N, Huc R, Granier A, Dreyer E (2006) Temperate forest trees and stands under severe drought: a review of ecophysiological responses, adaptation processes and long-term consequences. Annals of Forest Science, 63(6), 625-644.

Dorigo WA, Scipal K, Parinussa RM, Liu YY, Wagner W, De Jeu RAM, Naeimi V (2010) Error characterisation of global active and passive microwave soil moisture datasets. Hydrology and Earth System Sciences, 14(12), 2605-2616. 
Fischer EM, Knutti R (2014) Detection of spatially aggregated changes in temperature and precipitation extremes. Geophysical Research Letters, 41(2), 547-554.

Frank D, Reichstein M, Bahn M, Thonicke K, Frank D, Mahecha MD, Smith P, Velde M, Vicca S, Babst F, Beer C (2015) Effects of climate extremes on the terrestrial carbon cycle: concepts, processes and potential future impacts. Global Change Biology, 21(8), 2861-2880.

Heinsch FA, Reeves M, Votava P, Kang S, Milesi C, Zhao M, Glassy J, Jolly WM, Loehman R, Bowker CF, Kimball JS (2003) GPP and NPP (MOD17A2/A3) Products NASA MODIS Land Algorithm.MOD17 User's Guide, 1-57.

IPCC (2013) Summary for policymakers. In: Climate Change 2013: The Physical Science Basis. Contribution of Working Group I to the Fifth Assessment Report of the ntergovernmental Panel on Climate Change (eds Stocker TF, Qin D, Plattner G-K, Tignor M, Allen SK, Boschung J, Nauels A, Xia Y, Bex V, Midgley PM), 3-29. Cambridge University Press, Cambridge, UK and New York, NY, USA

JMA (2011) Global Temperature in 2010. Tokyo Climate Center News - Tokyo climate Center, Japan Meteorological Agency. http://ds.data.jma.go.jp/tcc/tcc/news/tccnews23.pdf (Last accessed on September 19, 2015).

Jung M, Reichstein M, Ciais P, Seneviratne SI, Sheffield J, Goulden ML, Bonan G, Cescatti A, Chen J, De Jeu R, Dolman AJ (2010) Recent decline in the global land evapotranspiration trend due to limited moisture supply. Nature, 467(7318), 951-954.

Korzoun, V.I. and Sokolov, A.A. (1978). World water balance and water resources of the earth. Water Development, Supply and Management (UK)(USA)(Canada)(Australia)(France)(Germany, FR). 
Koster RD, Dirmeyer PA, Guo Z, Bonan G, Chan E, Cox P, Gordon CT, Kanae S, Kowalczyk E, Lawrence D, Liu P (2004) Regions of strong coupling between soil moisture and precipitation. Science, 305(5687), 1138-1140.

Lawrence DM, Thornton PE, Oleson KW, Bonan GB (2007) The partitioning of evapotranspiration into transpiration, soil evaporation, and canopy evaporation in a GCM: Impacts on land-atmosphere interaction.Journal of Hydrometeorology, 8(4), 862-880.

Li Y, Ye W, Wang M, Yan X (2009) Climate change and drought: a risk assessment of cropyield impacts. Climate research (Open Access for articles 4 years old and older), 39(1), 31.

Lobell DB, Gourdji SM (2012) The influence of climate change on global crop productivity. Plant Physiology, 160(4), 1686-1697.

L'vovich MI, White GF, Belyaev AV, Kindler J, Koronkevic NI, Lee TR, Voropaev GV (1990) Use and transformation of terrestrial water systems. The earth as transformed by human action: Global and regional changes in the biosphere over the past, 300, 235-252.

Mu Q, Heinsch FA, Zhao M, Running SW (2007) Development of a global evapotranspiration algorithm based on MODIS and global meteorology data. Remote Sensing of Environment, 111(4), 519-536.

Mu Q, Zhao M, Running SW (2011) Improvements to a MODIS global terrestrial evapotranspiration algorithm. Remote Sensing of Environment, 115(8), 1781-1800.

Mu Q, Zhao M, Kimball JS, McDowell NG, Running SW (2013) A remotely sensed global terrestrial drought severity index. Bulletin of the American Meteorological Society, 94(1), $83-98$. 
Mueller B, Seneviratne SI (2012) Hot days induced by precipitation deficits at the global scale. Proceedings of the national academy of sciences, 109(31), 12398-12403.

NASA (2011) NASA Research Finds 2010 Tied for Warmest Year on Record. http://www.giss.nasa.gov/research/news/20110112/ (Last accessed on September 19, 2015).

Orvos PI, Homonnai V, Várai A, Bozóki Z, Jánosi IM (2015) Global trend analysis of the MODIS drought severity index. Geoscientific Instrumentation, Methods and Data Systems, 4(2), 189-196.

Peñuelas J, Canadell JG, Ogaya R (2011) Increased water-use efficiency during the 20th century did not translate into enhanced tree growth. Global Ecology and Biogeography, 20(4), $597-$ 608.

Peñuelas J, Lloret F, Montoya R (2001) Severe drought effects on Mediterranean woody flora in Spain. Forest Science, 47(2), 214-218.

Saleska SR, Didan K, Huete AR, Da Rocha HR (2007) Amazon forests green-up during 2005 drought. Science, 318(5850), 612-612.

Seneviratne SI, Lüthi D, Litschi M, Schär C (2006) Land-atmosphere coupling and climate change in Europe. Nature, 443(7108), 205-209.

Solomon S (Ed.) (2007) Climate change 2007-the physical science basis: Working group I contribution to the fourth assessment report of the IPCC(Vol. 4). Cambridge University Press.

Spinoni J, Naumann G, Carrao H, Barbosa P, Vogt J (2014) World drought frequency, duration, and severity for 1951-2010. International Journal of Climatology, 34(8), 2792-2804. 
Schwalm CR, Williams CA, Schaefer K et al. (2012) Reduction in carbon uptake during turn of the century drought in western North America. Nature Geoscience, 5(8), 551-556.

Teuling AJ, Seneviratne SI, Stockli R et al. (2010) Contrasting response of European forest and grassland energy exchange to heatwaves. Nature Geoscience, 3, 722-727.

Teixeira EI, Fischer G, van Velthuizen H, Walter C, Ewert F (2013) Global hot-spots of heat stress on agricultural crops due to climate change. Agricultural and Forest Meteorology, 170, 206-215.

Trenberth KE, Fasullo JT, Kiehl J (2009) Earth's global energy budget. Bulletin of the American Meteorological Society, 90(3), 311-323.

Tsakiris G, Vangelis H (2005) Establishing a drought index incorporating evapotranspiration. European Water, 9(10), 3-11.

UK-MetOffice (2011) 2010 - a near record year. http://www.metoffice.gov.uk/news/releases/archive/2011/2010-global-temperature (Last accessed on September 19, 2015).

Van Mantgem PJ, Stephenson NL, Byrne JC et al. (2009) Widespread increase of tree mortality rates in the western United States. Science, 323(5913), 521-524.

Vautard R, Yiou P, D'andrea F et al. (2007) Summertime European heat and drought waves induced by wintertime Mediterranean rainfall deficit. Geophysical Research Letters, 34(7).

Yu G, Song X, Wang Q, Liu Y et al. (2008) Water-use efficiency of forest ecosystems in eastern China and its relations to climatic variables. New Phytologist, 177(4), 927-937. 
Zhao M, Heinsch FA, Nemani RR, Running SW (2005) Improvements of the MODIS terrestrial gross and net primary production global data set. Remote sensing of Environment, 95(2), 164-176. 
5. Trading water for carbon: Planted forests are not efficient as natural forests in China during the past three decades $\S$

$\S$ To be submitted to Proceedings of the National Academy of Sciences 


\section{Abstract}

Planted forests have been widely established in China as an essential approach to improving the ecological environment and mitigating climate change. Large-scale forest planting programs, however, are rarely examined in the context of tradeoffs between carbon sequestration and water yield between planted and natural forests. We reconstructed evapotranspiration (ET) and gross primary production (GPP) data based on remote-sensing and ground observational data, and investigated the differences between natural and planted forests, in order to evaluate the suitability of tree-planting activity in different climate regions where the afforestation and reforestation programs have been extensively implemented during the past three decades in China. While the differences varied with latitude (and region), we found that, on average, planted forests consumed 5.79\% (29.13mm) more water but sequestered $1.05 \%\left(-12.02 \mathrm{gC} \mathrm{m}^{-2} \mathrm{yr}^{-1}\right)$ less carbon than naturally generated forests, while the amplitudes of discrepancies varied with latitude. It is suggested that the most suitable lands in China for afforestation should be located in the moist south subtropical region (SSTP), followed by the mid-subtropical region (MSTP), to attain a high carbon sequestration potential while maintain a relatively low impact on regional water balance. The high hydrological impact zone, including the north subtropical region (NSTP), warm temperate region (WTEM), and temperate region (TEM) should be cautiously evaluated for future afforestation due to water yield reductions associated with plantations. 


\subsection{Introduction}

China has the largest afforested and reforested area in the world ( $\sim 53.26$ million hectares in 2003 to 69 million hectares in 2013), which accounts for approximately $23 \%$ of the global plantation area (FAO, 2010; SFA, 2005; SFA, 2009; Peng et al., 2014). China's goal is to increase forest cover to $26 \%$ by 2050 via the largest plantation forestry program in the world (Wang et al., 2007). However, it has long been ignored that the new plantings may be vulnerable to the availability of both water and nutrition (Zhao et al., 2008; Huang et al., 2003; Liu et al., 2005), and climate change (Herron et al., 2002; Yu et al., 2015; Zomer et al., 2008).

For a long period, fast-growing but short-lived species were favored by Chinese foresters due to short-term impacts (Cao et al., 2011), which eventually lead to low resilience and high mortality ecosystems (Li, 2001; Cao, 2008; Wang et al., 2007), such as dwarf trees ecosystem (McVicar et al., 2010). A successfully established planted forest should increase carbon sequestration, while simultaneously allowing for adequate water yield for local societal uses. Consequently, either water use efficiency (WUE) or water yield index has been often used to evaluate the suitability of afforestation at a specific location (Gao et al., 2014; Farley et al., 2005). However, high WUE typically appears in drought-prone ecosystems (although often at the expense of carbon fixation), or accompanies relatively high water consumption. Afforestation policies that overly stress attainment of high WUE can deteriorate local ecosystems, especially in arid or semi-arid regions. Therefore, when selecting appropriate sites for plantations, both carbon fixation and water yield should be evaluated in terms of suitability and priority of afforestation in a specific region.

Previous studies comparing ET, Leaf Area Index (LAI), GPP data of large-scale planted forests have used data directly from MODIS products. However, researchers have noted that 
some of these analyses are inaccurate due to data errors (Zhao et al., 2005). When investigating relatively small scales such as the highly fragmented planted forests in China, the errors and noises could overwhelm the useful information if original MODIS products were used without careful preprocessing of data.

There appears a lack of research with a focus on differentiation of carbon sequestration and water consumption potential between planted and natural forests in large scale tree planting programs, which would be essential and helpful in sustainable forest management. For China, in particular, guidance derived from these analyses would be extremely important since the country has launched the largest plantation forestry program in the world and will continue to expand the project over the next three decades. In this study, we used improved data obtained from observations and remote sensing technology to 1) compare water yields and carbon sequestration between natural and planted forests in China; and 2) evaluate the suitability of afforestation activities in each of the climate regions where the afforestation and reforestation program has been extensively implemented. 


\subsection{Materials and methods}

\subsubsection{Data and study area}

This study mainly focused on the regions where tree planting programs were extensively implemented over the last few decades in China. These regions were classified into tropical region (TP), south subtropical region (SSTP), mid-subtropical region (MSTP), north subtropical region (NSTP), warm temperate region (WTEM), and temperate region (TEM) (Figure 4-1; Zheng et al., 2010).

The MODIS products, including albedo (MOD43C3), FPAR/LAI, and land cover (MOD12Q1) data, were downloaded from NASA Land Processes Distributed Active Archive Center (LP DAAC). Daily temperature (mean, maximum, and minimum), precipitation, and relative humidity were collected from 839 standard meteorological stations and summarized and interpolated into 8-day average images at $5 \times 5 \mathrm{~km}^{2}$ resolution using Anusplin (Ver. 4.1; Australian National University, Center for Resources and Environmental Studies, Canberra, Australia). In this study, a tri-variate partial thin plate spline incorporating a bi-variate thin plate spline as a function of longitude, latitude and constant linear dependences on elevation were used in simulating surfaces of 8-day climate variables (Yu et al., 2010; Yu et al., 2013a).

Data on planted forests in 2000s were provided by the State Forestry Administration of China (SFAC). Spatial coverage of planted forests in 1980s were extracted based on the planted forest and vegetation maps of 1980s and the most current Chinese planted forest map (see Supporting Information Figure S4). The vegetation map digitized by Compiling Committee of Vegetation Maps of 1:1,000,000 in China (CCVM, 2001) reflects the vegetation distribution of the 1980s. Hence, the planted forests in 1980s were extracted through overlaying of the CCVM's 
forest map and SAFC's planted forest map. Natural forests were derived from the data of Li et al. (2014)'s study and the CCVM's forest map.

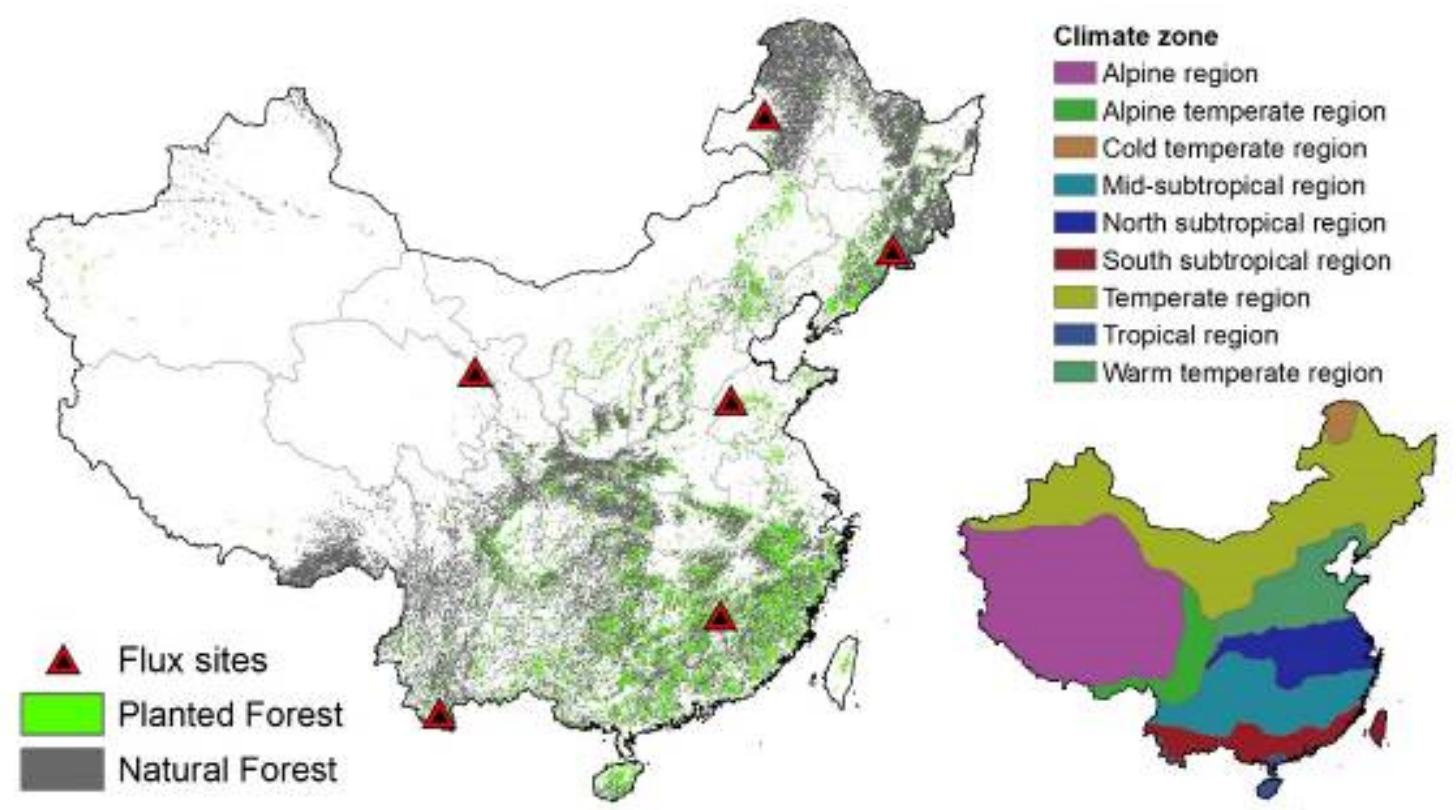

Figure 5-1 Distribution of planted forest and natural forest in different climate zones in 2000s

\subsubsection{Data improvement}

The MODIS data, including NDVI, LAI, FPAR, and albedo, were used for GPP and ET simulations in 2000s. Due to the relatively low temporal and spatial resolution of AVHRR data, the datasets were improved before using for ET simulations in 1980s. The inter-sensor calibration was conducted by using MODIS and AVHRR data for the overlapping coverages from 2000 to 2011. Pixel-by-pixel based linear regression models were built to improve the AVHRR data of 1980s. As elaborated in Zhao et al. (2005), GPP product (MOD17 version 005) was affected by three input sources: MODIS land cover product (MOD12Q1), meteorological data, and FPAR/LAI data (MOD15A2). These inputs (parameters such as FPAR/LAI data) were also used in MOD16 production, which would affect the accuracy if no preprocessing methods 
were applied. Therefore in our study, a couple of measures were taken to improve the input data for ET and GPP modeling. First, climate data obtained from meteorological stations were used to replace Data Assimilation Office (DAO) data sets, which were used in MOD17 and MOD16 production. DAO assimilated meteorological dataset was inaccurate under certain circumstances because they were not observed data and contain systematic errors (Zhao et al., 2005). The shortwave radiation data were downloaded from CISL Research Data Archive (http://rda.ucar.edu/) produced by the National Centers for Environmental Prediction (NCEP) Climate Forecast System Reanalysis (CFSR) in the University Corporation for Atmospheric Research, at resolution of $0.3125 \times 0.3122$ degree. The radiation data were then spatially interpolated into $5 \times 5 \mathrm{~km}^{2}$ and improved using fourth power cosine function, which was recommended and applied to MOD16 production by Zhao et al (2005).

Secondly, the FPAR/LAI (MOD15A2) products were improved by adopting the gap-fill algorithms introduced by Zhao et al (2005) to reduce the relict contamination effects from cloud cover (Myneni et al., 2002). The quality assessment fields of the MOD15A2 product has two quality control fields denoting cloud state, snow/ice presence, and the algorithm employed. This enabled us to retain the reliable FPAR/LAI values (retrieved by the main algorithm such as Radiation Transfer process) and re-gapfill the unreliable pixels derived from back-up algorithm (i.e., the empirical relationship between FPAR/LAI and NDVI) (Zhao et al., 2005). A simple linear interpolation was used to fill unreliable or missing data and reconstructed reliable FPAR/LAI time series data. Then, the FPAR, LAI, and NDVI data were smoothed using Double Logistic algorithm in Timesat software (v3.1, Eklundh \& Jonsson, Lund, Sweden), which has been widely used for vegetation index smoothing (Yu et al., 2013b). 
Finally, up-to-date forest maps were used to improve the simulation accuracy.

Misclassified land cover will lead to misuse of parameters from MOD17 Biome Parameter LookUp Table (BPLUT), resulting in unreliable conclusions (Zhao et al., 2005). A previous study reported an accuracy of 70-80\% in MOD12Q1 land cover product (Strahler et al., 2002), which could mask signals from spatially fragmented planted forests. Four datasets were used to improve delineation of man-made forests: 1) planted forest map from the State Forestry Administration of China (SFAForest); 2) forest map from Li et al. (2014) (LiForest); 3) MODIS land cover map in 2002; and 4) CCVM's 1:1,000,000 vegetation map of 1980s in China. In this study, SFAForest map was the base map with the highest priority, since it is the most authoritative distribution of planted forests in China. The natural forests of 2000s were extracted from the digitized LiForest with the PF areas removed. The LiForest were derived from Landsat (30m) and MODIS (250m) data and were validated according to TM images and Google Earth (Li et al., 2014). Other land cover types in 2000s were classified based on 2002 MOD12C1 data, except for the PF and NF areas defined in the prior steps (see Supporting Information Figure S3). The planted forests of 1980s were extracted through overlay processing of the CCVM's forest map and SFAForest map (see Supporting Information Figure S4). These procedures help reduce noises from different forest types and ensure parameters used in modeling and analyses for each pixel consistent for the same land cover type.

Additionally, the ultimate results of modelled ET and GPP were validated with observational data collected from six flux sites in China (see Supporting Information Table S1). 


\subsection{Results}

\subsubsection{Gross Primary Production and evapotranspiration modeling}

The reconstructed gross primary production (GPP) and evapotranspiration (ET) data are much improved when comparing with the unadjusted MODIS products as validated by the GPP and ET data obtained from six flux sites(Figure 5-2a, b). The $\mathrm{R}^{2}$ increased from $0.32(p<0.01)$ to $0.45(\mathrm{P}<0.001)$ for ET and from $0.0 .50(p<0.05)$ to $0.84(p<0.01)$ for GPP following improvements.
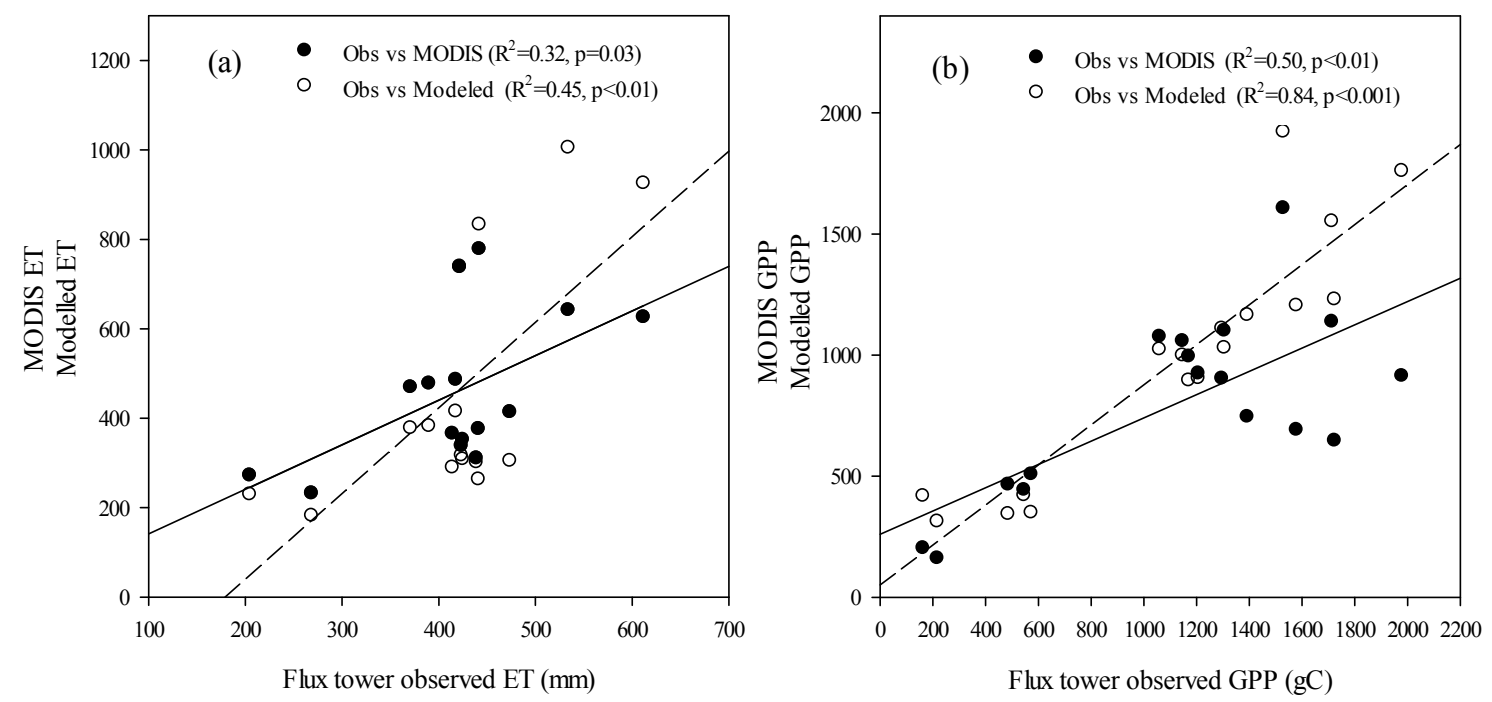

Figure 5-2 GPP and ET validation using flux data collect from ChinaFlux (solid black circle:

MODIS data; open circle: model simulations). Each dot represents average of a specific growing season in a site.

\subsubsection{Water consumptions derived from different land cover maps}

We examined the planted forest misclassification in MODIS land cover map. In total, only $45.4 \%$ of the verified PF pixels were correctly classified as forest. This forest type was most often misclassified, in order of frequency, as cropland, savanna, or grassland and shrubland 
(Figure 5-3). The rest of 5.91\% PF pixels were classified as other types, such as wetland, urban, and barren land.

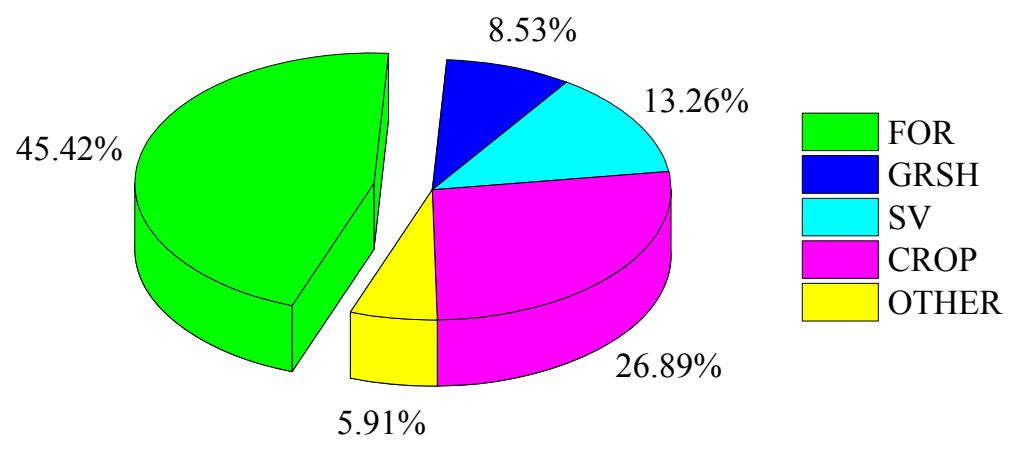

Figure 5-3 Misclassification of planted forests to other land cover types based on 2001 MODIS land cover map (FOR: forests; GRSH: grasslands and shrublands; SV: savanna; CROP: croplands; OTHER: non-vegetation and mosaic of cropland and natural vegetation.)
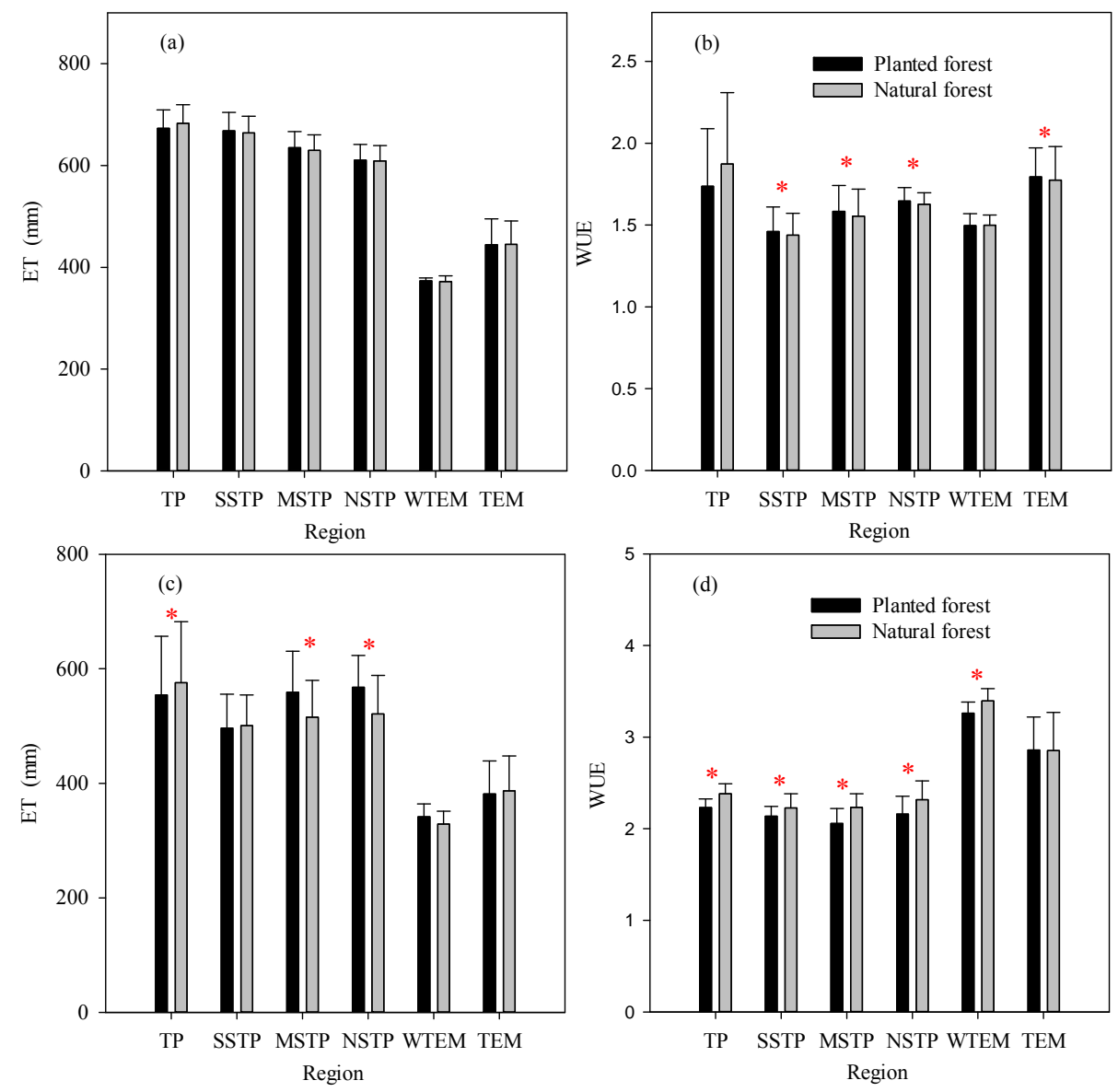
Figure 5-4 ET and WUE differences between PF and NF in different regions derived from MODIS (a\&b) and modeled (c\&d) results (*denotes a significant difference at $\mathbf{p}<0.05$; TP: tropical region; SSTP: south subtropical region; MSTP: mid-subtropical region; NSTP: north tropical region; WTEM: warm temperate region; TEM: temperate region.)

We randomly sampled 1000 grid cell circles with radius of $25 \mathrm{~km}$, which have at least $20 \%$ of both planted and natural forest cover. In general, there was no significant difference for the MODIS ET between PF and NF in all climatatic regions (Figure 5-4a). In comparison, the model simulated ET using the updated land cover map resulted in significantly lower ET for the PFs in the TP region $(p<0.05$; Figure 5-4c), and a higher ET for PF in the MSTP and NSTP regions $(p<0.05$, Figure 5-4c). For water use efficiency (WUE, defined as GPP/ET) derived from MODIS products, PF showed slightly higher values than NF in all regions except for TP and WTEM regions $(p<0.05$, Figure 5-4b). By contrast, simulation-based WUEs were lower in PF than in NF for the TP, SSTP, MSTP, NSTP, and WTEM regions ( $p<0.05$, Figure 5-4d), but not for the TEM region $(p=0.80$, Figure $5-4 d)$.

\subsubsection{Water yield under dryness stress}

We partitioned the entire study area into small watersheds, and summarized the climatic index in each of the watersheds with PF and NF coverage above $20 \%$, which resulted in a total of 45 watersheds in the entire study area (Figure 5-5). In each of the watershed, the Evaporative Index (ratio of ET and precipitation) and Dryness Index (ratio of PET and precipitation) were calculated in both PF and NF areas. Generally, EIs were higher in PF than in NF, indicating a lower water yield in PF. 


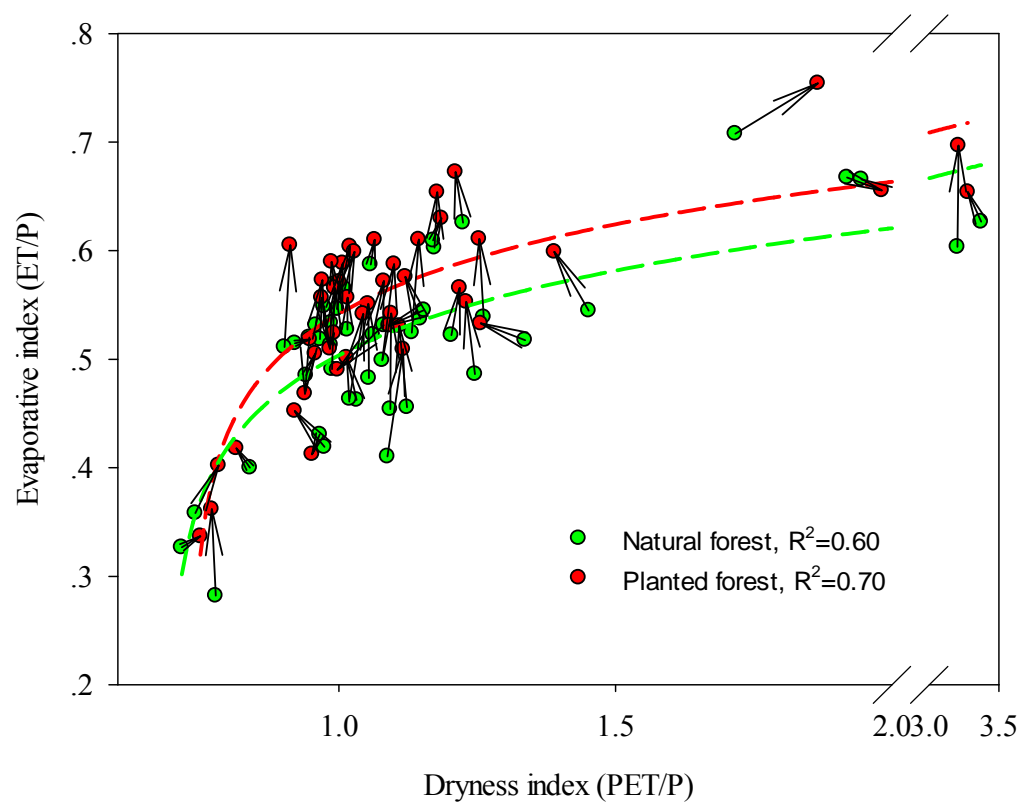

Figure 5-5 Watershed scale shift of the relationship between Evaporative index and Dryness index in NF and PF area (the arrow line was pointed from NF to the corresponding PF in each watershed; each point represents the average of the 2000-2011 period).

A higher EI was also detected in PF using annually averaged values of the entire study area (Figure 5-6a). The gaps of EI between PF and NF also increase with dryness (Figure 5-6a). GPP showed logarithmic relationship with EI in both $\mathrm{NF}\left(\mathrm{R}^{2}=0.64\right.$, Figure 5-6b) and PF regions $\left(\mathrm{R}^{2}=0.64\right.$, Figure 5-6b). Each year, $\mathrm{PF}$ had lower growing season GPPs accompanied with higher EI (Figure 5-6b). 

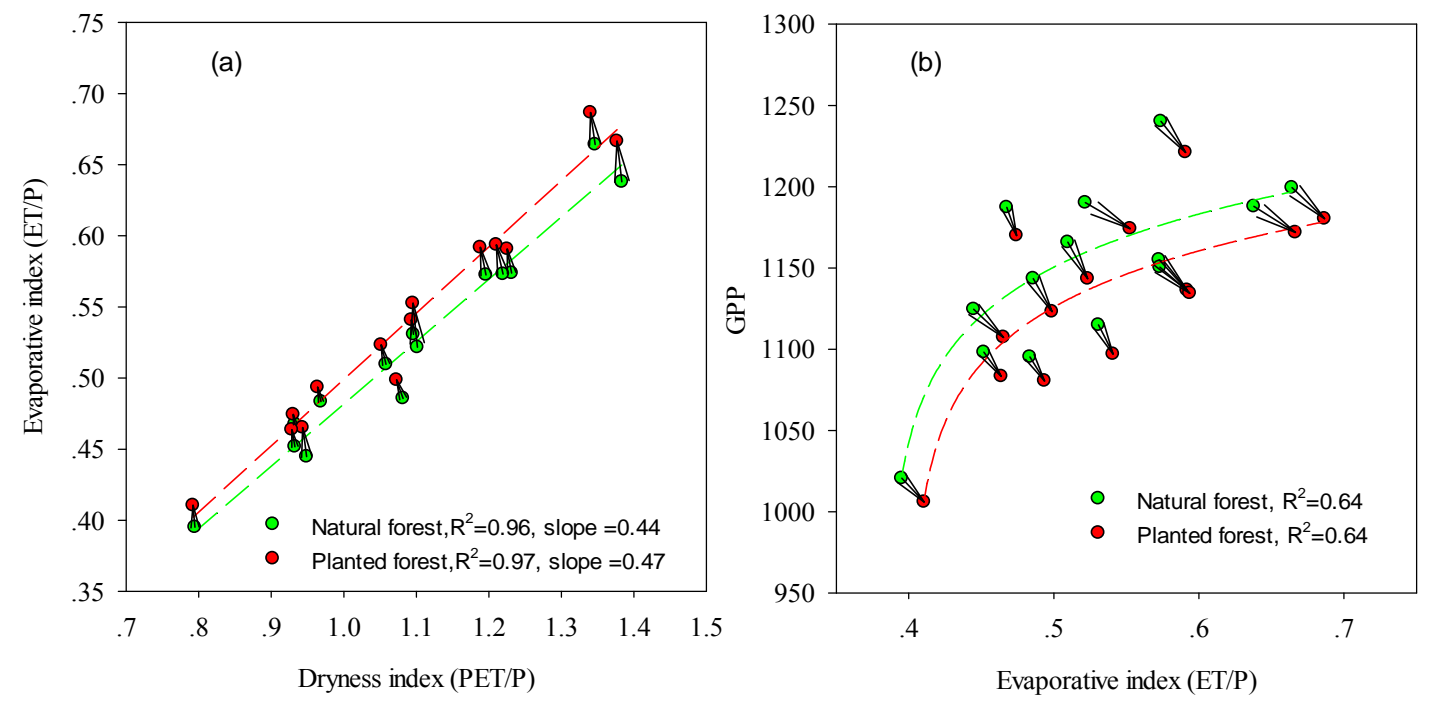

Figure 5-6 Inter-annual relationships between (a) Dryness Index and Evaporative Index, and (b) GPP and Evaporative Index from 2000 to 2013 (each point denotes the annual average

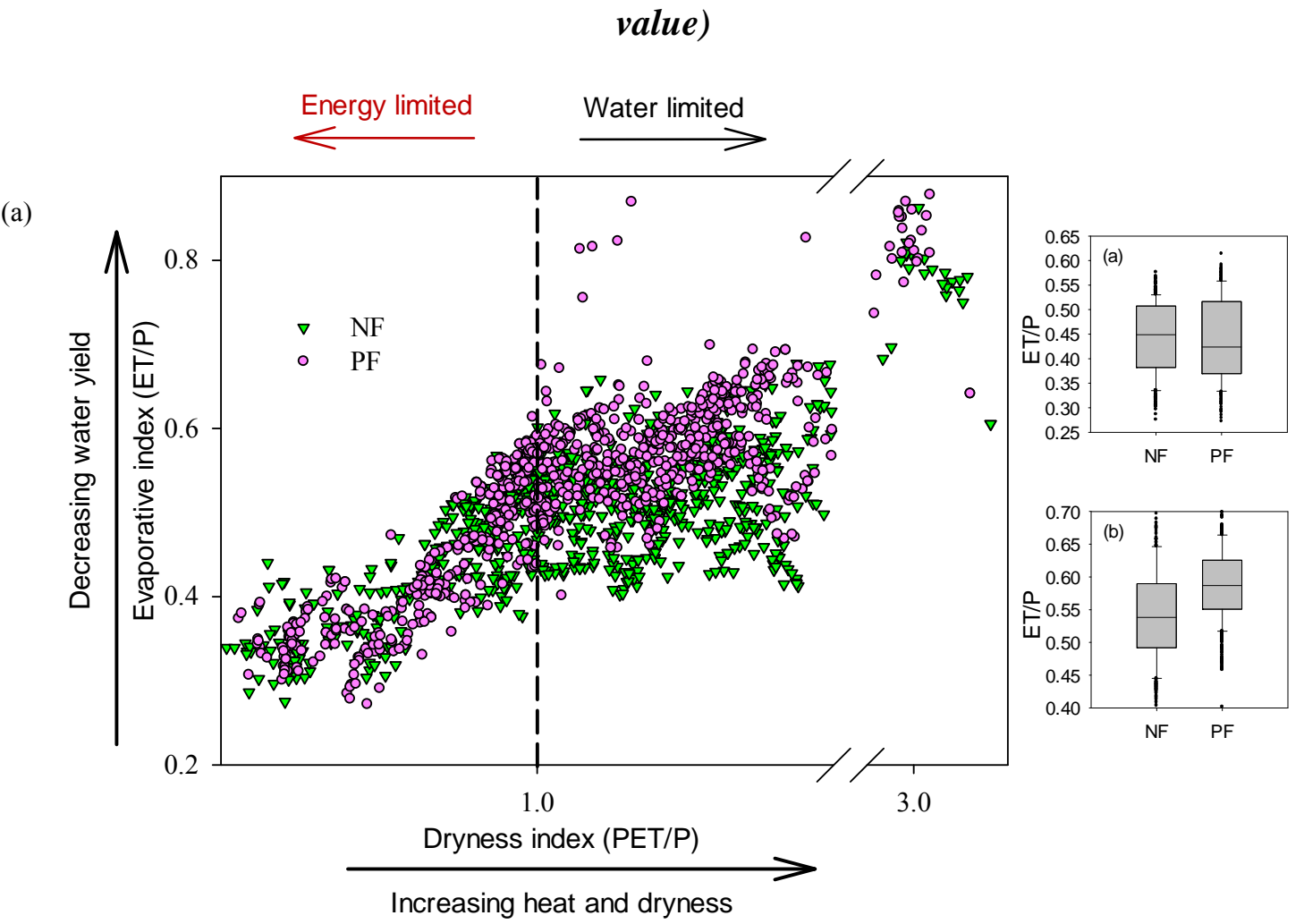

Figure 5-7 A Budyko diagram applied to sampled circles in forest areas of China. Differences of water yield trends under heat and dryness gradients between NF and PF (Dryness index $<1$ 
indicate energy limited points; dryness index $>1$ indicates water limited points; the inserted box graphs indicate the tests between NF and PF in energy (a) and water (b) limited regions, respectively.) (after Budyko (1974) and Creed et al. (2014))

In energy limited areas (Dryness index, DI $<1$ ), no significant difference existed in water yield $(p=0.10$, difference $=-0.01$ ) between PF and NF (Figure $5-7 \mathrm{a}$ ). When water becomes the limiting factor (DI >1), the water yield in PF area keeps decreasing with DI, while the decreasing rate of water yield was lower in NF area than in PF area. The water yield was significantly lower in PF area than in NF area when DI exceeded 1 (Figure 5-7b, $\mathrm{p}<0.0001$, difference $=0.047$ ).
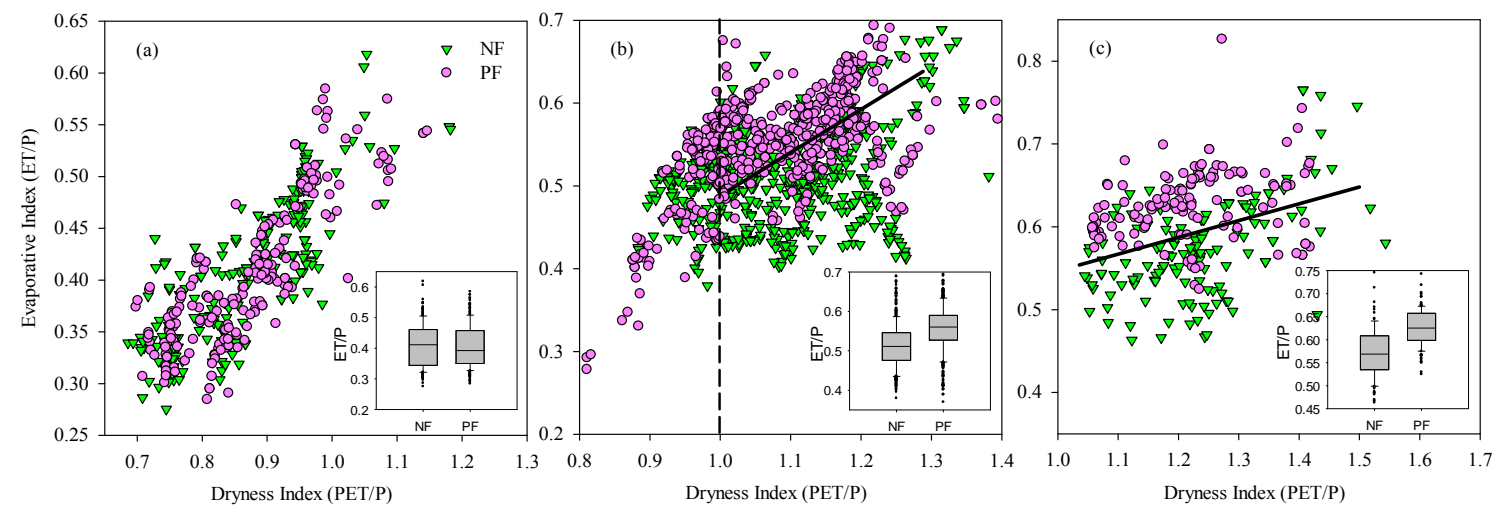

Figure 5-8 Relationships between Evaporative Index and Dryness Index in different regions of China (a: SSTP region; b: MSTP region; c: NSTP region).

The sampled points were further partitioned according to climate regions to compare the sensitivity of water yield in different regions to plantations. Evaporative index was relatively close for NF and PF in the SSTP region $(\mathrm{p}>0.10$, difference $=-0.0097)$; differences were larger and significant in both MSTP and NSTP regions $(p<0.0001$, difference $=0.041$ and 0.062 , respectively), indicating that the water yields in MSTP and NSTP regions were more sensitive to afforestation than in SSTP region (Figure 5-8).

To examine the change of water yield in PF and NF under climate change, we reconstructed ET and PET using the meteorological data and improved AVHRR datasets (NDVI, 
albedo, FPAR, and LAI). We randomly sampled 200 grid cell circles with radius of $100 \mathrm{~km}$, which have PF and NF coverage of above $10 \%$. A distinct shift of the averages and ranges of water yield (EI) and DI in both NF and PF was observed from 1980 s to $2000 \mathrm{~s}$ ( $p<0.001$; Figure 5-9). In 1980s, there was no significant difference found between DI and EI in PF and NF. In contrast, in 2000s, a significantly lower water yield (higher EI) existed in PF than in NF ( $p<$ 0.001; Figure 5-9).

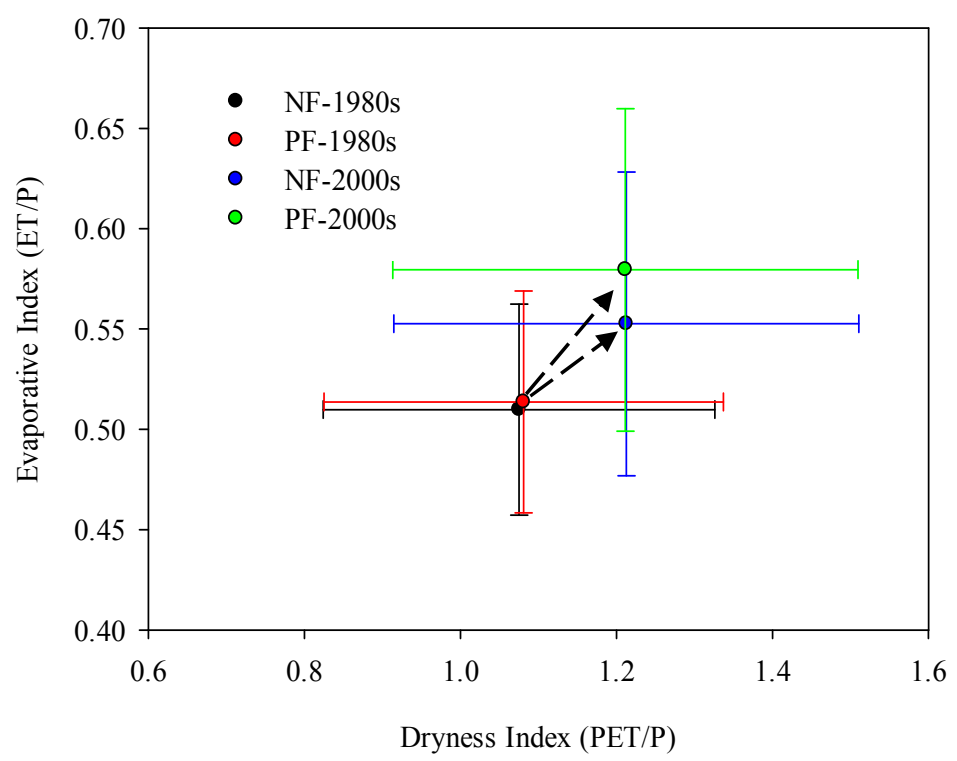

Figure 5-9 Changes of water yield-dryness patterns from 1980s to 2000s in PF and NF areas (the horizontal and vertical bar indicates standard deviation).

\subsubsection{Carbon and water change after afforestation}

Comparing predicted EI changes (post vs pre-afforestation) varied by region with TP $(90.02 \%)>\operatorname{TEM}(72.11 \%)>\operatorname{MSTP}(60.01 \%)>\operatorname{NSTP}(58.99 \%)>\operatorname{SSTP}(52.46 \%)>\mathrm{WTEM}$ (25.41\%). The average EI in WTEM (0.8, Figure 5-10a) was the highest and in TP $(0.45$, Figure 5-10a) was the second lowest among all regions, respectively. In SSTP region, however, the lowest EI (0.15, Figure 5-10a) was found with a relatively low increase of EI (30\%, Figure 5- 
10a) after afforestation. The absolute change of EI also showed a gradient pattern with TEM $(0.233)>\operatorname{NSTP}(0.222)>\operatorname{TP}(0.214)>\operatorname{MSTP}(0.191)>\operatorname{WTEM}(0.160)>\operatorname{SSTP}(0.130)$.

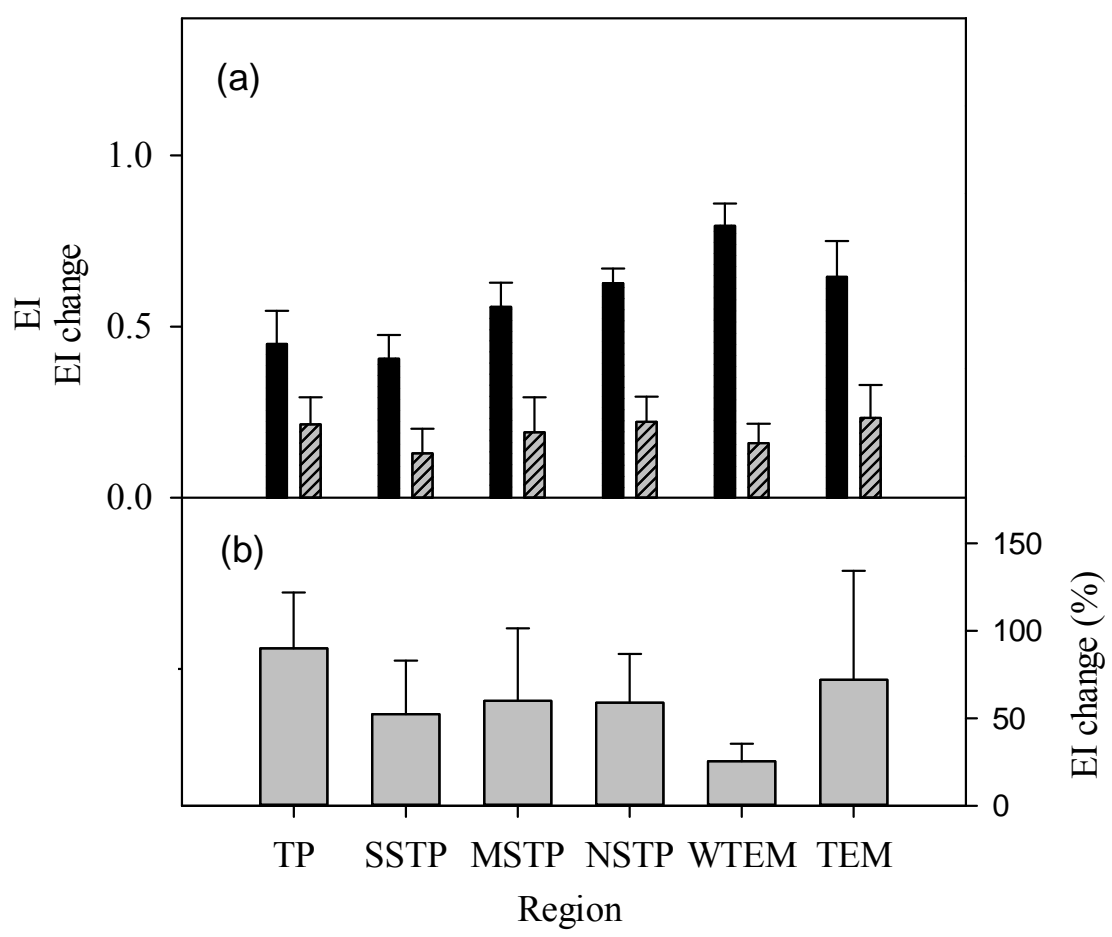

Figure 5-10 Evaporative index change after afforestation in different regions. (The EI differences were calculated by post-afforestation value - prior-afforestation value; the change percent were calculated by the ratio of the difference to prior-afforestation value)

Afforestation from grasslands, shrublands, woodland savanna, and croplands have enhanced GPP while reduced water yields varied by region (Figure 5-11). On average, postafforestation GPP increased by $521.53 \mathrm{~g} \mathrm{C} \mathrm{m}^{-2}$ per growing season in the study area, about $85.86 \%$ of the pre-afforestation GPP in the regions (Figure 5-11a, b). Additionally, afforestation increased ET by $56.30 \%(191.99 \mathrm{~mm})$ and reduced water yield $29.58 \%$ throughout the study area (Figure 5-11b, 12b). Though decreases of water yield in WTEM and TEM regions were relatively low $(65.02 \mathrm{~mm})$, the reductions accounted for $42.72 \%$ of water yield before afforestation (Figure 5-11b). 

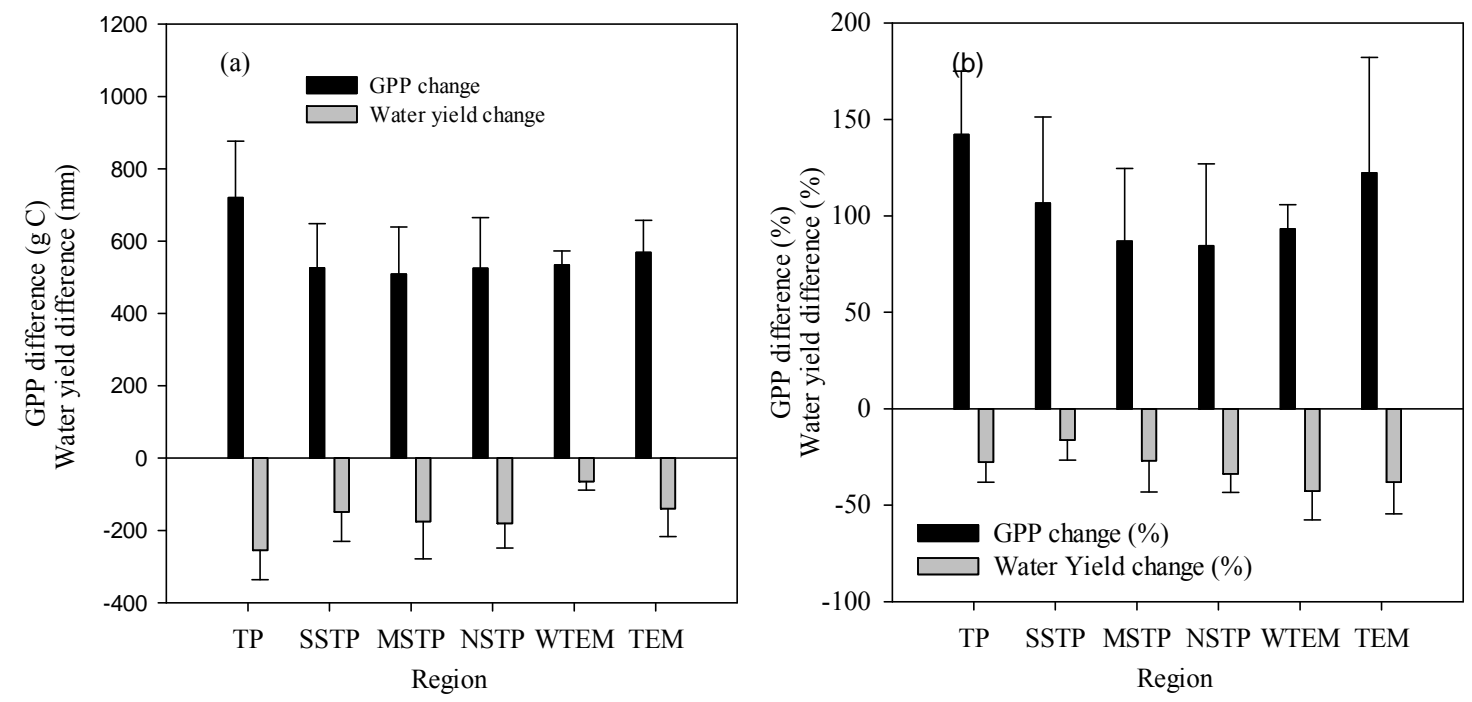

Figure 5-11 GPP and water yield change after afforestation from grasslands and shrublands in different climate regions.
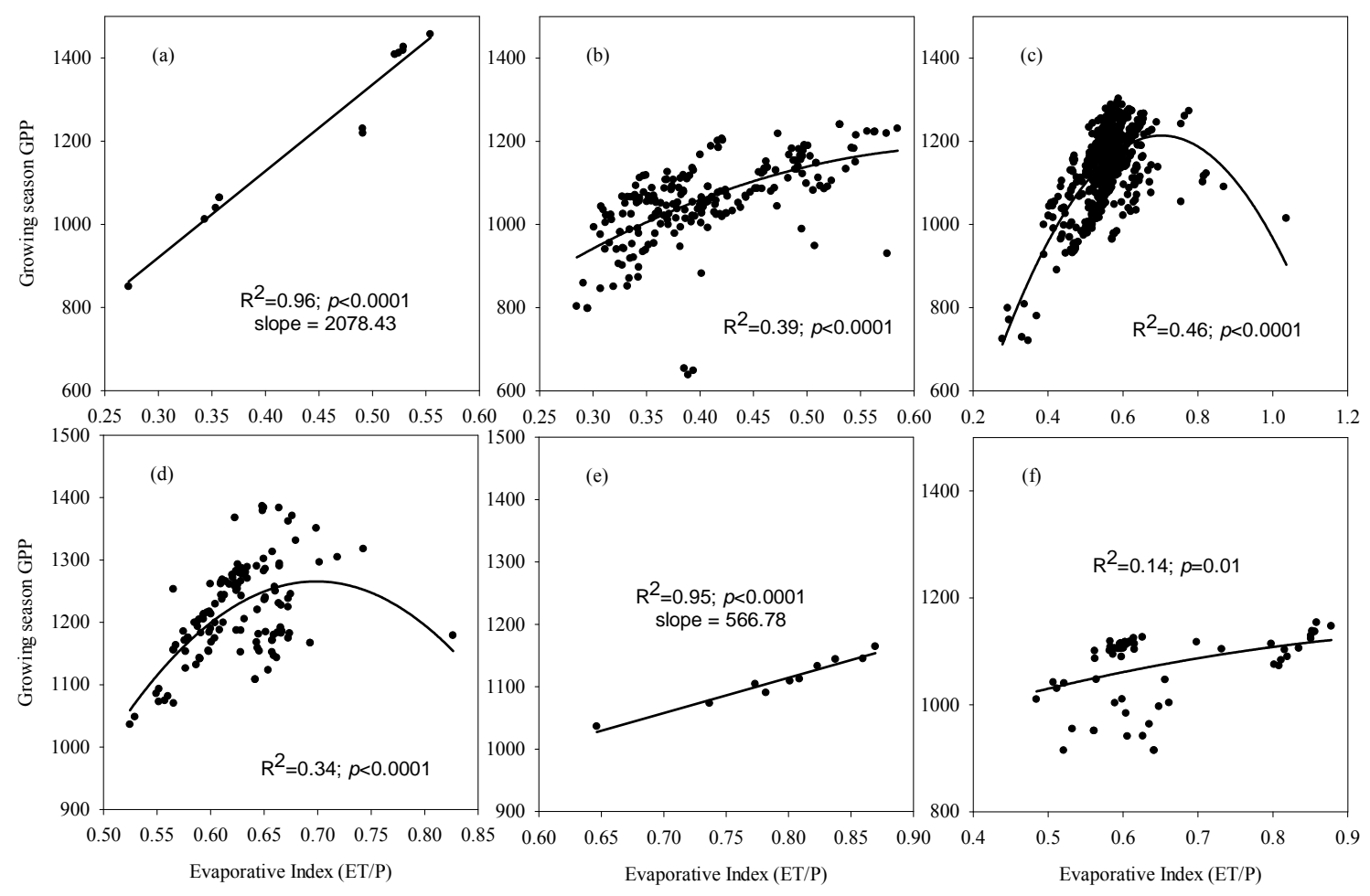

Figure 5-12 Water yield and carbon production - relationships between Evaporative Index and growing season GPP in different regions (each point denotes 14-year average of a sampled 
point in a specific region; higher EI indicates lower water yield; a for TP; b for SSTP; c for MSTP; $d$ for NSTP; e for WTEM; and f for TEM).

Generally, average water use efficiency increased with Evaporative Index, namely, higher WUE accompanied with a lower water yield (see Supporting Information Table S2). GPP peaked at EI of about 0.6-0.7 in the MSTP and NSTP regions (Figure 5-12). In TP and SSTP regions, GPPs peaked at higher EI $(>0.60)$, and indicated high potential of trading water for carbon (Figure 5-12a, b). In comparison, GPP presented a curvilinear trend from increasing to decreasing at an EI threshold value of about 0.65 in MSTP and NSTP regions (Figure 5-12c, d). In contrast, GPP increased slowly in high EI context in WTEM and TEM regions (Figure 5-12d, e). 


\subsection{Discussion}

\subsubsection{Gross Primary Production and evapotranspiration modeling}

The MODIS products, including MOD17 Gross Primary Production (GPP) and MOD16 evapotranspiration (ET), are reported to be contaminated by various sources of errors and thus rigorous preprocessing procedures are required before their use (Zhao et al., 2005). Target signals could be masked by noises and errors if raw MODIS datasets were directly used for analyses, especially for highly fragmented planted forests like in China. Although we used the same models applied in for MOD16 and MOD17 products we incorporated the improved inputs such as updated forest maps, inter-sensor calibrated remote sensing data, and high resolution climate data to reconstruct GPP and ET. When compared to data obtained from the six flux sites, model simulated GPP and ET were greatly improved over the corresponding raw MODIS products.

MODIS ET and GPP products (MOD16 and 17) were produced based on the biome type information derived from MODIS land cover product (MOD12Q1), which is accurate at about $70-80 \%$ as reported by Zhao et al. (2005). Our analyses, however, showed a much lower accuracy of MOD12Q1, in which 54.6\% of the PF pixels were misclassified as non-forest land cover types in China. The pixels were misclassified to woodland savanna, grasslands, and croplands, accounting for $48.67 \%$ of the total PF pixels. This resulted in a misuse of Biome Parameter Look-Up Table (BPLUT) for ET and GPP calculations in MODIS products, which not only led to a much lower GPP, but also diluted the essential difference between PF and NF if MOD12Q1 land cover map was used. For example, the flux sites of Qianyanzhou (QYZ, needleleaf forest) and Xishuangbanna (XSBN, evergreen broadleaf forest) were misclassified as 
woodland savanna in MOD12Q1. This misclassification resulted in lower growing season GPP in both QYZ (-156 $\left.\mathrm{g} \mathrm{C} \mathrm{m}^{-2} \mathrm{yr}^{-1}\right)$ and XSBN (-583 $\left.\mathrm{g} \mathrm{C} \mathrm{m}^{-2} \mathrm{yr}^{-1}\right)$ compared to GPP obtained from flux site observations. By comparison, our reconstructed model-based GPP estimates were greatly improved (-9 and $-259 \mathrm{~g} \mathrm{C} \mathrm{m}^{-2} \mathrm{yr}^{-1}$ lower for QYZ and XSBN sites, respectively).

The comparison of ET and WUE derived from raw MODIS data and model simulated results also revealed that a significant amount of data and differences between NF and PF were masked by errors in MODIS products. For example, model-based results indicated that the ET of PF was significantly higher than that of NF in mid-subtropical region (MSTP) and north subtropical region (NSTP); while there was no significant difference in MODIS-based ET between NF and PF in all climate regions (Figure 5-4a). Furthermore, the MODIS-based eWUE in PF was significantly higher than in NF area (except for tropical TP and warm temperate WTEM regions). In contrast, our model-based results showed that eWUE was significantly lower in PF than in NF area in most of the regions ( $p<0.05$, Figure 5-4d). Consequently, land cover misclassification would be an essential issue in dealing with ecological studies of planted forests in China when using MODIS or other satellite data. Our results revealed that noises and errors of the original MODIS GPP and ET products could overwhelm the important signals of differences between NF and PF. The use of MODIS products should be cautious and dependent on research goals and scales.

\subsubsection{Differences between natural and planted forest}

In the lowest latitude region of the study area (TP region), the ET was significantly higher in NF than in PF area, while in the mid-latitude of MSTP and NSTP regions, a significantly higher ET of $44.19 \mathrm{~mm} / \mathrm{yr}$ was found in PF than in NF area, which was $10.35 \%$ of 
the water yield in the PF (Figure 5-4a). Our results are different from a previous study by Peng et al. (2014), in which they reported an nonsignificant difference of ET between NF and PF. This disagreement could be due to that (1) higher ET in mid-latitude area of PF was partially offset by lower PF ET in lower latitude region at the scale of entire study area; and (2) the ET of PF based on MODIS data was affected by misclassification of land-cover.

Generally, PF showed lower carbon sequestration rates compared to natural forests during the period of 2000s. On average, PF had 6.5\% lower water use efficiency compared to NF during the same period (Figure 5-4b), indicating that planted forests consume more water without fixing more carbon than natural forests during the past three decades. These differences were small in the south subtropical region (SSTP; $-0.09,4.21 \%$ ) relative to the other regions except for temperate region (TEM). This implies that water-carbon trading performance of planted forests was similar to natural forests at least in the southern forests of China.

Based on the theoretical framework of Budyko curve (Budyko, 1971), Creed et al. (2014) innovatively introduced elasticity (ratio of Dryness to Evaporative index) to examine water yield resilience to climate warming. A higher Dryness Index (DI) implies a greater proportion of rainfall that is partitioned to evapotranspiration but only a small portion for water yield (Creed et al., 2014). In this study, the Budyko diagram based on randomly sampled circles showed PF with a larger impact on water yield when DI exceeded 1.0 (Figure 5-7), indicating afforestation in water limited regions would have a higher impact on water yield than in energy limited regions. These results also imply that arid and semi-arid regions are more sensitive and vulnerable to forest planting programs, which is also supported by the observation that empirically low water yield reduction, yet high percentage change in the arid northern regions (Figure 5-11). 
The Budyko curve also showed the discrepancy in water yield between PF and NF at a national scale in China. A shift of inter-annual EI-DI diagram from NF to PF indicates more intensive water consumption but a lower carbon sequestration ability (GPP) occurred in PF area (Figure 5-5, 6). Although the data needed to fully identify the discrepancy are limited, these results still support that natural forests are more efficient than man-made forests in trading water for carbon during the study period, thus signifying the importance of near-nature forest management strategies. Appropriate forest management measures are probably more effective than simply enlarging forest coverage in terms of carbon sequestration enhancement, since planted forests could attain or even exceed the efficiency of natural forests in trading water for carbon due primarily planted forests were on average much younger.

\subsubsection{Afforestation on non-forest lands}

Extensive forest plantation projects have been widely implemented since $1980 \mathrm{~s}$ throughout China as an essential approach to improving ecological environments and ecosystem services, including increasing the terrestrial carbon sink to mitigate global climate change. However, few studies have focused on comparing of carbon sequestration and water consumption between planted and natural forests, as well as identifying the differences of responses of water and carbon to large scale forest development programs in different climate regions. Our results showed that, from the changes of absolute value perspective, afforestation affected both GPP and water yield to a greater extent in the southern regions (Figure 5-11a). However, based on percent change, afforestation had greater impacts on reducing water yields with increasing latitude (Figure 5-11b). 
The siting of planted forests in all of the climate regions showed a gradient of suitability as a function of impact on water yield: $\mathrm{SSTP}>\mathrm{TP}>\mathrm{MSTP}>\mathrm{NSTP}>\mathrm{TEM}>\mathrm{WTEM}$ (Figure 5-11). Taking into account of the carbon sequestration potential index, this suitability gradient showed a sequence of $\mathrm{TP}>\mathrm{SSTP}>\mathrm{MSTP}=\mathrm{NSTP}>\mathrm{WTEM}=\mathrm{TEM}$ (Figure 5-12). Therefore, both $\mathrm{TP}$ and SSTP regions have the highest priority for forest establishment due to their large potentials of water trading for carbon. Planting trees in MSTP and NSTP regions should be considered in areas that maintain an EI lower than 0.65, since GPP would decrease above this EI threshold (Figure 5-12c, d). WTEM and TEM regions show very limited potential for enhancing carbon sequestration without substantially reducing water yield (Figure 5-12e, f).

Afforestation from grasslands, savanna, cropland, and shrublands has increased GPP and yet decreased water yield in China with the magnitude varying by region (Figure 5-11). However, in areas suffering from severe soil erosion, afforestation and reforestation could ultimately enhance the retention and infiltration of precipitation and reduce runoff. Although, in areas with chronic water shortages, the retained moisture is often drained more rapidly than it can be replenished (Cao, 2008). Limited water resources and inappropriate practices may convert the afforested areas into deteriorated ecosystems or result in reversion back to the native land cover (Jackson et al., 2002; Cao et al., 2008). For example, the lowest reduction of water yield was found in WTEM region $(65.02 \mathrm{~mm} / \mathrm{yr})$, but this accounted for $42.72 \%$ of water yield losses in the region, which was the largest percentage change among all regions (Figure 5-11b). Similarly, previous studies reported reduced water yields following afforestation of $50 \mathrm{~mm} / \mathrm{yr}(50 \%)$ in the semi-arid areas to about $300 \mathrm{~mm} / \mathrm{yr}$ (30\%) in the tropical regions (Wang et al., 2003; Cao et al., 2010; Sun et al., 2006). 
Nevertheless, failures of forestation activities because managers failed to recognize water stress issues were not uncommon during the past few decades. The overall survival rate of afforestation projects in China from 1952 to 2005 was only $24 \%$ (Wang et al., 2007). The ThreeNorth Shelter Forest Project, which was mainly implemented in TEM region, was reported to have a tree survival rate of only $15 \%(\mathrm{Li}, 2001$; Cao, 2008). Consequently, the Chinese governmental initiative to plant more trees in arid and semi-arid regions could be problematic unless new management techniques are adopted. Therefore, the six key forest protection projects, which were represented on 97\% of China's counties (Liu et al., 2008) and cost 725 billion yuan (about $\$ 110$ billion) from 2000-2009 (Cao et al., 2011; Wang et al., 2007), have huge hidden loss both economically and ecologically.

\subsubsection{Implications for future afforestation activities}

To mitigate climate change, China has targeted additional afforestation activities on about 40 million hectares of non-forested land by 2020 (SFA, 2009). However, to maximize the ecological and environmental benefits of forest plantations, the challenge will be how to scientifically and practically identify the most suitable species and locations for these plantations (Jackson et al., 2008; Peng et al., 2014). Therefore, the impacts of artificially established forests on water and carbon changes should be carefully examined to assess land suitability for afforestation in terms of future benefits.

Here, we found a distinct shift of the averages and ranges of water yield and dryness in both NF and PF areas from 1980s to 2000s (Figure 5-9). In 1980s, when the large scale plantation programs were initiated (Huang et al., 2012), PFs tended to be planted on low water stress sites. After 20 years, though rainfall has not shown significant changes in either NF or PF areas, the dryness was increased significantly for both areas (Figure 5-9). The Evaporative Index 
increased from about 0.51 to 0.58 in $\mathrm{PF}$, and from 0.51 to 0.55 for $\mathrm{NF}$, for a $5.88 \%$ reduction of water yield. This implies that man-made forests were more sensitive and vulnerable to climate change, namely a higher hydrological response to climate change. Therefore, vegetation establishment projects should be tailored to water availability and other ecological conditions (Normile, 2007). Consequently, to achieve a high carbon sequestration potential while maintaining a relatively low impact on regional water balance, plantings should consist of appropriate tree species, and, at least initially, be established on the most suitable land for afforestation in the TP, SSTP and MSTP regions. Planting in the NSTP, WTEM, and TEM regions, should be cautiously evaluated for afforestation, since the average reduction in water yield is about $35.54 \%$ in these regions.

Based on afforestation cost documented in 2005 (Supporting Information Table S2), more than 529 billion Chinese yuan (about $\$ 81$ billion) would be spent to achieve the commitment made by former Chinese President Hu Jintao in the 2009 U.N. Summit - to establish trees on 40 million ha in China by 2020. However, as stated by the Chinese Authority, approximately $54 \%$ of the available lands for afforestation are poor-quality and located in arid and semi-arid regions in China (SAF, 2014). The total investment on forestry programs will greatly exceed the budgetary estimate due to logistical issues, unfavorable geological conditions, and fragmented lands. Additionally, climate change does have extensive impacts on terrestrial ecosystems ( $\mathrm{Yu}$ et al., 2013b; Yu et al., 2014). Areas now marginally suitable for afforestation may soon be converted into unsuitable lands (Cao et al., 2011). Inappropriate forest plantation programs may not only lead to inefficient and high-cost forest practices but also present a potential risk and threat to the regional ecological environment. 


\section{Reference}

Bert, D., Leavitt, S. W., \& Dupouey, J. L. (1997). Variations of wood $\delta 13 C$ and water-use efficiency of Abies alba during the last century. Ecology,78(5), 1588-1596.

Budyko, M. I. (1971). Climate and life.

Cao, S., Wang, G., \& Chen, L. (2010). Questionable value of planting thirsty trees in dry regions. Nature, 465(7294), 31-31.

Cao, S. (2008). Why large-scale afforestation efforts in China have failed to solve the desertification problem. Environmental Science \& Technology,42(6), 1826-1831.

Compiling Committee of Vegetation Maps of 1:1,000,000 in China (2001) Atlas of Vegetation Maps of 1:1,000,000 in China. Science Press, Beijing.

Creed, I.F., Spargo, A.T., Jones, J.A., Buttle, J.M., Adams, M.B., Beall, F.D., Booth, E.G., Campbell, J.L., Clow, D., Elder, K. and Green, M.B. (2014). Changing forest water yields in response to climate warming: results from long-term experimental watershed sites across North America. Global change biology, 20(10), 3191-3208.

Dunne, T. and Black, R.D. (1970). Partial area contributions to storm runoff in a small New England watershed. Water resources research, 6(5), 1296-1311.

Farley, K.A., Jobbágy, E.G. and Jackson, R.B. (2005). Effects of afforestation on water yield: a global synthesis with implications for policy.Global change biology, 11(10), 1565-1576.

Food and Agriculture Organization of the United Nations (2010) Global Forest Resources Assessment 2010. Food and Agriculture Organization of the United Nations. Available at: http://www.fao.org/forestry/fra/fra2010/en/. Accessed February 7, 2012. 
Gao, Y., Zhu, X., Yu, G., He, N., Wang, Q. and Tian, J. (2014). Water use efficiency threshold for terrestrial ecosystem carbon sequestration in China under afforestation. Agricultural and Forest Meteorology, 195, 32-37.

Herron, N., Davis, R. and Jones, R. (2002). The effects of large-scale afforestation and climate change on water allocation in the Macquarie River catchment, NSW, Australia. Journal of Environmental Management, 65(4), 369-381.

Huang, M., Zhang, L. and Gallichand, J., 2003. Runoff responses to afforestation in a watershed of the Loess Plateau, China. Hydrological Processes, 17(13), 2599-2609.

Huang, L., Liu, J., Shao, Q. and Xu, X., 2012. Carbon sequestration by forestation across China: past, present, and future. Renewable and Sustainable Energy Reviews, 16(2), 1291-1299.

Huxman, T.E., Smith, M.D., Fay, P.A., Knapp, A.K., Shaw, M.R., Loik, M.E., Smith, S.D., Tissue, D.T., Zak, J.C., Weltzin, J.F. and Pockman, W.T., 2004. Convergence across biomes to a common rain-use efficiency. Nature,429(6992), 651-654.

Jackson, R.B., Banner, J.L., Jobbágy, E.G., Pockman, W.T. and Wall, D.H., 2002. Ecosystem carbon loss with woody plant invasion of grasslands. Nature, 418(6898), 623-626.

Jackson, R.B., Randerson, J.T., Canadell, J.G., Anderson, R.G., Avissar, R., Baldocchi, D.D., Bonan, G.B., Caldeira, K., Diffenbaugh, N.S., Field, C.B. and Hungate, B.A., 2008. Protecting climate with forests.Environmental Research Letters, 3(4), p.044006.

Li, C., Wang, J., Hu, L., Yu, L., Clinton, N., Huang, H., Yang, J. and Gong, P., 2014. A circa 2010 thirty meter resolution forest map for China. Remote Sensing, 6(6), 5325-5343.

Li, R., 2001. One of report of China's Six Key Forestry Programs: visiting of Sand Control Programs for areas in the vicinity of Beijing and Tianjin. Forestry \& Humans 9, 14-18 (in Chinese). 
Liu, Y.H., Wang, D., Gao, J., Deng, W., 2005. Land Use/Cover Changes, the Environment and Water Resources in Northeast China, Environmental Management, 36, 691-701.

McVicar, T.R., Van Niel, T.G., Li, L., Wen, Z., Yang, Q., Li, R. and Jiao, F., 2010.

Parsimoniously modelling perennial vegetation suitability and identifying priority areas to support China's re-vegetation program in the Loess Plateau: Matching model complexity to data availability. Forest Ecology and Management, 259(7), 1277-1290.

Mu, Q., Zhao, M. and Running, S.W., 2011. Improvements to a MODIS global terrestrial evapotranspiration algorithm. Remote Sensing of Environment, 115(8), 1781-1800.

Myneni, R.B., Hoffman, S., Knyazikhin, Y., Privette, J.L., Glassy, J., Tian, Y., Wang, Y., Song, X., Zhang, Y., Smith, G.R. and Lotsch, A., 2002. Global products of vegetation leaf area and fraction absorbed PAR from year one of MODIS data. Remote sensing of environment, 83(1), 214-231.

Normile, D., 2007. Getting at the roots of killer dust storms. Science 317, no. 5836: 314-316.

Peng, S.S., Piao, S., Zeng, Z., Ciais, P., Zhou, L., Li, L.Z., Myneni, R.B., Yin, Y. and Zeng, H., 2014. Afforestation in China cools local land surface temperature. Proceedings of the National Academy of Sciences, 111(8), 2915-2919.

Saleska, S.R., Didan, K., Huete, A.R. and Da Rocha, H.R., 2007. Amazon forests green-up during 2005 drought. Science, 318(5850), 612-612.

Saurer, M., Siegwolf, R.T. and Schweingruber, F.H., 2004. Carbon isotope discrimination indicates improving water-use efficiency of trees in northern Eurasia over the last 100 years. Global Change Biology, 10(12), 2109-2120.

State Forestry Administration, 2005. China’s Forestry Yearbook 2004. China Forestry Publishing House, Beijing. 
State Forestry Administration of the People's Republic of China, 2009. Seventh National Forest Resource Inventory Report (2004-2008) (State Forestry Administration of the People's Republic of China, Beijing).

State Forestry Administration of China, 2014. Http://www.forestry.gov.cn. Accessed August15, 2015.

Sun, P., Yu, Z., Liu, S., Wei, X., Wang, J., Zegre, N. and Liu, N., 2012. Climate change, growing season water deficit and vegetation activity along the north-south transect of eastern China from 1982 through 2006.Hydrology and Earth System Sciences, 16(10), 3835-3850.

Sun, G., Zhou, G., Zhang, Z., Wei, X., McNulty, S.G. and Vose, J.M., 2006. Potential water yield reduction due to forestation across China. Journal of Hydrology, 328(3), 548-558.

Wang, G., Innes, J.L., Lei, J., Dai, S., Wu, S.W., 2007. China's forestry reforms. Science 318, $1556-1557$.

Wang, G., Liu, Q., Zhou S., 2003, Research Advance of Dried Soil Layer on Loess Plateau. J. Soil Water Conserv. 17 (6), 156-169 (in Chinese).

Xu, L.K. and Hsiao, T.C., 2004. Predicted versus measured photosynthetic water-use efficiency of crop stands under dynamically changing field environments. Journal of Experimental Botany, 55(407), 2395-2411.

Yu, G., Song, X., Wang, Q., Liu, Y., Guan, D., Yan, J., Sun, X., Zhang, L. and Wen, X., 2008. Water-use efficiency of forest ecosystems in eastern China and its relations to climatic variables. New Phytologist, 177(4), 927-937.

Yu, Z., P. Sun, and S. Liu., 2010. Phenological change of main vegetation types along a NorthSouth Transect of Eastern China. Chinese Journal of Plant Ecology 34(3), 316-329. (Chinese with English abstract). 
Yu, Z., P. Sun, S. Liu, J. Wang, and A. Everman., 2013. Sensitivity of large-scale vegetation greenup and dormancy dates to climate change in the north- south transect of eastern China. International journal of remote sensing 34(20), 7312-7328.

Yu, Z., Liu, S., Wang, J., Sun, P., Liu, W. and Hartley, D.S. (2013). Effects of seasonal snow on the growing season of temperate vegetation in China.Global change biology, 19(7), 21822195.

Zhao, M., Heinsch, F.A., Nemani, R.R. and Running, S.W. (2005). Improvements of the MODIS terrestrial gross and net primary production global data set. Remote sensing of Environment, 95(2), 164-176.

Zhao, M. and Running, S.W. (2010). Drought-induced reduction in global terrestrial net primary production from 2000 through 2009. Science, 329(5994), 940-943.

Zhao, M.X., Zhou, J.B., Kalbitz, K. (2008). Carbon mineralization and properties of waterextractable organic carbon in soils of the south Loess Plateau in China. European Journal of Soil Biology. 44, 158-165.

Zomer, R.J., Trabucco, A., Bossio, D.A. and Verchot, L.V. (2008). Climate change mitigation: A spatial analysis of global land suitability for clean development mechanism afforestation and reforestation. Agriculture, ecosystems \& environment, 126(1), 67-80.

Zheng J, Yin Y, Li B (2010). A New Scheme for Climate Regionalization in China. ACTA GEOGRAPHICA SINICA. 65(1). (Chinese with English Abstract) 
6. Summary 
To slow down the increase of atmospheric $\mathrm{CO}_{2}$ concentration, effective evaluation and proper management of the terrestrial ecosystems is critical. Quantify the impacts of climate change on carbon (C) variation of terrestrial ecosystems are critical for reducing uncertainties on setting future climate mitigation actions. Additionally, terrestrial ecosystem vulnerabilities to the shift of water and heat pattern needs to be carefully assessed due to its implications of changes in the plant community compositions as well as the ecosystem functions. This study examined carbon and water changes in regional and global terrestrial ecosystems under human disturbances and climate change stresses. According to the results obtain from this study, the following conclusions can be drawn:

(1) Spring air temperature strongly regulated the SGS of both deciduous broad-leaf and coniferous forests; whilst the winter snow had a greater impact on the SGS of grassland and shrubs. Snow depth variation combined with air temperature contributed to the variability in the SGS of grassland and shrubs, as snow acted as an insulator and modulated the underground thermal conditions. Additionally, differences were seen between the impacts of winter snow depth and spring snow depth on the SGS; as snow depths increased, the effect associated went from delaying SGS to advancing SGS. The observed thresholds for these effects were snow depths of $6.8 \mathrm{~cm}$ (winter) and $4.0 \mathrm{~cm}$ (spring). Our findings suggest that temperate vegetation phenology is dependent on both seasonal air temperature and soil thermal conditions regulated by both snowfall and snow depth.

(2) Aboveground warming could result in attenuated snow cover, which would consequently increase the freezing potential of soil, and offset the enhanced aboveground C emission from temporarily suppressed underground respiration. Our study focused on $\mathrm{CO}_{2}$ emission due to the limited data availability. However, the different feedbacks of greenhouse 
gases (e.g. $\mathrm{CO}_{2}, \mathrm{~N}_{2} \mathrm{O}$, and $\mathrm{CH}_{4}$ ) aggravate the uncertainty in quantifying the effects of snow on global climate change, which needs to be further studied through eddy-covariance flux measurements and manipulation experiments. Further investigation is certainly needed in order to comprehensively understand and assess the impact of snow dynamics on global $\mathrm{C}$ cycling and balancing.

(3) Rainfall and soil moisture during drought period were dramatically lower than these in non-drought period, while air temperatures were higher than normal during drought period with amplitudes varied by land cover types. The length of recovery days (LRD) presented an evident gradient of high in mid- latitude region and low in low (tropical area) and high (boreal area) latitude regions. As average GPP increased, the LRD showed a significantly decreasing trend among different land covers. Moreover, the drought-induced GPP reduction was found in the mid-latitude region, but a slightly enhanced GPP was found in the tropical region under drought impact. The water use efficiency, however, showed a pattern of decreasing in the north Hemisphere and increasing in the south Hemisphere. The findings underline the importance of direct concurrent impacts and direct lagged impacts of droughts. More works are required to fully quantify the direct and indirect impacts of drought extremes to terrestrial ecosystems.

(4) On average, planted forests consumed 5.79\% (29.13mm) more water but sequestered $1.05 \%\left(-12.02 \mathrm{gC} \mathrm{m}^{-2} \mathrm{yr}^{-1}\right)$ less carbon than naturally generated forests, while the amplitudes of discrepancies varied with latitude. It is suggested that the most suitable lands in China for afforestation should be located in the moist south subtropical region (SSTP), followed by the mid-subtropical region (MSTP), to attain a high carbon sequestration potential while maintain a relatively low impact on regional water balance. The high hydrological impact zone, including the north subtropical region (NSTP), warm temperate region (WTEM), and temperate region 
(TEM) should be cautiously evaluated for future afforestation due to water yield reductions associated with plantations.

These conclusions are beneficial to improve understanding about regional and global C budget, reduce the uncertainties of $\mathrm{C}$ emission patterns at different spatial scales, which may potentially benefit international negotiators with rigorous emission limits for greenhouse gases. 


\section{Appendix A. Supplemental Information for Chapter 3}

Appendix S1 Supplementary information describing full details of validations of the two snow datasets used in this study.

Appendix S2 Supplementary information providing validation of the model simulation performed.

Appendix S3 Supplementary analyses of correlation between interannual winter soil temperature, snow cover depth, and air temperature in the study area.

Appendix S4 Supplementary analyses of correlation between interannual snow cover depth, winter air temperature, and model simulated net ecosystem exchange

Appendix S1 Supplementary information describing full details of validations of the two snow datasets used in this study.

\section{Snow data validation}

Two snow data products were used in this study. Both snow data sets are global in coverage, but with different spatial scales and temporal ranges. The first set of snow data is the Canadian Meteorological Centre's (CMC) snow depth analysis data, which has relatively high resolution (24 km resolution), covers from August 1998 to December 2012, and was used to explore the relationships between snow and $\mathrm{C}$ fluxes at site level. This product was validated at the flux site locations where snow was measured ( 56 observations from 12 sites; $\mathrm{R}^{2}=0.47$, $p<0.0001)$. We analyzed the long-term snow depth re-analysis from National Centers for Environmental Prediction / Climate Forecast System Reanalysis (CFSR). Snow depth from 
CFSR analysis was further validated using measured snow depth data available in all of the flux sites $\left(\mathrm{R}^{2}=0.30, p<0.0001\right)$. Both snow datasets were validated to be good quality for analysis.

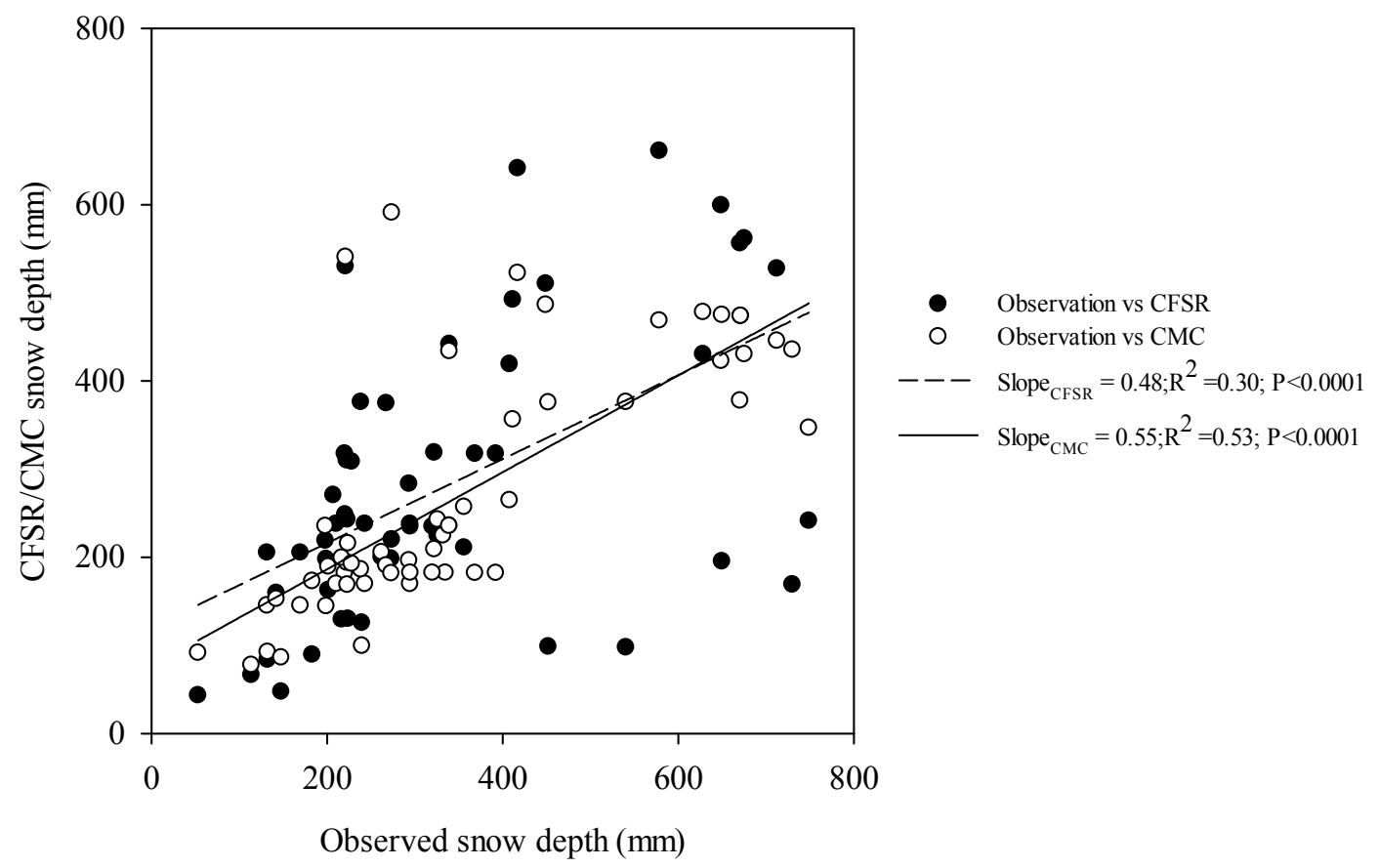

Figure S1 snow depth comparison between site observed value and two data products from CMC and CFSR respectively. (Open circles denotes CMC snow depth vs observation snow depth, close circle denotes CFSR snow depth vs observation snow depth data). 
Appendix S2 Supplementary information providing validation of the model simulation performed.

\section{Biome-BGC modeling validation}

Biome-BGC simulation was validated using observational data obtained from flux towers.

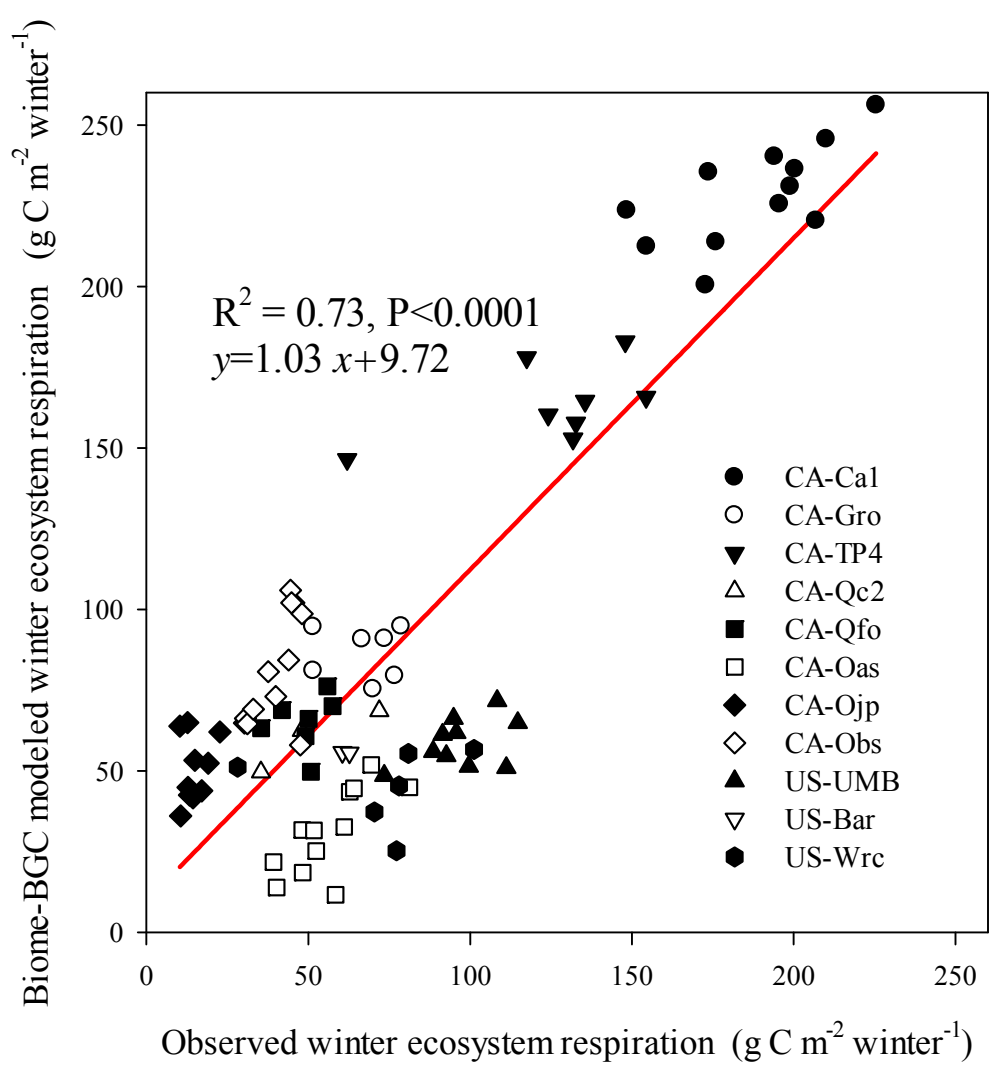

Figure S2 Biome-BGC modeled ecosystem respiration vs observed winter ecosystem respiration. 
Appendix S3 Supplementary analyses of correlation between interannual winter soil temperature, snow cover depth, and air temperature in the study area.
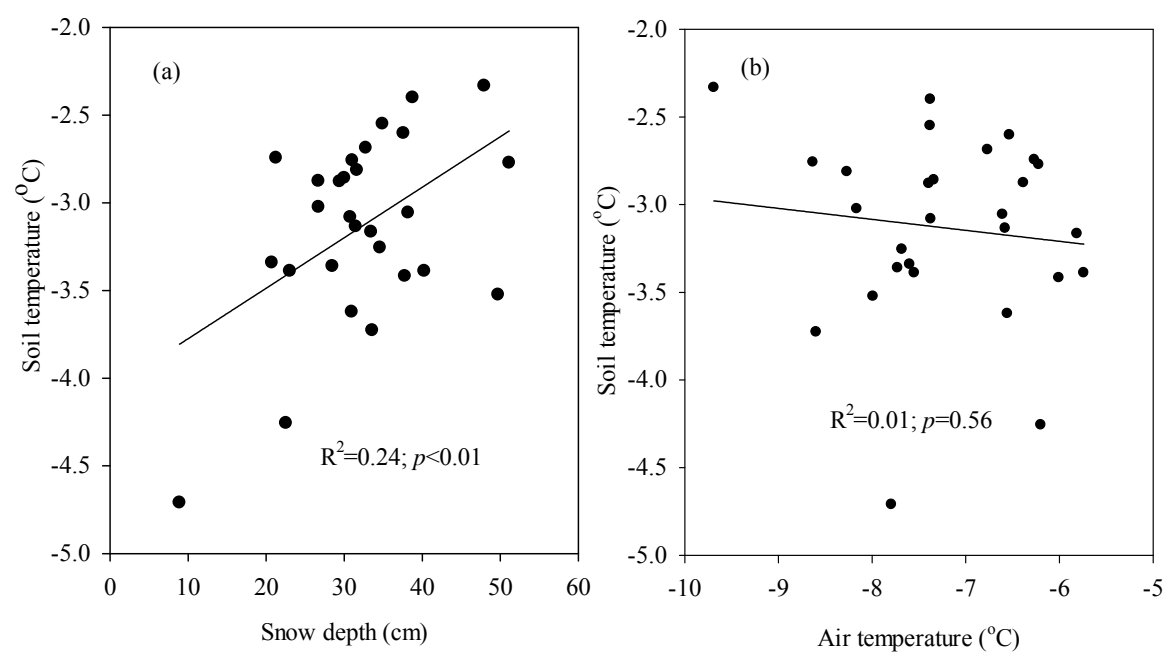

Figure S3. Correlation between interannual winter soil temperature, snow cover depth, and air temperature in the non-permafrost region of Northern forest area from 1982 to 2009. The snow data was the CFSR snow data.

Appendix S4 Supplementary analyses of correlation between interannual snow cover depth, winter air temperature, and model simulated net ecosystem exchange.
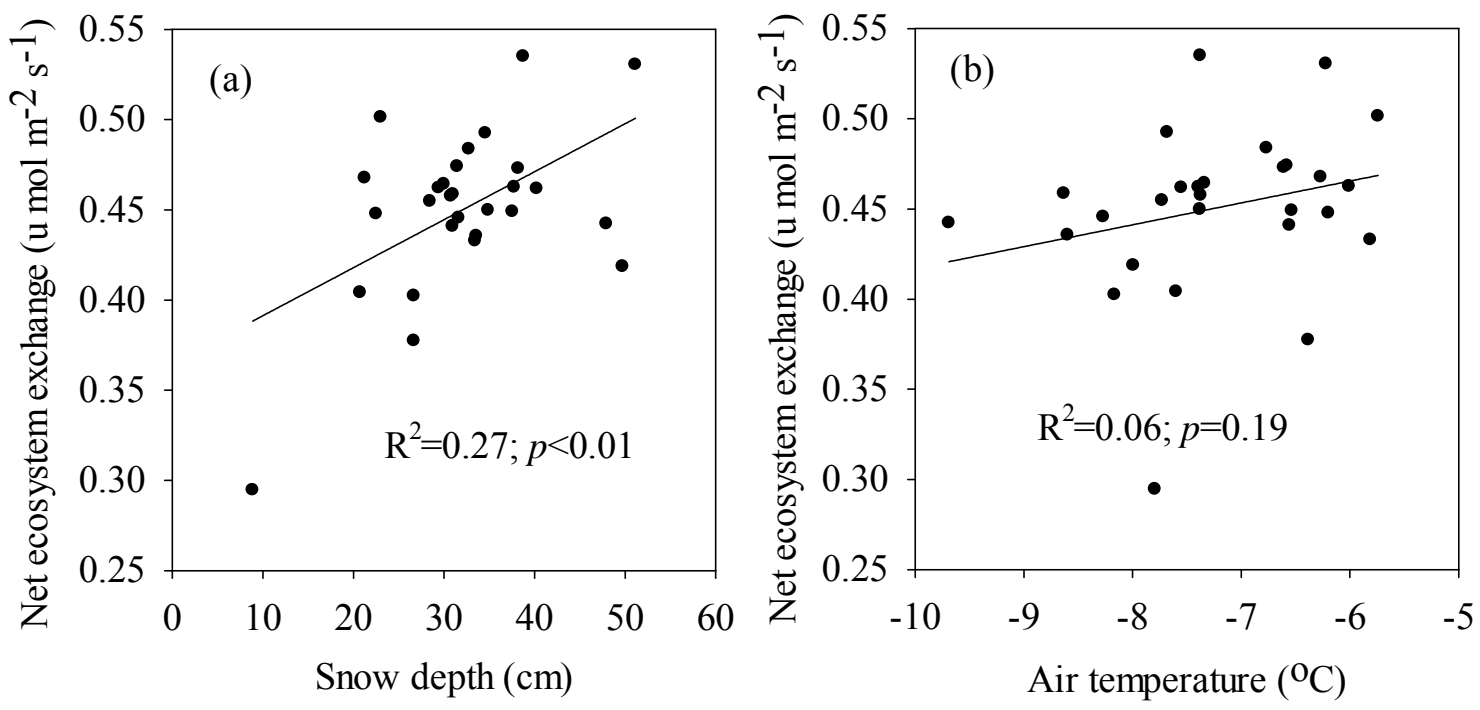
Appendix S4. Correlation between interannual snow cover depth, winter air temperature, and model simulated net ecosystem exchange in the non-permafrost region of Northern forest area from 1982 to 2009 . The snow data was the CFSR snow data. 


\section{Appendix B. Supplemental Information for Chapter 4}

\section{Soil moisture gap-filling}

Global coverage daily soil moisture (SM) dataset was downloaded from ESA Global Monitoring of Essential Climate Variables (ECV) with spatial resolution at 0.25 degree from 1978 to 2013 (http://www.esa-soilmoisture-cci.org/). The SM data were retrieved from active and passive microwave sensors, including C-band scatterometers (ERS-1/2 scatterometer, METOP Advanced Scatterometer) and multi-frequency radiometers (SMMR, SSM/I, TMI, AMSR-E, Windsat).

Soil moisture data is global coverage excluding areas with dense vegetation (tropical, boreal forests), strong topography (mountains), ice cover (Greenland, Antarctica, Himalayas), a large fractional coverage of water, or extreme desert areas. The area with dense vegetation coverage is blanked because the soil moisture signal emitted from the surface is largely absorbed by the vegetation canopy, making the reflection no longer contain a detectable soil moisture signal for the sensor used (Dorigo et al., 2010). The original soil moisture (SM) data has a lot of gaps because of sensors fails or sensitive to vegetation due to changes in observation wavelength. Here, algorithms were developed to gap-fill the missing data. First, we summarized the daily SM data from 1978 to 2013 (12845 layers) into monthly average SM of each year (432 layers). Second, the 432 monthly layers were further aggregated to a 12 monthly layers, which can be treated as a climatological status of monthly SM. Thirdly, the climatological SM layers were used as a "baseline" condition and a variate for interpolation using Anusplin. For each of the month from 1978 to 2013 , a sample of 1000 pixels were randomly picked globally. The global SM was then interpolated to monthly images using a tri-variate partial thin plate spline incorporating a bi-variate thin plate spline as a function of longitude, latitude, and constant linear dependences on climatological SM (Yu et al., 2010; Yu et al., 2013). Finally, the missing-data 
area in the monthly SM data summarized from original daily product will be replaced with interpolated data. Fig1.b showed the gap-filled result before and after interpolation. The areas with dense vegetation, mainly the tropical forests around the equator, were blanked. The ice cover regions, including Greenland, Antarctica, and Himalayas, were also excluded due to unmeaningful soil moisture in these regions.
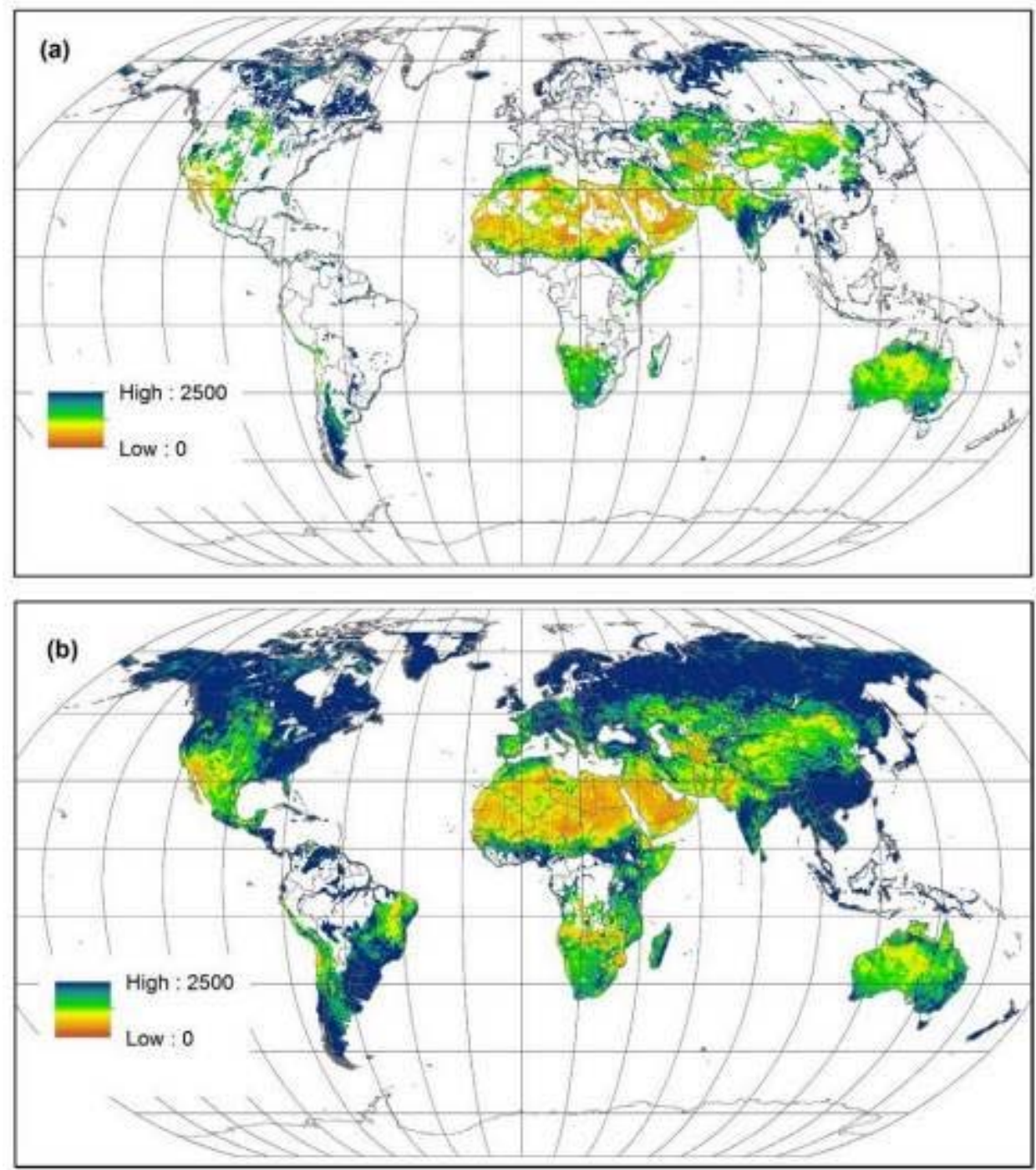
Figure S1 An example of volumetric soil moisture data before and after gap-filling process. The ice cover and dense vegetation area were blanked. (a: June 1988 before gap filling; b: June 1988 after gap filling)

\section{References:}

Yu, Z., P. Sun, and S. Liu. "Phenological change of main vegetation types along a North-South Transect of Eastern China." Chinese Journal of Plant Ecology 34, no. 3 (2010): 316-329. (Chinese with English abstract).

Yu, Z., P. Sun, S. Liu, J. Wang, and A. Everman. "Sensitivity of large-scale vegetation greenup and dormancy dates to climate change in the north- south transect of eastern China." International journal of remote sensing 34, no. 20 (2013): 7312-7328.

Dorigo, W. A., K. Scipal, R. M. Parinussa, Y. Y. Liu, W. Wagner, R. A. M. De Jeu, and V. Naeimi. "Error characterisation of global active and passive microwave soil moisture datasets." Hydrology and Earth System Sciences 14, no. 12 (2010): 2605-2616. 


\section{Appendix C. Supplemental Information for Chapter 5}

We collected and compared the modelled ET outputs with observed ET from six flux sites in China (Tab. S1).

Table S1 flux sites used in ET validation

\begin{tabular}{llll}
\hline Site & Longitude & Latitude & Forest type \\
\hline CBS & $127.09^{\circ} \mathrm{E}$ & $42.40^{\circ} \mathrm{N}$ & Mixed Forest \\
QYZ & $115.07^{\circ} \mathrm{E}$ & $26.74^{\circ} \mathrm{N}$ & Needle Leaf Forest \\
XSBN & $101.02^{\circ} \mathrm{E}$ & $21.95^{\circ} \mathrm{N}$ & Evergreen Broadleaf Forest \\
HLBE & $119.94^{\circ} \mathrm{E}$ & $49.33^{\circ} \mathrm{N}$ & grassland \\
$\mathrm{HB}$ & $101.33^{\circ} \mathrm{E}$ & $37.66^{\circ} \mathrm{N}$ & grassland \\
$\mathrm{YC}$ & $116.34^{\circ} \mathrm{E}$ & $36.50^{\circ} \mathrm{N}$ & crop \\
\hline
\end{tabular}

Table S2. Afforestation cost of six key forestry programs in different regions during period of 2001 to 2005 (yuan/ha)

\begin{tabular}{cccccc}
\hline \multirow{2}{*}{ Region } & \multicolumn{5}{c}{ Year } \\
\cline { 2 - 5 } & 2001 & 2002 & 2003 & 2004 & 2005 \\
\hline Northeast of China & 2056 & 7642 & 6340 & 9643 & 14259 \\
Northern China & 2641 & 3199 & 3605 & 6657 & 11841 \\
Eastern China & 4605 & 2422 & 4269 & 22196 & 17019 \\
Central China & 2254 & 3197 & 3464 & 5016 & 9006 \\
Southern China & 6130 & 2999 & 3009 & 4990 & 9572 \\
Northwest of China & 2603 & 2840 & 2872 & 7514 & 8406 \\
Southeast of China & 1286 & 4793 & 4911 & 10723 & 15193 \\
\hline
\end{tabular}



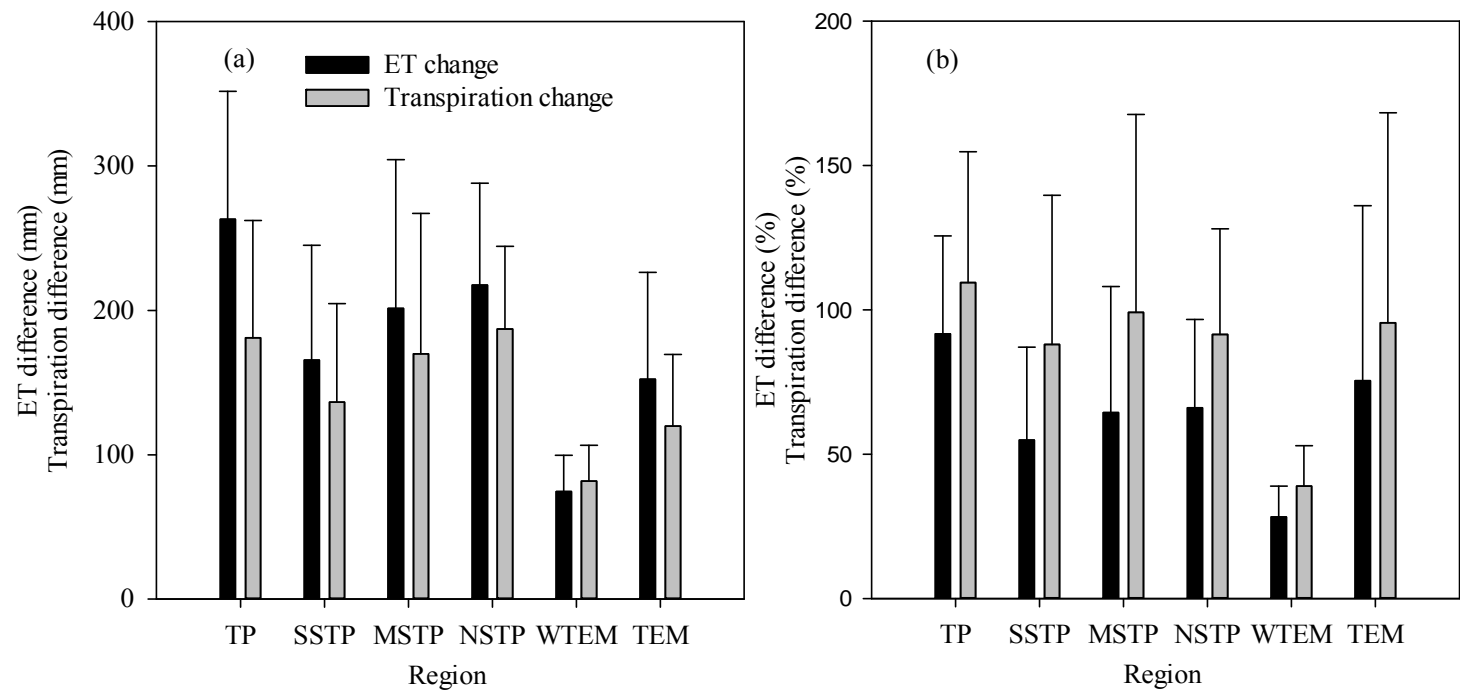

S1 ET and transpiration change after afforestation from grasslands, shrublands and croplands at different climate regions

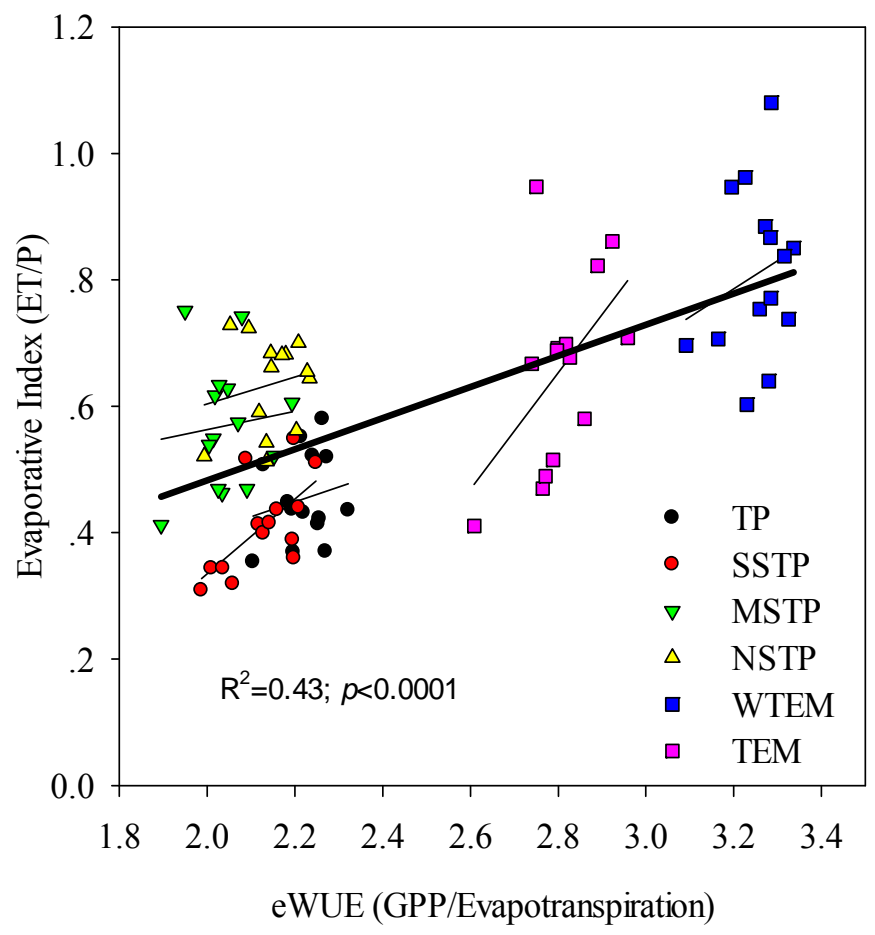

Figure S2 Relationships between water use efficiency and Evaporative Index in different regions (each point denotes average of all sampled points in a specific climate region in a year) 


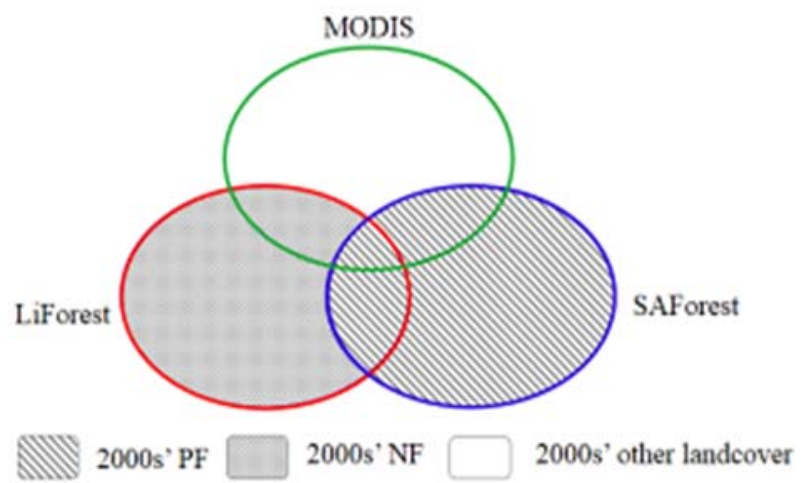

Figure S3 Method and data to identify planted forest, natural forest and other land cover types in 2000s (MODIS: MOD12Q1 land cover map in 2002; LiForest: forest map by Li et al. (2014);

SAForest: planted forest map released by the State Forestry Administration of China)

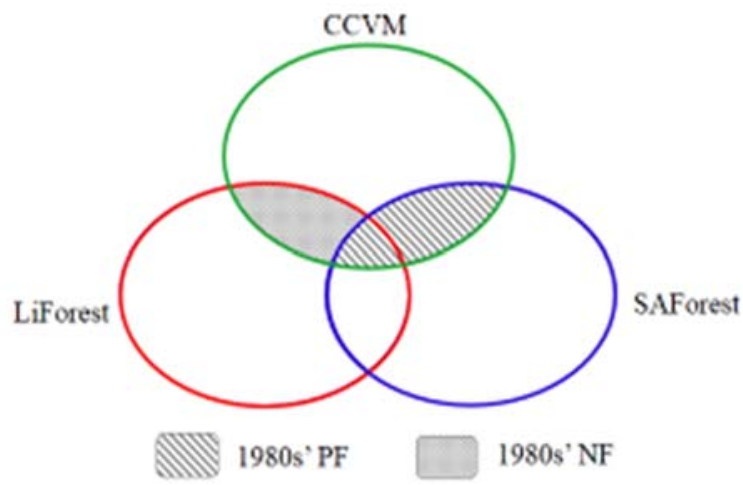

Figure S4 Method and data to identify planted and natural forest in 1980s (CCVM: The forest map digitized from Compiling Committee of Vegetation Maps of 1:1,000,000 in China; LiForest: forest map by Li et al. (2014); SAForest: planted forest map released by the State Forestry Administration of China) 